Taís Aparecida de Assis Garcia Moreira

\title{
Estudo da corrosão de Poli(N-vinilcarbazol), obtido via polimerização radical vivo
}

São Paulo

2008 
Taís Aparecida de Assis Garcia Moreira

\title{
Estudo da corrosão de Poli(N-vinilcarbazol), obtido via polimerização radical vivo
}

\author{
Dissertação apresentada à Escola \\ Politécnica da Universidade de São Paulo \\ para obtenção do Título de Mestre em \\ Engenharia Elétrica.
}

São Paulo

2008 
Taís Aparecida de Assis Garcia Moreira

\section{Estudo da corrosão de Poli(N-vinilcarbazol), obtido via polimerização radical vivo}

Dissertação apresentada à Escola

Politécnica da Universidade de São Paulo

para obtenção do Título de Mestre em

Engenharia Elétrica.

Área de Concentração:

Engenharia Elétrica

Microeletrônica

Orientador:

Prof.Dr. Roberto Koji Onmori

\section{São Paulo}




\section{Este exemplar foi revisado e alterado em relação à versão original, sob responsabilidade única do autor e com a anuência de seu orientador.}

São Paulo, 07de julho de 2008.

Assinatura do autor

Assinatura do orientador

\section{FICHA CATALOGRÁFICA}

Moreira, Taís Aparecida de Assis Garcia

Estudo da corrosão de Poli(N-vinilcarbazol), obtido via polimerização radical vivo / T.A.A.G. Moreira. -- ed.rev. --São Paulo, 2008.

$106 \mathrm{p}$.

Dissertação (Mestrado) - Escola Politécnica da Universidade de São Paulo. Departamento de Engenharia de Sistemas Eletrônicos.

1.Polimerização 2.Corrosão dos materiais 3.Polímeros (materiais) 4.Microeletrônica I.Universidade de São Paulo. Escola Politécnica. Departamento de Engenharia de Sistemas Eletrônicos II.t. 
Dedico esta Dissertação a Deus, que nunca me decepciona, sempre me acolhe em Seus braços a meus pais pelo apoio e dedicação, a meus amigos,e que amigos, companheiros de qualquer situação! 


\section{AGRADECIMENTOS}

Ao Professor Roberto Koji Onmori, pela orientação, pela confiança e amizade durante esse tempo de trabalho. Obrigada por tudo!

A professora Wang Shu Hui, do Departamento de Engenharia de Metalúrgica e Materiais, pelos textos revisados, sempre pelas dicas e incentivo, obrigada.

Aos colegas: Daniela, Tunísia, Shirrrrley, Nair, Carlos, Zé Carlos, Daniel, Edmilson, Rafael, Mario, Celso, pelas discussões, favores, passeios nos congressos, risadas, incentivos, conselhos, enfim pelo tempo que se dedicaram a mim.

Aos técnicos de laboratório: Rita, Teresa, Cris, Joãozinho, Alexandre, Julio César e Adir, pela disposição em ajudar sempre que precisei.

A todos que de alguma forma contribuíram na minha formação acadêmica e humana, cada um que passou por minha vida merece um pouquinho desse agradecimento! 
“Ecce nova facio omnia".

"Eis que faço novas todas as coisas" (Ap 21,5) 


\section{RESUMO}

O principal objetivo deste trabalho é a obtenção de trilhas com largura de dezenas de microns de Poli(N-vinilcarbazol) (PVK). Essas trilhas terão uma possível utilização em conjunto com outros materiais poliméricos como camada condutora na obtenção de um dispositivo semicondutor com material totalmente orgânico.

O polímero escolhido foi o PVK, obtido a partir da síntese do monômero de $N$-vinilcarbazol, utilizando a técnica de polimerização radical livre "viva", na presença do iniciador bimoleculares TEMPO (2,2,6,6-terametilpiperidinil-1-óxi)/BPO (peróxido de benzoíla) na razão molar 1:1,33. Além disso, a massa molar de $50.000 \mathrm{~g} / \mathrm{mol}$ para o PVK foi escolhida, previamente, devido às suas boas características elétricas condutoras, quando dopadas com perclorato de lítio.

Para a remoção e definição de geometria do PVK foi usada a técnica de plasma "etching" por ser um processo limpo, de fácil manuseio e grande possibilidade de controle de parâmetros, além da possibilidade de usar diversos gases. Por outro lado, os parâmetros de corrosão, através de plasma de oxigênio foram modificados com a finalidade de obter uma condição ideal para o processo de remoção e em seguida o polímero foi caracterizado novamente, verificando as possíveis mudanças nas características físico-químicas resultante do processo.

Testes com a corrosão em ambiente úmido com tolueno, também foram realizados para verificar as condições favoráveis e desfavoráveis nas técnicas de corrosão e as suas compatibilidades com os diversos materiais utilizados. Por fim, nas caracterizações elétricas e físico-químicas, geometrias pré-determinadas foram utilizadas para permitir estudos de parâmetros de análise, como a definição dos limites mínimos das geometrias, efeitos de borda, limite mínimo de largura de linha, taxa de remoção, excesso de remoção e a condutividade elétrica.

Palavras-chave: Poli( $N$-vinilcarbazol), corrosão, plasma. 


\section{ABSTRACT}

The main objective of this work is to obtain trails with ten microns width of Poly ( $N$-vinylcarbazole) (PVK). These trails will have a possible use in set with other polymeric materials as conducting layer in the attainment of a device semiconductor with total organic material. The polymer studied was the PVK from the synthesis of vinylcarbazole monomer, using the method called "living free radical" in the presence of a bimolecular system of initiators BPO ( benzoyl peroxide) and TEMPO (2,2,6,6-tetramethylpiperidinyloxy). The $50.000 \mathrm{~g} / \mathrm{mol}$ molar mass was used previously, resulted of its good conducting electric characteristics when doped with lithium percolate. To remove and to define the PVK geometry, the plasma technique was used because it is a clean, easy and rapid process, many possibility of parameters control and possibility to use several gas. Using oxygen plasma, the corrosion parameters had been modified to get the best condition to remove all PVK film without modifies the photoresist film. After the process, the polymer was characterized again to verify the possibility of changes in the physicist-chemistries characteristics of the PVK film.

The wet corrosion using toluene had been made to verify the parameters and conditions in the techniques to remove the PVK films and its compatibilities with the other materials used as photoresist, aluminum etc. In the electric, optical and physicist-chemistries characterizations, some predetermined geometries had been used to study and to analyze parameters as the definition and the minimum limits of the geometries, effect of edge, the minimum width, the corrosion rate, excess of corrosion and the electric conductive.

Keywords: poly( $N$-vinylcarbazole), etching, plasma. 


\title{
LISTA DE ABREVIATURAS E SÍMBOLOS
}

\author{
Abreviaturas
}

$\begin{array}{ll}\text { BPO } & \text { Peróxido de benzoíla } \\ \text { DSC } & \begin{array}{l}\text { Differential Scanning Calorimetry (Calorimetria Diferencial de } \\ \text { Varedurra) }\end{array} \\ \text { EDS } & \text { Espectrometria de Energia Dispersiva de Raios-X } \\ \text { GPC } & \text { Cromatografia de Permeação em Gel } \\ \text { IR } & \text { Espectro de Infravermelho (infra-red) } \\ \text { LEDs } & \text { Light Emission Diode (diodos emissores de luz) } \\ \text { LiClO }_{4} & \text { Perclorato de lítio } \\ \text { MEV } & \text { Microscopia Eletrônica de Varredura } \\ \text { MO } & \text { Microscópio óptico } \\ \text { OLEDs } & \text { Organics Light Emission Diode (diodos emissores de luz } \\ & \text { orgânicos) } \\ \text { PLEDs } & \text { Polymer Light Emission Diode (diodos emissores de luz } \\ \text { PVK } & \text { poliméricos) } \\ \text { TEMPO } & \text { Poli(N-vinilcarbazol) } \\ \text { UV-Vis } & 2,2,6,6 \text {-terametilpiperidinil-1-óxi } \\ \text { VK } & \text { Espectroscopia na região do Ultravioleta e Visível } \\ \text { CMOS } & N \text {-vinilcarbazol } \\ & \text { Complementary Metal Oxide Semiconductor (Complementar } \\ \text { R.F. } & \text { Metal- Óxido-Semicondutor) } \\ \text { D.C. } & \text { Rádio freqüência } \\ & \text { Corrente contínua }\end{array}$




\section{Símbolos}

$\begin{array}{ll}\sigma & \text { condutividade elétrica, } \mathrm{S} \cdot \mathrm{cm}^{-1} \\ \lambda & \text { comprimento de onda }\left(\mathrm{nm} \mathrm{ou} \mathrm{cm}^{-1}\right) \\ \mathrm{R} & \text { resistência elétrica, } \Omega(\mathrm{o} \mathrm{h} \mathrm{m}) \\ \pi & \text { orbital ligante } \\ \pi^{*} & \text { orbital antiligante } \\ \mathrm{J} & \text { densidade de corrente }\left(\mathrm{A} / \mathrm{cm}^{2}\right) \\ V & \text { tensão elétrica }(\mathrm{V}) \\ \rho & \text { resistividade elétrica }(\Omega . \mathrm{cm})\end{array}$




\section{LISTA DE EQUIPAMENTOS}

Perfilômetro

ALPHA STEP500 (LME//EPUSP)

Espectroscopia de Infravermelho:

Espectrofotômetro BioRad Digilab Division, Modelo QS-300 FTS-40

(LME/PSI/EPUSP).

Espectroscopia de UV-Vis:

Espectrofotômetro Simadzu, modelo 1650PC (LME/PSI/EPUSP).

Microscopia de Varredura (MEV):

SEM - Philips, Modelo XL-30. (Laboratório de Materiais - PMT)

SEM - FEG, modelo Nova NanoSem400, fabricado por FEI Company. (LSI/PSI/EPUSP)

Condutividade Elétrica:

Analisador de parâmetros HP4145, Estação de trabalho para componentes em microeletrônica, Went worth model 900 (LME/PSI/EPUSP).

Plasma RF:

Plasma Technology, modelo: Plasma Lab TTL (LME/PSI/EPUSP).

Plasma DC:

"Glove Box" da Empresa Prestvácuo (LME/PSI/EPUSP).

Deposição de Ouro

Sputter Coaterr. S150B (LSI/PSI/EPUSP) 


\section{LISTA DE FIGURAS}

Figura 1: Redução do custo por bit para memórias DRAM. (FONTE: R. BLEWER) ....20

Figura 2: Estrutura do poliacetileno. 31

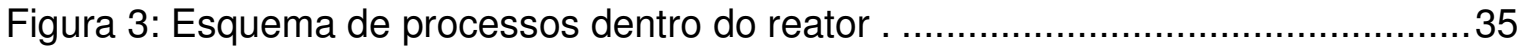

Figura 4: Curva característica de distribuição de potencial de plasma DC. ..................38

Figura 5: Diagrama de blocos do de um reator de plasma do tipo DC.......................39

Figura 6: Equipamento gerador de plasma de oxigênio por RF do Plasma Technology, modelo: Plasma Lab. TTL. ........................................... 40

Figura 7: Esquema de um processo de corrosão, por meio de plasma.

Figura 8: a) Perfil ideal de resiste; b) Resiste negativo com coeficiente de absorção elevado; c) Resiste negativo com coeficiente de absorção muito baixo. 42

Figura 9: Polimerização de $N$-vinilcarbazol, via radical livre, utilizando um sistema de iniciadores bimoleculares. (a) BPO, (b) TEMPO e (c) homopolímero de Poli(N-vinilcarbazol) (PVK).

Figura 10: Espectro de infravermelho para amostras de PVK puro e dopado com porcentagens de $1 \%, 2 \%$ e $3 \%$ de $\mathrm{LiClO}_{4}$. .54

Figura 11: Espectro de infravermelho para amostras de PVK sem dopantes. .55

Figura 12: Espectro de infravermelho para amostras de PVK puro e dopado com porcentagens de 1\%, $2 \%$ e $3 \%$ de $\mathrm{LiClO}_{4}$, na faixa de 400 a $1000 \mathrm{~cm}^{-1} \ldots . .56$

Figura 13: Espectro de UV-Vis para PVK puro e dopado com porcentagens em massa de $\mathrm{LiClO}_{4}$

Figura 14: Dados de Calorimetria Diferencial de Varredura (DSC), variação de temperatura de 50 a $300^{\circ} \mathrm{C}$, com passos de $10^{\circ} \mathrm{C}$

Figura 15: Esquema de obtenção de filme de PVK a partir do método denominado de "spin coating".

Figura 16: Fotos de Microscopia óptica, de resiste AZ1518 antes (a) e depois (b) da exposição com tolueno. (aumento de 500 vezes).

Figura 17: Microscopia óptica de trilha obtida a partir de corrosão úmida com tolueno.

Figura 18: Filme de PVK com fotoresiste: taxa de corrosão de 0,855 $\mu \mathrm{m} / \mathrm{min}$. 64

Figura 19: Filme de PVK sem fotoresiste: taxa de corrosão de 1,180 $\mu \mathrm{m} / \mathrm{min}$. .64 
Figura 20: Comportamento da espessura em função do tempo de exposição do filme de PVK no plasma DC de argônio.

Figura 21: a) Microscópio óptico com aumento de 500 vezes. b) Detalhe ampliado da foto. 66

Figura 22: Fotos obtidas por MEV, a) antes e b) após a exposição do filme de PVK no plasma de argônio.

Figura 23: Foto (MO) do PVK da região atacada e protegida (não atacada) com aumento de 500 vezes.

Figura 24: Camada de Poli( $N$-vinilcarbazol) removida em função do tempo para o plasma de oxigênio.

Figura 25: Taxa de remoção de Poli(N-vinilcarbazol) em função do tempo fluxo de gás.

Figura 26: Taxa de remoção de Poli( $N$-vinilcarbazol) em função da potência. .72

Figura 27: Taxa de remoção de Poli( $N$-vinilcarbazol) em função da pressão de gás...73

Figura 28: Taxa de remoção de resiste em função do tempo fluxo de gás. .74

Figura 29: Taxa de remoção de resiste em função do fluxo de gás (extraído da referência 104). 75

Figura 30: Taxa de remoção resiste em função da potência. .76

Figura 31: Taxa de resiste em função da potência (extraído da referência ). .76

Figura 32: Taxa de resiste em função da pressão. .77

Figura 33: Taxa de remoção de resiste em função da pressão (extraído da referência 104).

Figura 34: Detalhes no defeito de fotogravação, problema na abertura, imagem de microscopia óptica. 80

Figura 35: Trilhas interrompidas por falhas na fotogravação, imagens de microscopia óptica. .80

Figura 36: Estruturas que apresentaram "over etching", imagens de microscopia óptica.

Figura 37: Microscopia óptica de trilhas com aumento de 250 vezes. .82

Figura 38: Analisador de parâmetros, e detalhe das pontas em seqüência. .83

Figura 39: Diagrama esquemático para as medidas elétricas. .84

Figura 40: Gráfico da resistividade em função da porcentagem de $\mathrm{LiClO}_{4}$. .85

Figura 41: Relação da condutividade elétrica em função da porcentagem de $\mathrm{LiClO}_{4}$. 86

Figura 42: Filme de PVK dopado com 2\% de $\mathrm{LiClO}_{4}$ e dopado com 3\% de $\mathrm{LiClO}_{4} . . . .87$ 
Figura 43: Microscopia eletrônica de varredura, aumento de 118x, de estruturas com PVK e PVK dopado com 1\% de $\mathrm{LiClO}_{4}$, respectivamente..........................88

Figura 44: Microscopia eletrônica de varredura com aumento de 1200x, de estruturas com PVK e PVK dopado com 1\% de $\mathrm{LiClO}_{4}$, respectivamente. . 88

Figura 45: Microscopia eletrônica de varredura com aumento de 836x, de estruturas com PVK dopado com $1 \%$ de $\mathrm{LiClO}_{4}$ 


\section{LISTA DE TABELAS}

Tabela 1- Tempo previsto pelo equipamento e tempo cronometrado em cada

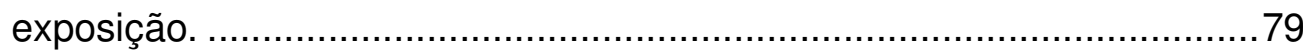

Tabela 2 - Valores de resistividade elétrica e condutividade elétrica em função da porcentagem de dopantes no PVK.................................................... 84 


\section{SUMÁRIO}

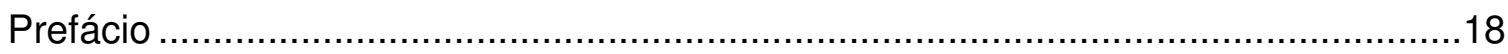

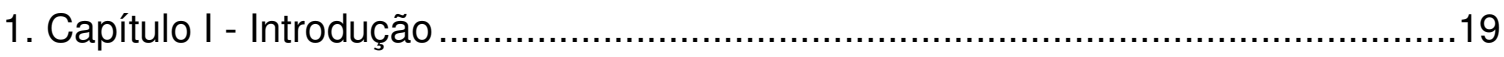

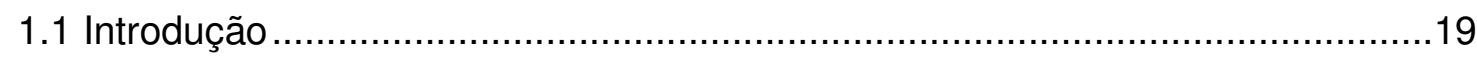

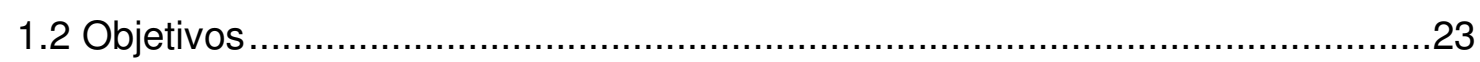

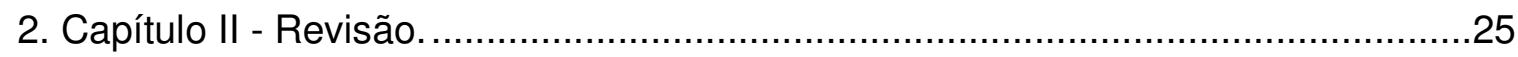

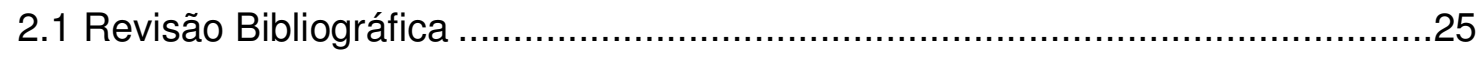

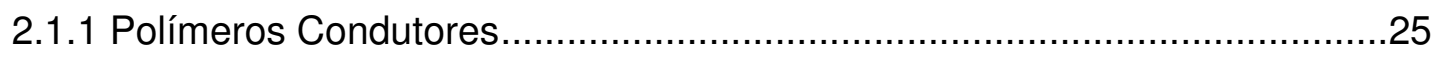

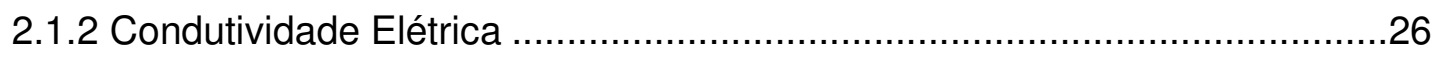

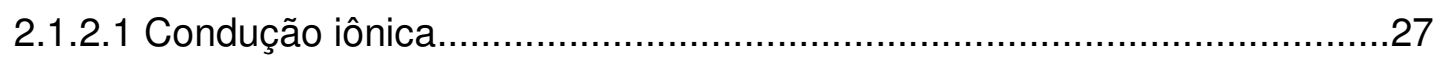

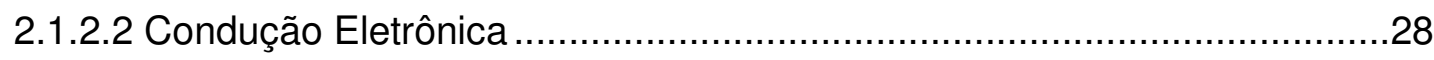

2.2 Fotoluminescência e Eletroluminescência ....................................................29

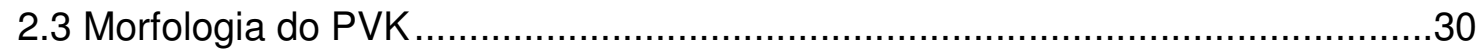

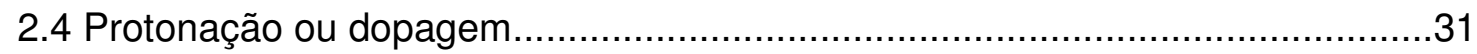

2.5 Métodos de Polimerização "viva" Existentes …………………......................32

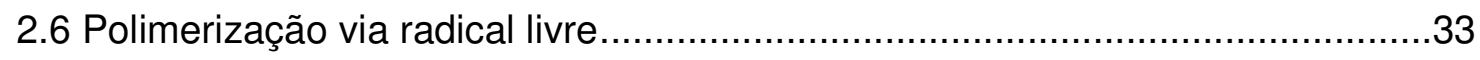

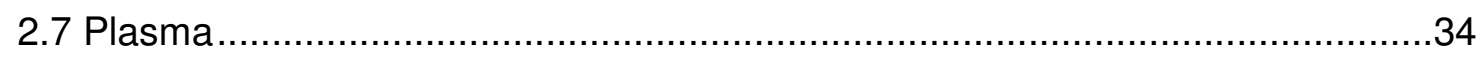

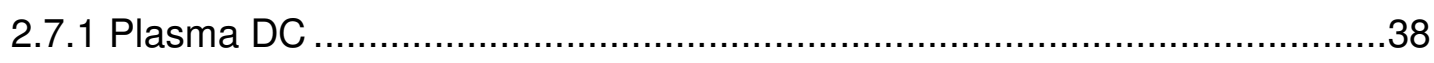

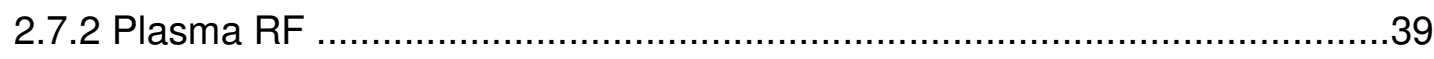

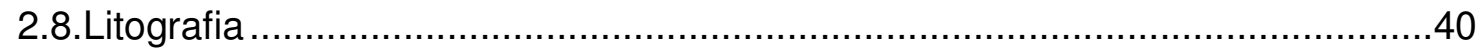

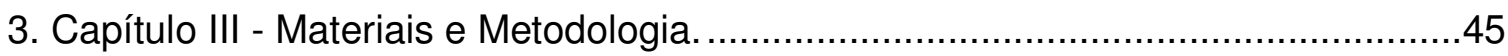

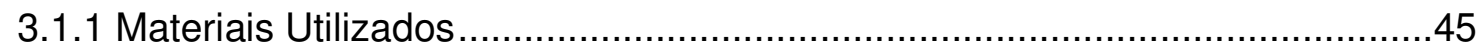

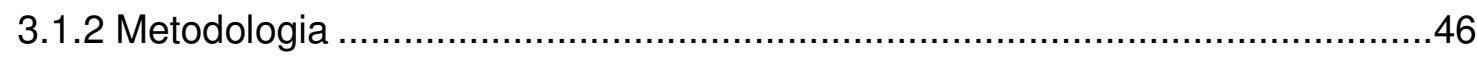

3.1.3 Síntese do Homopolímero de $\mathrm{N}$-vinilcarbazol ............................................46

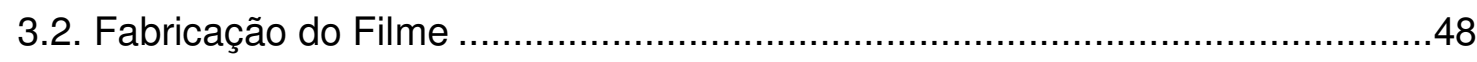

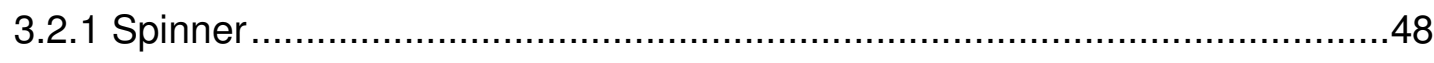

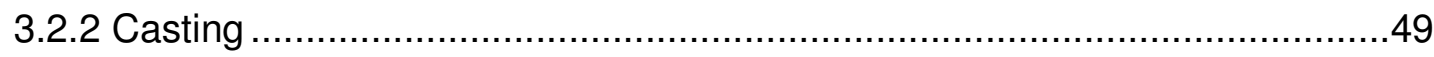

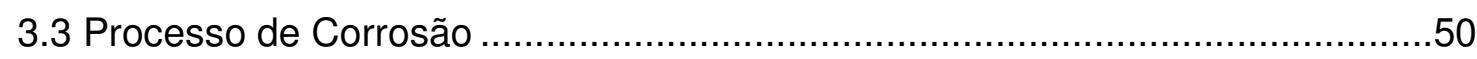

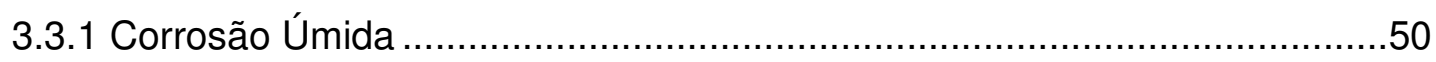

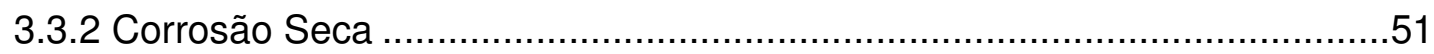




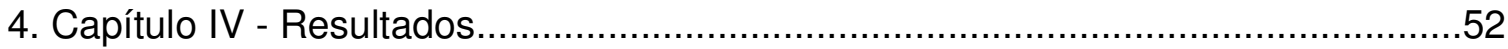

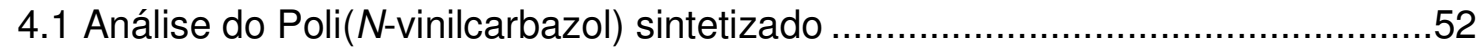

4.1.1 Cromatografia de Permeação em Gel (GPC) ........................................52

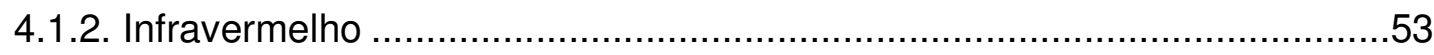

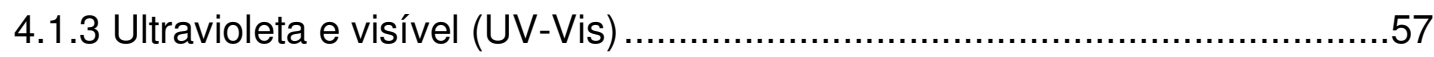

4.1.4 Calorimetria Diferencial de Varredura (DSC) ……................................58

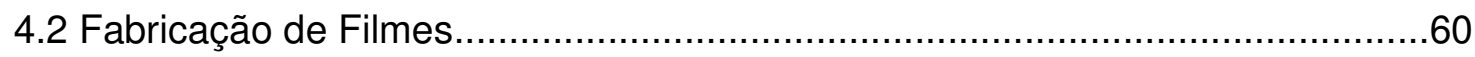

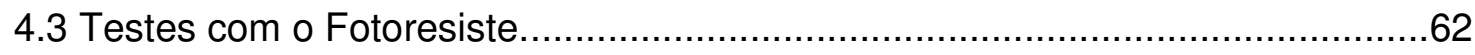

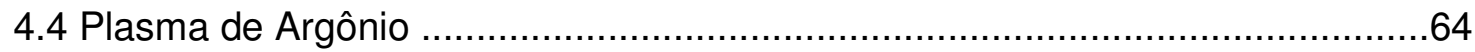

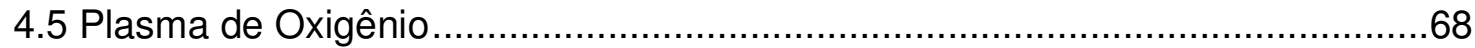

4.5.1.Estudo dos parâmetros de Plasma de oxigênio ………………………....70

4.5.2. Estudo dos parâmetros de plasma de oxigênio e fotoresiste $A Z$...............73

4.6. Fabricação das trilhas usando "Pattern Generator"..........................................79

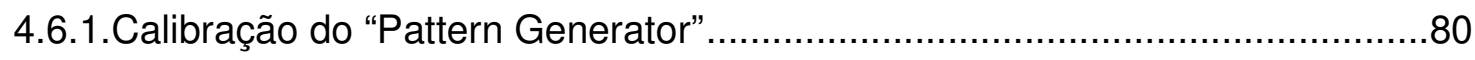

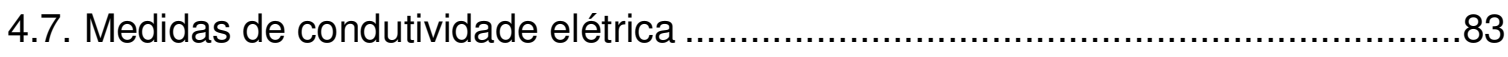

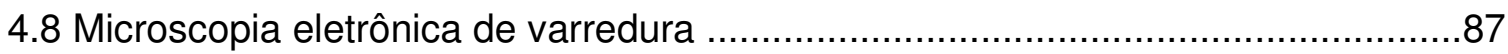

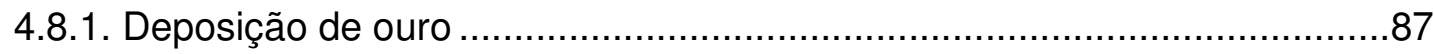

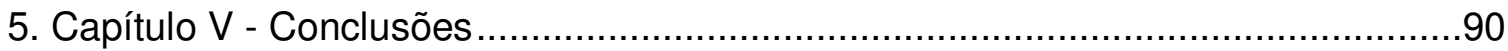

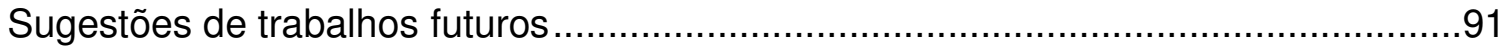

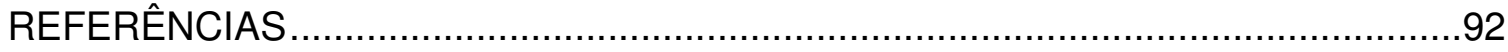

ANEXO A - APRESENTAÇÃO EM CONGRESSOS ……..................................103

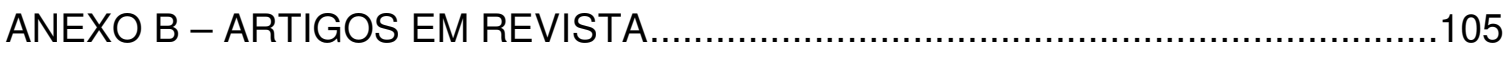

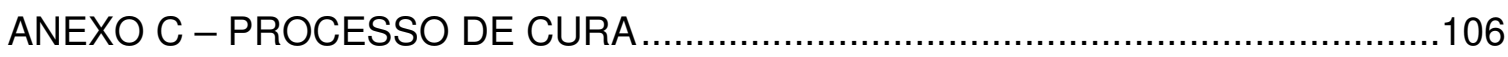




\section{Prefácio}

O objetivo pessoal é aprender a pesquisar e dar continuidade aos estudos. Aprender a lidar com desafios, construir algo novo, manter a motivação no meio de derrotas e incertezas.

Aprender a utilizar novos equipamentos, organizar métodos investigativos, extrair dados e parâmetros e analisar resultados, e finalmente chegar às conclusões. Para tal propósito, o material de análise nesse estudo foi o Poli ( $N$-vinilcarbazol), um polímero de fácil obtenção, fácil manuseio. Esse material foi estudado para a futura aplicação como trilhas eletricamente condutora.

A dissertação foi dividida em 5 capítulos. No capítulo I é apresentada uma breve introdução do trabalho. No capítulo II são apresentados às características do material, os métodos utilizados. No capítulo III são descrita a metodologia utilizada e os procedimentos. No capítulo IV os resultados dos procedimentos estão apresentados e analisados, e finalmente no capítulo $V$ está apresentada a conclusão do presente trabalho. 


\section{Capítulo I - Introdução}

No capítulo I, é apresentado resumidamente o estudo das principais propriedades do Poli( $N$-vinilcarbazol) (PVK) e suas possíveis aplicações como camada eletricamente condutora em dispositivos semicondutores, umas das etapas para posteriormente ser utilizado na fabricação de um dispositivo eletro-eletrônico feito totalmente de material polimérico.

\subsection{Introdução}

No mundo de hoje, onde informatização é uma ferramenta essencial para inúmeras atividades humanas, há grande demanda por circuitos eletro-eletrônicos cada vez mais complexos, capazes de desempenhar as mais diversas funções.

À primeira vista, estes circuitos poderiam utilizar exatamente a mesma tecnologia empregada por seus antecessores. No entanto, quanto maior o número de componentes de um circuito integrado, em uma mesma tecnologia, menor a tensão elétrica de trabalho, maior a sua dissipação de potência, maior a sua área (implicando incremento de defeitos) e a dificuldade de sincronização de sinais.

Além disso, as tarefas cada vez mais complexas a serem executadas exigem aumento de velocidade de resposta do circuito, para que sua execução ocorra em tempo hábil. Para que haja esse aumento de velocidade, uma alternativa é a redução das capacitâncias envolvidas tanto no chaveamento dos dispositivos eletrônicos quanto na propagação dos sinais, que, novamente, depende da redução nas dimensões empregadas na fabricação do circuito.

Verifica-se na prática que, quanto menor as dimensões dos dispositivos, menor o custo por função executada, como é mostrado na Figura 1. A quantidade de dispositivos que pode ser colocada em lâmina de silício, por exemplo, é tão importante que os custos de fabricação são baseados principalmente na área ocupada pelo circuito. Assim, redução das dimensões mínimas (e conseqüente 
avanço da tecnologia) é fundamental para tornar um produto no estado da arte viável.

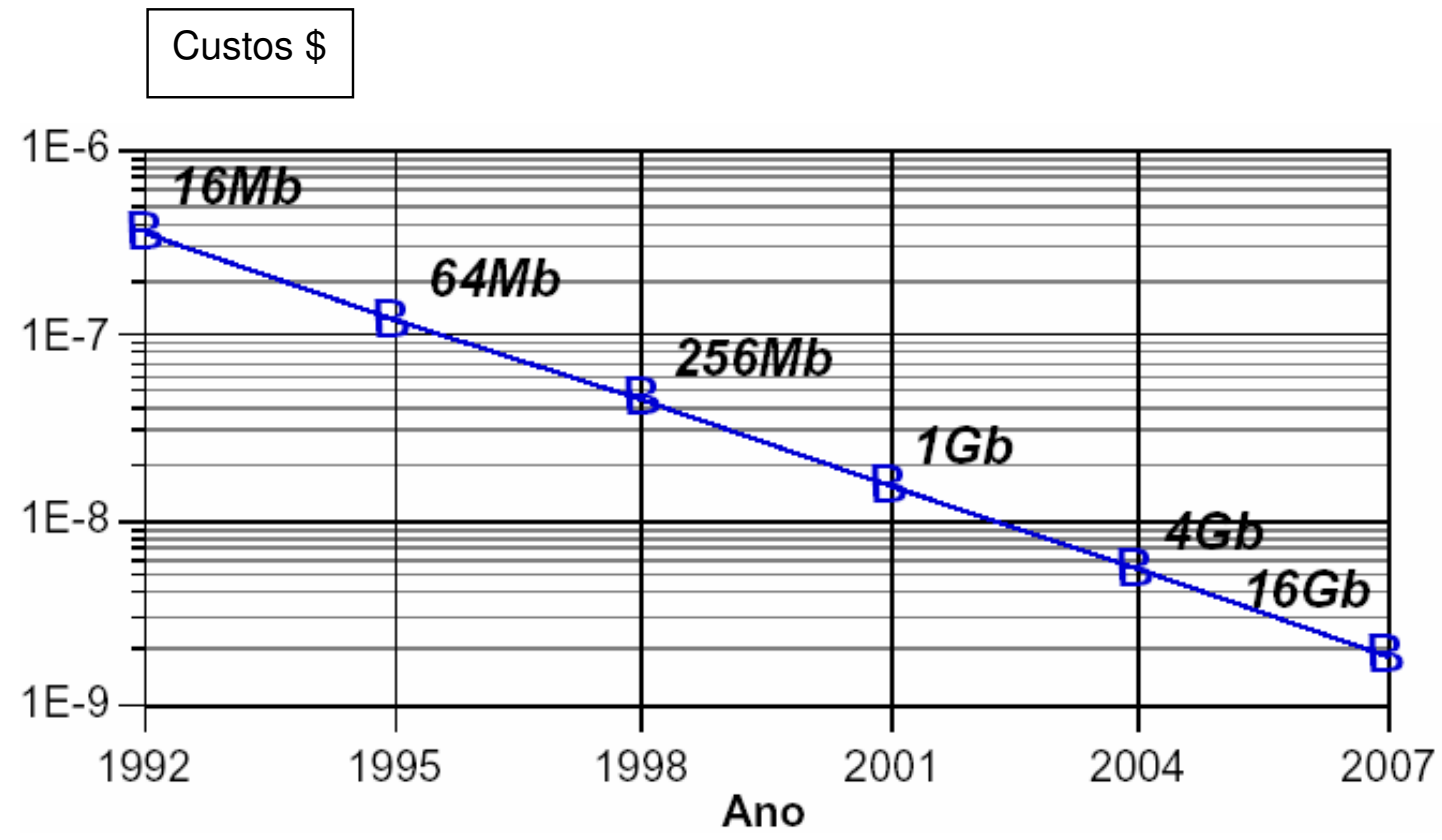

Figura 1: Redução do custo por bit para memórias DRAM. (FONTE: R. BLEWER ${ }^{1}$ )

$\mathrm{Na}$ indústria de semicondutores, $60 \%$ do tempo total para fabricação de uma lâmina de silício (4 a 25 semanas) é destinado às etapas litográficas ${ }^{2}$. Isto ocorre porque até 20 dessas etapas podem ser necessárias para a fabricação de circuitos CMOS ("Complementary Metal Oxide Semiconductor"). Estima-se que a litografia corresponda a cerca de $35 \%$ do custo total de fabricação de um circuito integrado ${ }^{3}$.

Portanto, a seleção de uma etapa adequada a cada fase da produção tornase crítica, dependendo da viabilidade técnica, de considerações econômicas e de avaliações tais como volume de produção, tempo de produção, planejamento do produto, entre outros.

Historicamente o silício tem mais de 60 anos de mercado e suas etapas de fabricação são bastante conhecidas e dominadas. Entretanto novos materiais estão sendo descobertos e sendo bastante estudados. Essa nova área é denominada polímeros condutores. O papel dos materiais poliméricos na indústria eletrônica era tradicionalmente associado com suas propriedades elétricas isolantes ou fotossensíveis, para uso, por exemplo, na tecnologia de fotogravação.

Foi no trabalho de MacDiarmid ${ }^{4}$ que os químicos e físicos se inspiraram a considerar a possibilidade de usar polímeros como condutores elétricos e em 
diversas aplicações como camadas ativas em dispositivos opto-eletrônicos, eletrônicos, biosensores e leds (diodos emissores de luz), entre outros.

Atualmente diversos polímeros condutores estão sendo estudados e desenvolvidos e muitos estão sendo utilizados na indústria de aparelhos eletroeletrônicos como condutores elétricos e eletroluminescentes.

O Poli( $N$-vinilcarbazol) (PVK) apresenta essas propriedades ${ }^{5}$ sendo um material de considerável interesse acadêmico e industrial, devido às suas características elétricas incomuns. Ele tem sido utilizado como material dielétrico de alta temperatura na indústria elétrica e como fotocondutor em copiadoras. Já é muito utilizado na indústria de painéis eletroluminescentes (leds), dopado usualmente com iodo, bromo e recentemente com perclorato de lítio ${ }^{6}$.

As vantagens de utilização do PVK em dispositivos eletro-eletrônicos é sua alta estabilidade térmica, de fácil manuseio, de fácil obtenção (síntese e filmes finos), já que ele possui diversos solventes (benzeno, tolueno e clorofórmio) incluindo sua alta aderência em materiais como vidro, metais (alumínio) e com outros polímeros (no presente estudo, apresentou ótima aderência com o fotoresiste utilizado). Outras vantagens pouco exploradas, até o momento, são suas altas temperaturas de transição vítrea, $\mathrm{T}_{\mathrm{g}}$, cerca de $190{ }^{\circ} \mathrm{C}$, e seu índice de refração elevado, $\eta=1,62$, pois sua utilização em dispositivos não ocorre em temperaturas de trabalho tão elevada.

Por outro lado, as desvantagens devem-se à alta taxa de oxidação em contato com meio ambiente e rigidez dos filmes obtidos. Estes fatos, porém, podem ser minimizadas através de cuidados no processamento e mantendo o polímero em atmosfera inerte (combatendo a oxidação).

Outro motivo de interesse são suas propriedades fotocondutoras, ou seja, aumento de sua condutividade elétrica sob iluminação. Esse tipo de material é importante em aplicações comerciais, tais como fototransistores e fotodetectores ${ }^{7}$. O aumento observado na condutividade é um resultado direto do aumento dos portadores de carga, gerados através da absorção e posterior emissão de fótons. Em fotocondutores inorgânicos tradicionais, tais como o selênio ou o silício, existe uma banda de condução, assim os processos de fotogeração envolvem simplesmente a excitação direta de um elétron da banda de valência à faixa de condução ${ }^{8}$. 
Há alguns anos, dispositivos eletroluminescentes orgânicos atraíram muita atenção por causa da sua alta luminescência, baixa tensão de operação, e uma variedade de cores na emissão. Nestes dispositivos, a energia elétrica é transformada em luz por meio da excitação das moléculas orgânicas. Os processos da excitação envolvem a injeção de lacunas/elétrons na camada orgânica, gerando, por meio da recombinação destes portadores, a excitação dessas moléculas.

Até o presente momento, poucos pesquisadores deram importância ao estudo e fabricação de trilhas eletricamente condutoras orgânicas. Normalmente metais como alumínio e ouro são utilizados para essa finalidade.

O presente trabalho inicia o estudo da utilização de trilhas eletricamente condutoras fabricadas com PVK, para em um futuro próximo obter um dispositivo eletrônico feito com material polimérico.

Os materiais poliméricos condutores normalmente são depositados sobre toda a superfície. Poucos estudos descrevem, ou estudam a limitação de geometrias e desenvolvimento das mesmas para a fabricação de dispositivos, com novos materiais poliméricos, como por exemplo, placas de circuitos impresso com trilhas fabricadas com material polimérico.

Nesse trabalho, portanto, o PVK foi estudado e analisado para a possível aplicação das técnicas já conhecidas de fotogravação e corrosão úmida (em meio de um solvente químico) e corrosão por plasma para a fabricação dessas trilhas eletricamente condutoras.

Foi feito nesse trabalho o estudo das condições de corrosão em ambiente seco (plasma) e úmido (solvente), a fim de determinar parâmetros melhores para a construção das trilhas. Diferentes geometrias foram testadas, para o estudo das condições de corrosão do polímero. Sendo assim os pontos centrais das técnicas utilizadas foram analisadas nesse presente trabalho. 


\subsection{Objetivos}

Até o presente momento ainda não é possível depositar o PVK sobre a superfície e obter diretamente as trilhas com as definições previamente estabelecidas. O processo convencional é depositar o PVK sobre toda a superfície e, usando o processo fotolitográfico, as regiões não protegidas serão removidas por corrosão úmida ou seca. Após a remoção do fotoresiste, o resultado são as trilhas de PVK de acordo com a geometria desejada.

O principal objetivo desse trabalho é implementar e caracterizar um conjunto de processos em microeletrônica para obtenção e caracterização de trilhas eletricamente condutoras feitas de filmes de Poli(N-vinilcarbazol) (PVK), como parte de um processo para a fabricação de um dispositivo feito totalmente de material polimérico.

Essa trilha deve ser o resultado da remoção parcial do material PVK previamente depositado sobre toda a superfície de um substrato de vidro. Para essa finalidade, foi usado o processo de fotolitografia após a deposição do filme onde o material fotossensível resultante protegerá a camada de PVK, assim resultando na geometria desejada.

Para isso alguns estudos preliminares foram feitos como a compatibilidade do material polimérico com o fotoresiste, plasmas de argônio e oxigênio e solventes do fotoresiste e do PVK.

Outros objetivos do trabalho foram:

a) a síntese do PVK via radical vivo,

b) a caracterização físico-química por GPC, IV e UV-vis,

c) estudo da obtenção dos filmes finos através do uso de dois métodos: "casting" e "spin coating";

d) estudo da remoção do polímero a partir de solventes químicos e processos de corrosão através do uso de plasma de oxigênio e de argônio e;

e) verificação dos limites geométricos das trilhas.

Com esses estudos, abre-se um caminho, em um futuro próximo, da fabricação de um dispositivo totalmente feito de material orgânico, bem como 
entender as dificuldades operacionais e obtenção de dados bastante concretos para a fabricação do mesmo. 


\section{Capítulo II - Revisão.}

Nesse capítulo estão apresentados levantamentos das principais características do Poli(N-vinilcarbazol) (PVK) como a sua morfologia, condutividade elétrica e suas aplicações em dispositivos eletro-eletrônicos. Também é mostrado um estudo de alguns parâmetros importantes para os futuros trabalhos na obtenção desses dispositivos.

\subsection{Revisão Bibliográfica}

Neste item foi feita uma revisão das principais propriedades físico-químico do Poli(N-vinilcarbazol) (PVK), bem como suas possíveis aplicações em dispositivos opto-eletrônicos fabricados com material orgânico como camada ativa.

\subsubsection{Polímeros Condutores}

A descoberta de que polímeros orgânicos podem conduzir carga elétrica criou esta nova classe de materiais: os polímeros intrinsecamente condutores.

Os polímeros condutores têm atraído a atenção de inúmeros grupos de pesquisa desde sua descoberta por MacDiarmid e seu grupo de pesquisas ${ }^{4}$ em 1977, tanto pela importância científica em se entender este novo fenômeno de condução elétrica assim como o seu potencial em aplicações tecnológicas, como por exemplo, os painéis luminosos denominados de PLED's (polymer light emission diode). Estes materiais podem combinar as propriedades mecânicas e processabilidade dos polímeros convencionais com um comportamento elétrico, ótico e magnético semelhante aos metais e semicondutores inorgânicos. Esta característica faz com que estes materiais se enquadrem na categoria dos chamados "metais sintéticos". . Devido as suas qualidades e propriedades elétricas e 
ópticas, um grande impulso foi dado nos últimos anos na pesquisa e como conseqüência, uma grande aplicação tecnológica destes materiais como: baterias recarregáveis, diodos emissores de luz, eliminação de carga estática em microeletrônica, proteção contra corrosão e recobrimento de materiais dentre outros.

Desde então, não cessaram os estudos visando a otimização de sua condutividade elétrica, sem que haja prejuízo das propriedades físicas dos materiais poliméricos. Os polímeros condutores podem ter valores de condutividade que vão desde isolante até condutor dependendo do grau de dopagem ${ }^{10,11}$. A principal característica que tornam esses polímeros condutores é a existência de uma seqüência de ligações duplas e simples conjugadas na cadeia polimérica e passam de isolantes a condutores elétricos através de um processo de oxi-redução também chamado de dopagem ou protonação.

É importante conhecer essas propriedades elétricas com a finalidade de obter trilhas feitas de material orgânico apresentando boa condutividade elétrica, satisfazendo os mínimos requisitos para a sua função.

\subsubsection{Condutividade Elétrica}

Nos polímeros condutores existem basicamente dois tipos de condução de cargas, o eletrônico e o iônico, podendo também, em um mesmo sistema ocorrer ambos os tipos de condução. Foram propostos métodos ${ }^{12,13,14}$ para determinação de condutividade iônica e eletrônica separadamente. 


\subsubsection{Condução iônica}

A condução iônica ocorre através do transporte de massa (íons) no polímero.

Os fenômenos que envolvem o transporte iônico em polímeros condutores diferem daqueles envolvidos no transporte iônico em eletrólitos sólidos poliméricos. Os processos de redução em polímeros condutores são de certa forma, resultantes de processos de entrada e saída de íons na interface entre a matriz polimérica e a solução e movimentos de íons no polímero em si. Os eletrólitos sólidos poliméricos 15, 16, 17, 1819 são basicamente formados por um polímero não-condutor que contém um sal iônico dissolvido em sua matriz e o transporte iônico ocorre através do movimento segmentado da cadeia polimérica ${ }^{20}$. Trata-se, portanto, de um polímero condutor extrínseco. Muitas das aplicações dos polímeros intrinsecamente condutores estão relacionadas às suas propriedades de transporte. Desse modo, torna-se indispensável o conhecimento dos mecanismos de transporte de massa nestes materiais.

A difusão é devida a um gradiente de concentração e a migração a efeitos de campo elétrico. Assim, enquanto a difusão ocorre para todas as espécies, a migração afeta somente espécies carregadas, devido à existência de dipolos permanentes ou dipolos-induzidos ${ }^{21}$.

$\mathrm{Na}$ literatura podem ser encontrados estudos mais detalhados sobre o fenômeno de transporte de massa em soluções ${ }^{26,27}$ incluindo teorias mais recentes $^{22}$ e para eletrólitos sólidos poliméricos ${ }^{27,23}$.

Randles mostrou em 1947 que, qualquer cela eletroquímica pode ser representada por um circuito elétrico equivalente ${ }^{24}$. Esse circuito deveria incluir a combinação de resistências e capacitores representando:

- a dupla camada, que é uma região de acúmulo de carga, geralmente associada a uma interface. Elemento: capacitor $\left(\mathrm{C}_{\mathrm{d}}\right)$

- a impedância do processo. Elemento: $Z_{f}$

- a resistência não compensada, que é a resistência existente entre os eletrodos de trabalho e referência. Elemento: resistor $\left(R_{\Omega}\right)$. 


\subsubsection{Condução Eletrônica}

De acordo com a teoria de bandas (valência e condução) importada da física do estado sólido do silício cristalino, quando há fornecimento de energia, um elétron pode passar da banda de valência para a banda de condução. Esta saída do elétron leva a um espaço vazio, denominado de lacuna, o qual se comporta como uma carga positiva. As alterações químicas são controladas principalmente pela distribuição dos elétrons nos níveis de valência e a química (estrutura) das moléculas em estados eletronicamente excitados será consideravelmente diferente daquela no estado fundamental ${ }^{34}$. O elétron e a lacuna produzidos desta forma podem se movimentar independente dentro da estrutura cristalina, resultando no fenômeno de transporte de cargas ou condutividade elétrica sob uma polarização elétrica externa.

O modelo de banda desenvolvido anteriormente presume uma estrutura periódica perfeita, idêntico àquele encontrada em monocristais de grandes dimensões. Os materiais orgânicos muito raramente apresentam tal regularidade. Os polímeros, em particular, são caracterizados por longas cadeias de unidades monoméricas ligadas entre si por ligações covalentes. As ligações podem ser do tipo $\sigma$, como no polietileno e sua estrutura de banda, calculada por Andrée ${ }^{25}$, mostra um gap (diferença de energia entre a banda de condução e valência) muito grande (acima de $3 \mathrm{eV}$ ), colocando o polietileno como um isolante.

Ligações tipo $\sigma$ e $\pi$ podem ser alternadas, como o poliacetileno (ligações do tipo "trans"). Neste caso, o elétron pertencente a cada átomo de carbono poderá ser deslocalizado ao longo da cadeia do polímero que se comportara como um condutor $^{26}$. Entretanto, existe um grupo de polímeros com alternância de ligações simples e dupla na presença de anéis aromáticos (ligações do tipo "cis"), que levam a periodicidade ao longo da molécula e também produzem o mesmo efeito.

Esta regularidade, entretanto nunca é perfeita porque as cadeias nunca são rígidas e, para temperaturas maiores que as de transição vítrea, os movimentos moleculares passam a ser importantes. 


\subsection{Fotoluminescência e Eletroluminescência}

A descoberta em Cambridge, da eletroluminescência, emissão de luz quando um polímero conjugado é excitado por corrente elétrica ${ }^{4}$, resultou em um grande avanço no desenvolvimento de diodos emissores de luz para painéis luminosos e outros propósitos.

Painéis luminosos orgânicos representam uma alternativa em relação às já bem conhecidas tecnologia de telas como os de tubos de raios catódicos, plasmas e de cristal liquido.

A excitação de elétrons pode ser produzida de várias formas e levar os diferentes tipos de luminescência. A irradiação de material com fótons leva a fotoluminescência, a qual é subdividida em fluorescência e fosforescência, de acordo com a etapa intermediária seguida pelo processo de decaimento.

Eletroluminescência é a luz gerada pela eletricidade em materiais em processo não incandescente. Esta definição é muito generalizada para acomodar dois mecanismos de excitação muito diferentes que levam a emissão de luz: eletroluminescência de alto campo e eletroluminescência injetada. No primeiro caso, os elétrons acelerados pelo campo elétrico tornam-se suficientemente energéticos para excitar os centros luminescentes no instante de suas colisões.

$\mathrm{Na}$ eletroluminescência injetada, as cargas de sinais transportadas são injetadas em um semicondutor. Suas combinações levam a emissão de fótons ${ }^{27}$.

Atualmente, os polímeros fotocondutores usados na prática, são baseados em dois tipos de sistemas. No primeiro deles, a porção fotocondutora faz parte da cadeia do polímero como um grupo interno ou pendente, como, por exemplo, copolímeros em bloco e polímeros com cadeias laterais ${ }^{28,29}$. O segundo sistema envolve cromóforos de baixa massa molar embebidos na matriz polimérica. Algumas blendas poliméricas obtidas pela formação de polímeros conjugados têm sido recentemente utilizadas em leds, pois aumentam a eficiência da eletroluminescência. 


\subsection{Morfologia do PVK}

O Poli(N-vinilcarbazol) (PVK), desde sua descoberta como material fotoluminescente, é muito utilizado em desenvolvimento dispositivos eletroluminescentes como os PLED's.

PVK é um polímero vinílico aromático e termoplástico transparente, com ótima estabilidade térmica e química. Por exemplo, tem uma temperatura fusão de $300^{\circ} \mathrm{C}^{30,31,32}$ e uma temperatura de transição de vítrea $\left(T_{g}\right)$ de $211^{\circ} \mathrm{C}{ }^{33}$. Apesar da boa estabilidade térmica, esta propriedade nunca foi utilizada completamente por causa da extrema fragilidade do material (baixa resistência mecânica).

O PVK tem elevado índice de refração, de 1,69 e é um material fotocondutor, um isolante na obscuridade, e torna-se eletricamente condutor sob a exposição à radiação ultravioleta. Na presença de uma intensa luz de laser, existe a possibilidade de mudança morfológica e é considerado assim um material foto refrativo. PVK tem outras propriedades eletrônicas excelentes ${ }^{34}$ e também é solúvel em solventes orgânicos comuns como benzeno, tolueno e clorofórmio. Essas propriedades do PVK foram compiladas em artigos de revisão ${ }^{35,36}$. Também foram feitas muitas tentativas para melhorar o mecanismo e processamento característico do PVK por polimerização, orientação, mistura e copolimerização.

Uma análise detalhada de transições eletrônicas no polímero é determinada por Johnson ${ }^{37}$. Quatro faixas distintas atribuíram a transições $\pi-\pi^{*}$ foram observadas a $345 \mathrm{~nm}, 295 \mathrm{~nm}, 262 \mathrm{~nm}$ e $237 \mathrm{~nm}$. A migração de energia de um cromóforo para um local de geração de portador faz um papel importante na geração de carga de foto-condutividade.

Muitos estudos foram feitos para esclarecer o processo de migração em PVK e em polímeros relacionados ${ }^{38,39}$. Ledwith e colaboradores ${ }^{40}$ concluíram que polímeros, os quais contêm pendentes de carbazol, não exibem emissão de excitação excluindo aqueles cromóforos de carbazol que estão ligados diretamente à coluna vertebral do polímero. Esta conclusão foi confirmada pela investigação das propriedades fotoluminescentes de soluções de vários polímeros ${ }^{41,42}$.

O PVK é um polímero preparado do monômero Vinilcarbazol (VK) e é o primeiro e o mais estudado entre os fotocondutores orgânicos ${ }^{43,44,45}$. Tem sido mostrado, através da estrutura de seu monômero, VK, que o nitrogênio 
eletronegativo captura o elétron da dupla ligação via efeito indutivo. Por outro lado, elétrons não emparelhados do nitrogênio são doados a dupla ligação, pra criar uma dupla ligação rica em elétrons. Este último efeito domina no curso da competição entre efeitos de indução e conjugação. PVK tem sido largamente utilizado em materiais eletroluminescente como transportador de lacunas (tipo $p$ ).

\subsection{Protonação ou dopagem}

Normalmente, os polímeros condutores são chamados de "polímeros conjugados" porque são formados por cadeias contendo duplas ligações $C=C$ conjugadas. Esta conjugação permite que seja criado um fluxo de elétrons em condições específicas, como discutido a seguir. Os elétrons $p$ da dupla ligação podem ser facilmente removidos ou adicionados para formar um íon, neste caso, polimérico. Como podemos ver na Figura 2 do poliacetileno:

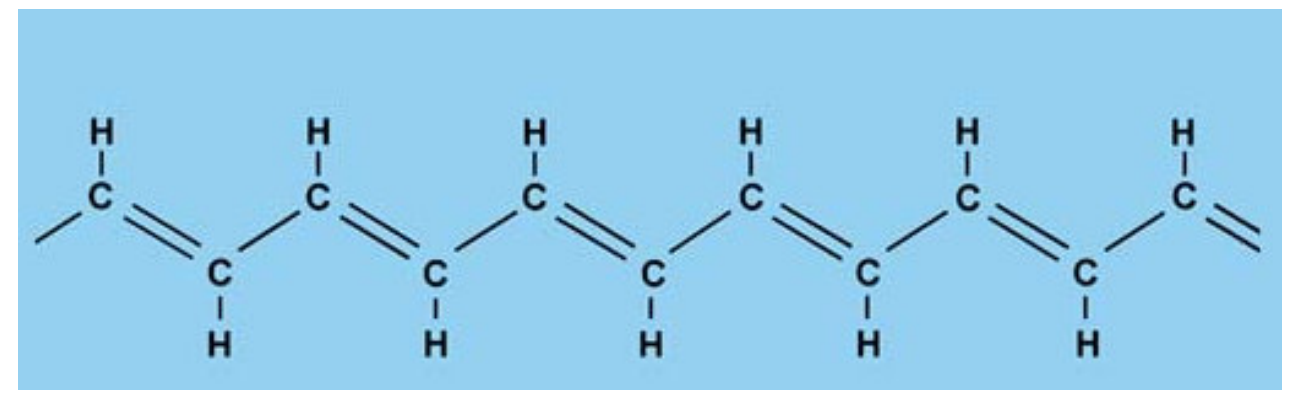

Figura 2: Estrutura do poliacetileno.

A oxi-redução da cadeia polimérica é efetuada por agentes de transferência de carga (aceitadores/doadores de elétrons), convertendo o polímero de isolante em condutor ou semicondutor. Nos semicondutores inorgânicos, a condutividade só é alcançada pela inserção de elementos (dopantes) que possam doar ou receber elétrons, a fim de proporcionar um fluxo de elétrons e assim gerar portadores de corrente elétrica.

Wang e Herron ${ }^{46}$ demonstraram outro método novo de dopar PVK e esse pode ser convertido prontamente em um semicondutor do tipo p. Oxidação de filmes de polímeros através de substâncias químicas ${ }^{47}$ ou eletroquímicas ${ }^{48}$ introduzindo 
cátions como radical, torna esses filmes coloridos e condutivos. Outros métodos de dopagem são com iodo, bromo em massa ${ }^{49}$ ou implantação de íons ${ }^{50}$.

Contudo, em sólidos unidimensionais dos quais os polímeros condutores fazem parte, pode ser energeticamente favorável localizar a carga que aparece sobre a cadeia (criando um defeito) e ter ao redor desta carga uma distorção local do retículo (relaxação) - Teorema de Peierl ${ }^{51}$.

Esse processo resulta no aparecimento de estados eletrônicos localizados no interior do "band-gap". Considerando-se o caso da oxidação, isto é, a remoção de um elétron da cadeia, há a formação de um cátion radical (também chamado de polaron em química de sólidos). Esta pode ser interpretada como a redistribuição de elétrons $\mathrm{p}$, que polariza a cadeia polimérica apenas localmente, produzindo uma modificação de curto alcance na distribuição espacial dos átomos.

Em termos químicos, um polaron consiste em um íon radical com carga unitária e spin $=1 / 2$, associado a uma distorção do retículo e à presença de estados localizados. No processo de formação do polaron, a banda permanece cheia e a condução vazia, e não há o aparecimento do caráter metálico, uma vez que o nível parcialmente ocupado está localizado na banda de gap.

\subsection{Métodos de Polimerização “viva” Existentes}

Nos últimos anos, a polimerização "viva" se tornou importante na engenharia e ciência de polímeros de ambos os pontos de vista acadêmico e industrial.

O termo "vivo" foi introduzido por Szwarc ${ }^{52,53}$, que utilizou este termo para distinguir as polimerizações em que os processos de finalização de cadeia, como a terminação e reações de transferência, são ausentes. Nesse caso, o polímero mesmo após a polimerização, permanece com o final da cadeia ativo.

A polimerização "viva" fornece um bom controle sobre a massa molar, distribuição de massa molar e arquitetura macromolecular dos polímeros produzidos. Isto gerou o desenvolvimento de novos materiais poliméricos com propriedades físicas e mecânicas novas ou aperfeiçoadas ${ }^{54}$.

As técnicas viáveis que oferecem apreciável controle sobre a massa molar, distribuição de massa molar e estrutura macromolecular são as polimerizações 
"vivas" (aniônica e catiônica) ${ }^{55,56}$. Entretanto, a versatilidade das polimerizações "vivas" iônicas é limitada por dificuldade do crescimento de cadeias finais com muitos grupos funcionais deferentes ou monômeros. As condições experimentais para a realização da síntese exigem exclusão de água e oxigênio e a utilização de reagentes e solventes de altíssima pureza, reduzindo a aplicabilidade das polimerizações "vivas" aniônicas e catiônicas a uma estreita faixa de estruturas possíveis.

A técnica de polimerização "viva", via radical livre, é oposta, em muitos aspectos, às polimerizações iônicas, uma vez que ela representa bons rendimentos, é compatível com uma ampla gama de grupos funcionais ou monômeros, mas oferece pequeno ou nenhum controle sobre a estrutura macromolecular.

O desenvolvimento de um processo tipo radical livre "vivo", que combine os atributos desejáveis de sistemas radicais livres tradicionais com a polimerização "viva", constituirá um avanço significativo, não somente na síntese de polímeros, mas na ciência de polímeros em geral.

\subsection{Polimerização via radical livre}

Do ponto de vista comercial, os polímeros vinílicos são os mais importantes de todos os tipos de polímeros. Além disso, uma grande variedade de tipos de monômero é compatível com a técnica de polimerização via radical livre, o que não é verdade com as polimerizações iônicas.

Alguns monômeros, principalmente estireno e metacrilato de metila e alguns cicloalcenos, sofrem polimerização sob aquecimento na ausência de um iniciador radical livre. Entretanto, a maioria dos monômeros requer algum tipo de iniciador. Vários iniciadores do tipo radical livre podem ser empregados ${ }^{57}$ e podem ser classificados dentre de quatro tipos: peróxidos e hidroperóxidos, composto azo, iniciadores redox e alguns compostos que formam radicais sob a influência da luz conhecidos como foto-iniciadores.

As radiações de alta energia (partículas $\alpha$ e $\beta$, raios $X$ e $\gamma$ ) podem também promover a polimerizações via radical livre, porem são pouco utilizadas. 
A polimerização por plasma ${ }^{58,59}$, polimerização iniciada por um gás parcialmente ionizado gerado por uma descarga elétrica em radiofreqüência, é amplamente utilizada para a preparação de camadas de revestimentos e isolamento, especialmente em aplicações na microeletrônica e na medicina. Entretanto, o mecanismo de polimerização, é complexo e parece envolver ambas as espécies: radical livre e iônica.

Foi demonstrado que a polimerização via radical livre pode ocorrer na ausência de agentes de terminação ou transferência de cadeia. Nestes casos, os radicais terminais de cadeia permanecem ativos quando todo o monômero é utilizado. A adição de mais monômero resulta em um aumento adicional de massa molar ou, se o monômero adicionado é diferente do monômero inicial, um copolímero em bloco pode ser formado. Estes polímeros com finais de cadeias ainda ativos são chamados de polímeros "vivos".

Vários grupos de pesquisa têm produzidos polímeros "vivos" pela adição de um radical livre e estável do tipo nitróxido para a polimerização de uma ampla faixa de monômeros ${ }^{60,61}$. Um exemplo é a polimerização de estireno com peróxido de benzoíla na presença de 2,2,6-6 tetrametilpiperidinil-1-óxi (TEMPO) ${ }^{62}$.

\subsection{Plasma}

O plasma é um gás parcialmente ionizado constituído de número igual de cargas positivas (íons) e negativas (elétrons) e um número de moléculas neutras (não ionizadas).

A Figura 3 mostra um esquema simplificado do processo de formação do plasma, bem como sua atuação em um substrato genérico.

Processos com plasma vêm sendo continuamente utilizados como objeto de estudo e pesquisa para o desenvolvimento de dispositivos semicondutores em microeletrônica, como por exemplo, na deposição e corrosão de uma variedade de filmes, dielétricos entre tantos outros mais ${ }^{63,64}$. Dentre estes, podemos citar os processos que envolvem a corrosão de fotoresiste, que normalmente são empregados nos processos de litografia, a corrosão do alumínio, que muitas vezes 
são empregados nos processos de multicamadas, e na corrosão do silício, para a abertura de trincheiras e microcanais ${ }^{65,66,67}$.

Outro campo de atuação dos processos que envolvem plasma está na deposição de filmes finos ${ }^{63}$. A deposição de filmes por plasma se destaca pela redução da temperatura (menor $400^{\circ} \mathrm{C}$ ), na qual os filmes são depositados ${ }^{68,69}$.

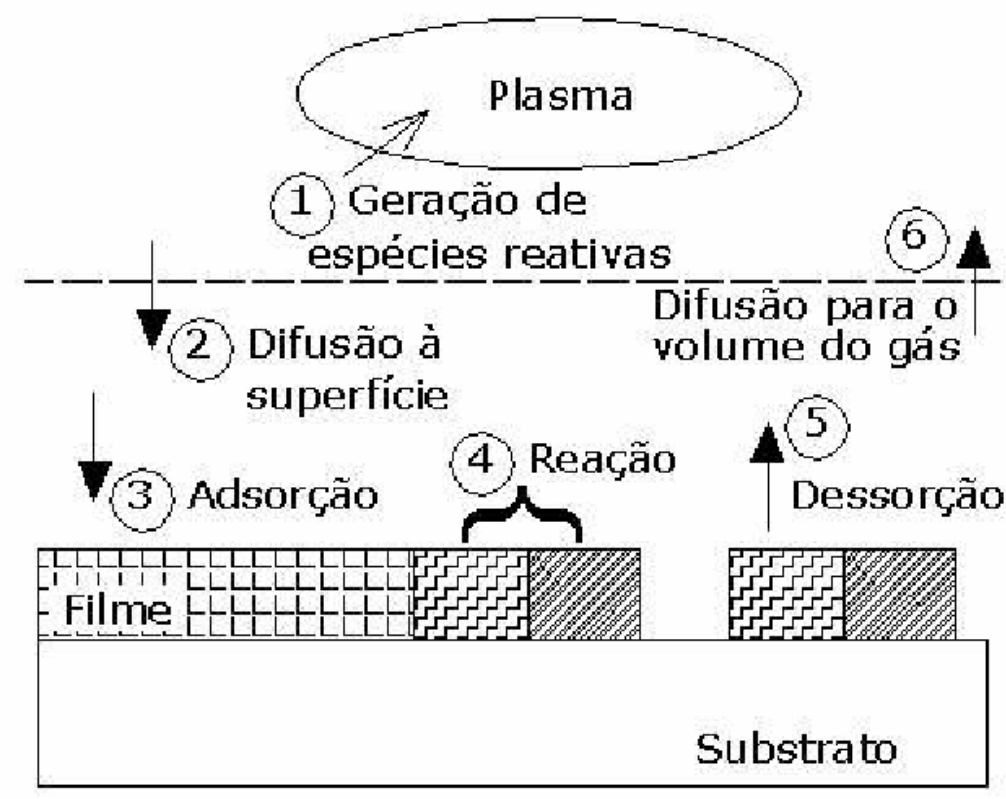

Figura 3: Esquema de processos dentro do reator ${ }^{70}$.

Processos com plasma oferecem um grande numero de vantagens. Uma destas vantagens, muitas vezes exigida em VLSI (Very-Large-Scale Integration) é necessidade de se obter um perfil de corrosão vertical, fato este, algumas vezes limitado, por exemplo, nos processos que envolvem corrosões úmidas.

O plasma depende de alguns parâmetros como: pressão, densidade, temperatura, presença de campos magnético e elétrico. Essas variáveis foram estudadas nessa dissertação diante da remoção de PVK como "parâmetros de ajuste".

Simultaneamente com o rápido crescimento de polimerização com plasma, outros métodos de preparação de filmes finos poliméricos foram desenvolvidos:

- Electron beam (feixe de elétrons);

- Absorção por UV de vapor orgânico;

- Evaporação simples. 
Atualmente muitas pesquisas estão sendo feitas com a utilização de plasma em processos com polímeros. A superfície polimérica tem sido tratada com plasma a fim de se maximizar algumas propriedades, como, aderência e dopagem.

O bombardeando com íons na superfície com energias suficientes podem causar reordenamento das moléculas, ou emissão de átomos da superfície. A energia limiar para emissão desses átomos leves é da ordem de $30-120 \mathrm{eV}^{71}{ }^{72}$, e a taxa de emissão é alcançada quando a diferença de potencial do plasma e da ordem de $100 \mathrm{eV}$.

No caso de substratos flutuantes (não aterrados) ou aterrados a média das energias dos íons não é suficiente para causar emissão de partículas. De qualquer modo, alguns processos na superfície são afetados por adsorção ou desorção. Radicais livres podem ser criados na superfície por adsorção excitada de moléculas neutras e algumas partes da energia podem ativar reações.

Uma alta intensidade de fluxo de elétrons pode causar aquecimento no substrato; e altas energias dos elétrons defeitos na superfície. Outros processos caudados por bombardeamento de íons incluem:

- A dissociação de moléculas adsorvidas;

- Defeitos na superfície, reações;

- Limpeza ou remoção de impurezas;

- Ionização, excitação e fragmentação de moléculas adsorvidas.

De qualquer modo, elétrons altamente energéticos, gerados dentro do plasma, refletem para o eletrodo negativo, no caso de descargas R.F. (rádio freqüência) ou para o catodo no caso de descargas D.C. (Direct Current - corrente contínua)

O bombardeamento de elétrons na superfície, resulta em (adsorção de átomos):

- Excitação, ionização ou fragmentação de moléculas;

- Dissociação resultando em desorção ou adsorção de elétrons estimulados.

O efeito de não formação de polímero (exemplos são plasmas de gases monoatômicos como $\mathrm{He}, \mathrm{Ar}, \mathrm{N}_{2}$ ) podem ser vistos em dois tipos de reação ${ }^{73,74}$. Reação de ativação de amostras com o polímero e formação de radicais livres no polímero.

A incorporação do nitrogênio ou oxigênio na superfície do polímero por plasma de $\mathrm{N}_{2}$ ou $\mathrm{O}_{2}$ são típicos exemplos dessa primeira reação. Um efeito secundário 
geralmente é a formação de carbonilas e hidroxilas e, para alguns níveis até "crosslinking" dependendo do tipo de substrato, desde que, a degradação do polímero na superfície leve a perda de massas.

Usando esta reação fundamental de plasma, muitas propriedades poliméricas podem ser controladas desde a reflexão óptica, adesão, coeficiente de fricção, energia superficial, permeabilidade, e biocompatibilidade de polímeros ${ }^{75}$.

A vantagem dessa técnica é apenas a modificação superficial não havendo modificações internas ou estruturais. Isso se deve ao baixo índice de penetração dos íons, os quais são de baixa energia.

$\mathrm{Na}$ polimerização de polímeros condutores via plasma, temos o PVK como um dos polímeros mais estudados, especialmente por suas aplicações em sistemas holográficos ${ }^{76}$. O primeiro estudo comparativo das propriedades elétricas do PVK em filmes preparados via solução e por plasma a partir do monômero VK em suporte de alumínio foi publicado por Nespürek e colaboradores ${ }^{77}$. A fotocondução de filmes de PVK foi detalhada por Inoue e colaboradores ${ }^{78}$.

Um estudo feito por Voudas e colaboradores ${ }^{79}$ mostra a clara dependência da taxa de corrosão com a espessura inicial de filmes poliméricos: a taxa diminui com a diminuição da espessura inicial do polímero; isto é, a resistência à corrosão de um filme fino é maior que a massa polimérica.

Também é mostrado que a $T_{g}$ de filmes finos é diferente, em geral, da $T_{g}$ do mesmo material mais espesso. Essa diferença na $T_{g}$ indica a diferença de propriedades estruturais e físicas (como a conformação, orientação, densidade entre outros) em função da espessura do polímero. Essas diferenças são refletidas em diferentes comportamentos durante o processo de plasma e subseqüentemente nas diferentes taxas de corrosão. 


\subsubsection{Plasma DC}

A descarga DC é produzida ao aplicar uma tensão contínua entre dois eletrodos em um sistema de baixa pressão.

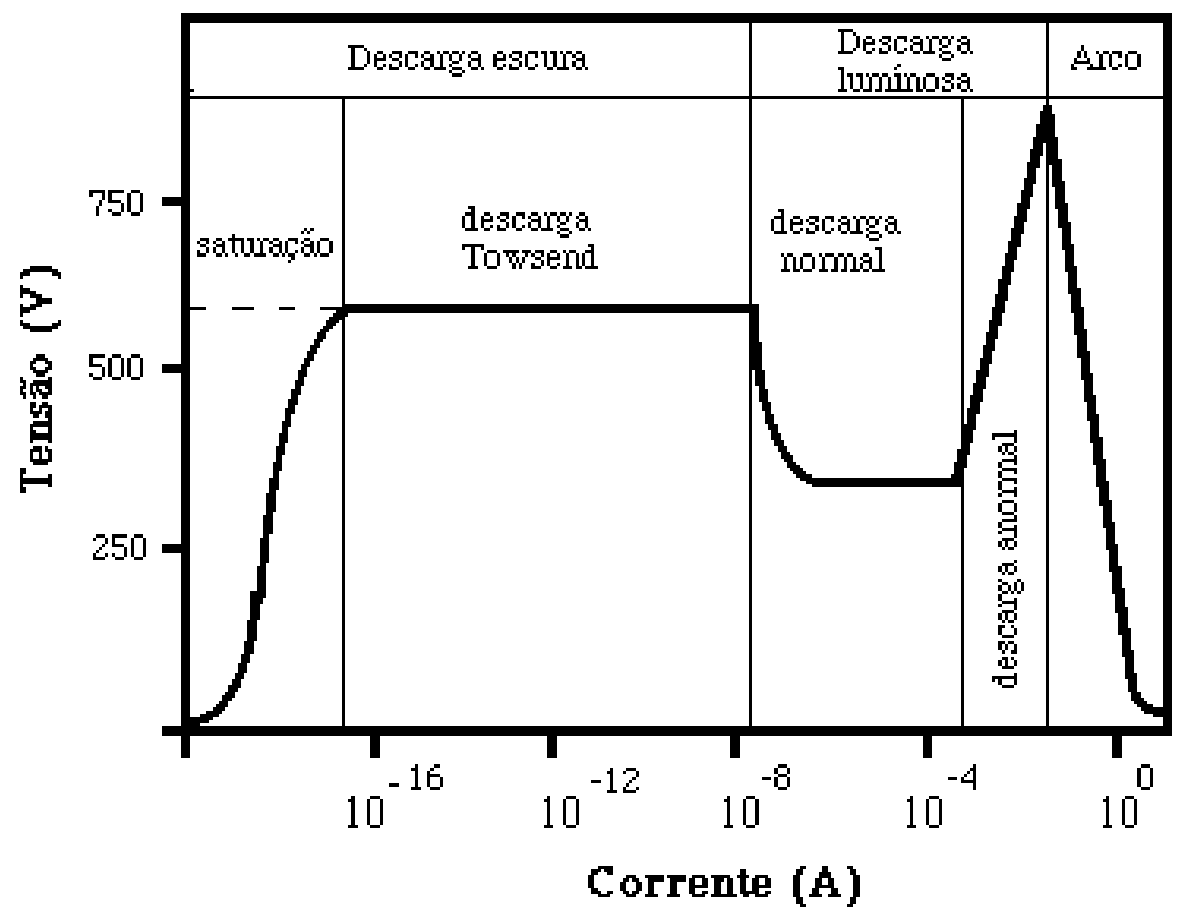

Figura 4: Curva característica de distribuição de potencial de plasma DC.

Para ter início a descarga são necessários "elétrons semente", que são gerados por raios cósmicos ou por efeito fotoelétrico, gerado pela luz ambiente, sendo assim a aceleração dos elétrons é constante e não alternada como no caso de plasma gerados a partir de rádio freqüência. Com a aplicação de um potencial elétrico entre os eletrodos, a descarga do gás é gerada, obtendo a seguinte distribuição de potencial. Conforme o diagrama (Figura 4) é possível verificar que a tensão de operação de um plasma DC varia entre 300-500V e a corrente permanece em torno de $10^{-8}$ a $10^{-4} \mathrm{~A}$, região de descarga luminosa.

O reator do plasma de argônio é do tipo tensão continua (DC). Esse mantém parâmetros como porcentagem de potência e pressão e é assistido por uma bomba mecânica de vácuo. O diagrama de blocos é ilustrado na Figura 5. 


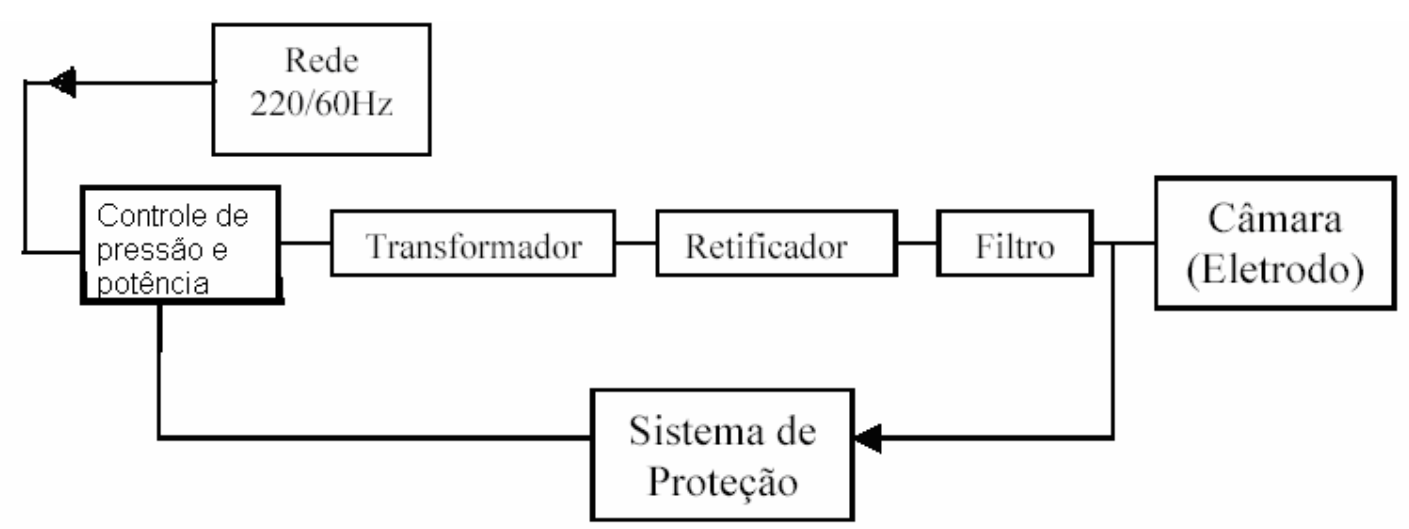

Figura 5: Diagrama de blocos do de um reator de plasma do tipo DC.

\subsubsection{Plasma RF}

O plasma, resultado da ação de uma onda senoidal denominado rádio freqüência $(R F)$, são os mais usados em processamento de materiais e situam-se na faixa de $\mathrm{MHz}$, o valor estipulado internacionalmente é de $13,56 \mathrm{MHz}$, pois essa freqüência não gera harmônicas que interfiram nas telecomunicações. A descarga RF é muito parecida com a descarga DC, mas apresenta uma característica bastante importante que é a baixa mobilidade dos íons em um sistema de alta freqüência, gerando assim, um potencial eletrostático nos eletrodos que possibilita a aceleração dos íons contra os eletrodos. Plasmas de RF podem ser excitados e mantidos, usando eletrodos condutivos ou dielétricos, enquanto que descargas DC, podem ser obtidas somente através de eletrodos condutores. Esses também podem ser obtidos indutiva ou capacitivamente com os eletrodos internos ao sistema de vácuo.

Outras características dos plasmas obtidos a partir de RF são as ionizações muito mais eficientemente dos gases que em DC, o bombardeamento iônico dos eletrodos pode ser controlado por um potencial DC, sem que este afete o processo de geração do plasma, enquanto que em DC, os eletrodos são submetidos à um alta tensão que favorece o ataque iônico com íons de alta energia, além de serem obtidos a pressões menores que plasmas DC.

Os experimentos de corrosão foram realizados em um reator tipo RIE (Reactive Ion Etching). O equipamento utilizado é um reator com acoplamento 
capacitivo, de placas paralelas, Plasma Technology modelo TTL (Figura 6). Os eletrodos são de alumínio com 249 mm de diâmetro e a câmara de aço inoxidável. O sinal de radio freqüência $(R F)$ utilizado para gerar o plasma é obtido de uma fonte RFX-600 da Advanced Energy Corp., operando na freqüência de 13,56MHz com potência máxima permitida de $600 \mathrm{~W}$. O reator consegue controlar os seguintes parâmetros: temperatura $\left(25^{\circ} \mathrm{C}\right)$, pressão (mtorr), fluxo de gás (sccm) e potência de RF (W). O sistema não possui controle de gases de saída, ou gases residuais.

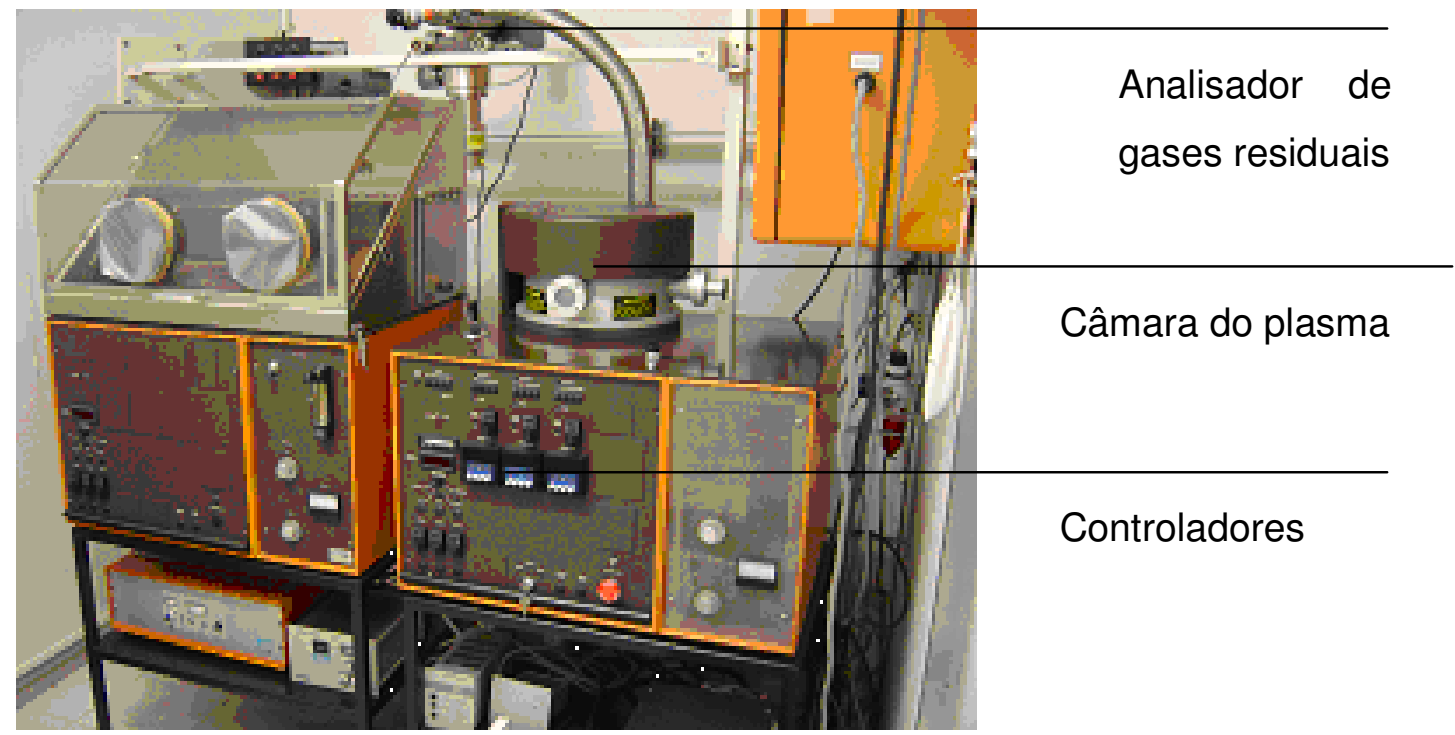

Figura 6: Equipamento gerador de plasma de oxigênio por RF do Plasma Technology, modelo: Plasma Lab. TTL.

\subsection{Litografia}

$\mathrm{Na}$ fabricação de circuitos integrados, uma das etapas mais significativas é a litografia ${ }^{80}$. Nesta etapa, são formados os padrões a serem transferidos para as camadas de materiais que compõe os dispositivos ${ }^{81}$. Durante o processo de litografia, a lâmina é coberta com uma fina camada de um material fotossensível e, após sua cura, é exposta a radiação (litografia óptica) ${ }^{82}$, ou a um feixe de elétrons (litografia por feixe de elétrons) ${ }^{83}$, ou ainda, a um feixe de raios-X (litografia por raios-X) para a formação dos padrões. 
O processo litográfico consiste em obter um desenho geometricamente plano de um filme de material resistente através de uma imagem óptica. Este material resistente, geralmente polimérico, protege o substrato sobre o qual está aderido do ataque químico a ser realizado posteriormente. Após o ataque químico, retira-se o filme, e o substrato terá uma topografia sobre a superfície que corresponderá ao positivo ou negativo fotográfico da imagem óptica inicial, dependendo apenas do tipo de resiste utilizado (Figura 7).

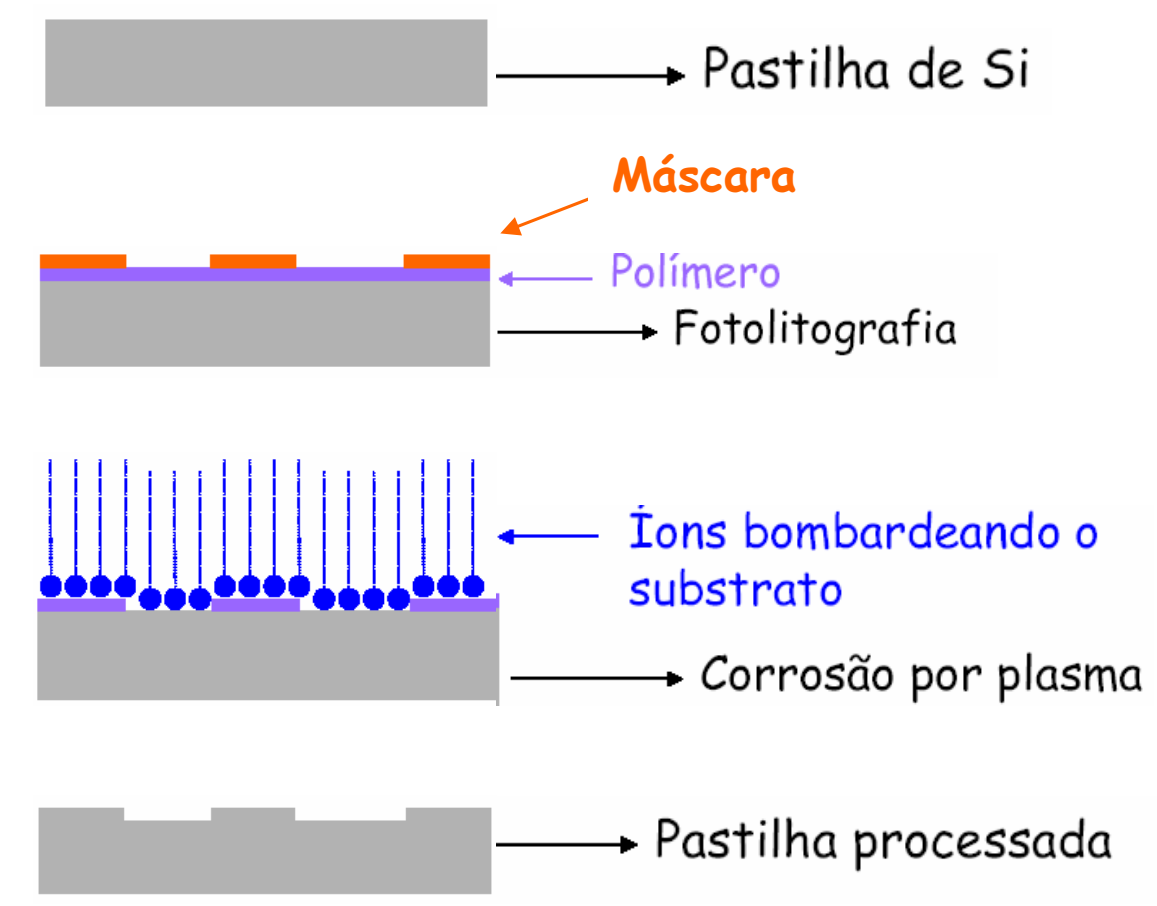

Figura 7: Esquema de um processo de corrosão, por meio de plasma.

Quando se utiliza uma imagem óptica para a transferência de imagem, o processo é denominado fotolitográfico ${ }^{84}$. A litografia é um dos maiores responsáveis pelo sucesso dos produtos microeletrônicos, pois ela é um dos processos que mais afeta o rendimento de produção.

Um circuito integrado moderno contém milhões de dispositivos eletrônicos ${ }^{85}$, com tamanhos típicos de poucos micrômetros. Nenhuma ferramenta física pode ser adequada para uma fabricação nessa escala. Ao invés disto, utiliza-se uma radiação luminosa como meio de conseguir realizar remoções seletivas do material da superfície do substrato ${ }^{86}$. A radiação tipicamente utilizada situa-se na faixa de comprimento do ultravioleta (UV). 
A maior parte da fabricação de Cls (Circuitos Integrados) é abrangida pelo uso de UV, apesar do crescente interesse de se usar raios-X e feixe de elétrons.

A fotolitografia depende do filme fotossensível denominado fotoresiste ou resiste. Um fotoresiste precisa ter duas propriedades principais:

i) se exposto a uma radiação apropriada causará uma mudança na solubilidade do mesmo;

ii) resistir ao ataque do agente corrosivo capaz de remover o material do substrato.

Num processo fotolitográfico, o fotoresiste é aplicado sobre o substrato, esse conjunto é irradiado através de uma placa de máscara ${ }^{87}$, sobre o qual está impressa uma cópia do que se deseja transferir ao substrato, em material opaco a radiação.

A placa de máscara pode ser obtida por um original, com o auxilio do Gerador de Padrões (Pattern Generator) ${ }^{88,89}$.

Um dos fatores importantes é o conjunto de características do resiste que está sendo empregado. Naturalmente, é desejável que o perfil do resiste já revelado seja perpendicular à superfície da lâmina, como mostra a Figura 8. No entanto, a absorção de energia ${ }^{90,91}$ no resiste, durante a exposição, dificilmente resulta nesse tipo de perfil, pois seu coeficiente de absorção não se comporta como o desejado.

Um coeficiente de absorção de energia muito alto gera um perfil do tipo cogumelo, Figura 8b, pois a maior parte da energia é absorvida na superfície (efeito pelicular) e, na realidade, o resiste abaixo da superfície será sub-exposto. Note que, neste exemplo, se assume um resiste que, na ausência de exposição, é completamente removido da superfície da lâmina (resiste negativo).

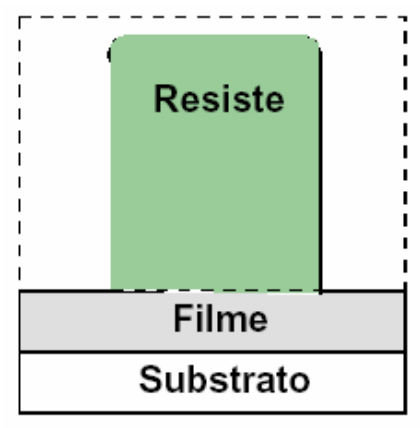

a)

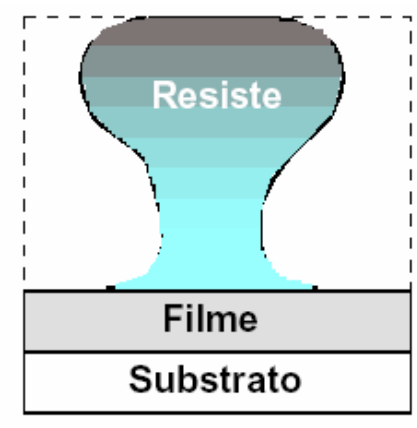

b)

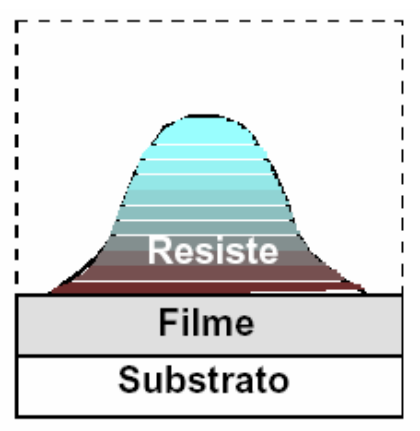

c)

Figura 8: a) Perfil ideal de resiste; b) Resiste negativo com coeficiente de absorção elevado; c) Resiste negativo com coeficiente de absorção muito baixo. 
Da mesma forma, um coeficiente de absorção de energia muito baixo gera um perfil do tipo triangular, Figura 8c, devido a uma subexposição da superfície, considerando que esta permanece mais tempo sob ação do banho revelador.

Efeitos de interação com o substrato também alteram o perfil do resiste ${ }^{92}$. Em litografia óptica é muito conhecido o fenômeno de ondas estacionárias (standing waves), decorrente da reflexão de luz da interface resiste/substrato, propiciando o aparecimento de fenômenos de interferência construtiva e destrutiva que causam a distribuição não uniforme de energia absorvida ao longo da espessura do resiste.

As etapas litográficas compreendem, em geral, a preparação da superfície da lâmina, o revestimento com fotoresiste, um cozimento pré-exposição (pré bake), a exposição à radiação, um cozimento pós-exposição, a revelação, um cozimento pósrevelação (pós bake), e, por fim, após sua utilização como máscara de resiste: a remoção (stripping) do mesmo.

Considerando-se que um dispositivo tenha sido adequadamente fabricado do ponto de vista de processamento, deve-se levar em conta ainda a existência de defeitos. Defeitos podem ser classificados como puntiformes aleatórios ou nãoaleatórios $^{93}$. Os defeitos não-aleatórios estão associados ao processamento em si, tais como resolução e registro inadequados, corrosão incompleta e deposições nãouniformes. São considerados defeitos puntiformes aqueles com dimensões menores que $10 \mu \mathrm{m}$ e localizados aleatoriamente. Sua origem, normalmente, é a contaminação por partículas provenientes da atmosfera ou dos equipamentos e materiais empregados no processamento. Um defeito capaz de inutilizar uma pastilha (chip) é chamado de defeito fatal (killing defect) e, no caso de particulados, é geralmente aceito que um defeito puntiforme de $1 / 3$ do tamanho da dimensão crítica é um defeito fatal ${ }^{94}$.

Com o aumento da área e a aproximação das vias de interconexão, o número e o tamanho dos defeitos precisam ser diminuídos. Uma vez que defeitos têm limitado o aumento no tamanho das pastilhas, a única forma de aumentar a complexidade dos circuitos é diminuindo-se a dimensão crítica. Por exemplo, para a produção de circuitos integrados com dimensões mínimas de 0,5 $\mu \mathrm{m}$ (como memórias de $16 \mathrm{Mb}$ ) são necessárias densidades de defeitos menores que 0,1 defeito $/ \mathrm{cm}^{2}{ }^{95}$. 
As técnicas litográficas de maior interesse atual para a fabricação dos circuitos integrados são a litografia óptica, a litografia por feixe de elétrons e a litografia por raios X. A aplicação de cada uma dessas técnicas está intrinsecamente ligada ao volume de produção e à resolução desejada. Por exemplo, circuitos para pesquisa e desenvolvimento são de grande diversidade e fabricados em baixíssimos volumes, uma vez que o mais importante é testar novos conceitos. Portanto, eles requerem determinado tipo de sistema litográfico que, certamente, não se aplica a uma fábrica preocupada em produzir um único tipo de componente em grande volume.

A litografia óptica é responsável pela maior parte da produção atual de circuitos impressos. A impressão por projeção ${ }^{96}$, sempre que os requisitos técnicos sejam satisfeitos, é, em geral, o método de produção mais econômico. Em litografia óptica, o principal objetivo é obter-se maior resolução com maior profundidade de foco.

A experiência tem mostrado que litografia óptica pode continuar sendo a solução. Por outro lado, a evolução da tecnologia de semicondutores tem fornecido exemplos dramáticos de aceitação de novas tecnologias, como a transição de difusão em fase de vapor para implantação iônica, processamento térmico em fornos para processamento térmico rápido e corrosão em banho líquido para corrosão por plasma.

Outra forma de melhorar o processo litográfico é atuando-se nos equipamentos periféricos de processo (considerando-se um mesmo equipamento de exposição e resiste), que podem ser aperfeiçoados de forma a garantir uma maior reprodutibilidade do processo litográfico e, com isso, podem até melhorar a sua resolução. Um exemplo disso é a integração de estações de processamento de resistes com os equipamentos de exposição ${ }^{97}$.

No entanto, as áreas que concentram os maiores esforços na melhoria da litografia são a de equipamentos de exposição (incluindo-se as máscaras por eles utilizadas) e a dos materiais dos resistes. 


\section{Capítulo III - Materiais e Metodologia.}

Nesse capítulo são apresentadas as partes de desenvolvimento do trabalho. Em primeiro plano é descrita a obtenção do Poli( $N$-vinilcarbazol). Os materiais utilizados, a metodologia e as sínteses e reações químicas envolvidas.

Em seguida é descrita as etapas do processo para a obtenção de um filme fino de PVK pelo método de "spin coating".

Após a obtenção do filme de PVK, a etapa do processo fotolitográfico para a delimitação de geometria é descrita.

Finalmente é descrito o processo de corrosão úmida e seca (plasma) para a remoção do PVK. A preparação e fabricação de filmes e os tipos de corrosões e remoções envolvidas.

\subsubsection{Materiais Utilizados}

Para a preparação do Poli( $N$-vinilcarbazol) foram utilizados os seguintes materiais para a sua síntese:

- $\mathbf{N}$-vinilcarbazol (Aldrich, $99 \%$ ) foi recristalizado duas vezes em metanol e seco sob vácuo por $24 \mathrm{~h}$.

- Peróxido de benzoíla (BPO) (Aldrich, $75 \%$ ) foi recristalizado em etanol.

- TEMPO (Aldrich, $98 \%$ ) foi utilizado como recebido pelo fornecedor.

- Solventes como: clorofórmio, metanol e tolueno foram utilizados sem purificação prévia.

Nos processos seguintes foram utilizados:

- Fotoresiste AZ 1518, Hoechst;

- Revelador AZ 351, Hoechst;

- Acetona 


\subsubsection{Metodologia}

Nesse item é descrita a metodologia do trabalho para a síntese do material poli $(N$-Vinilcarbazol).

\subsubsection{Síntese do Homopolímero de $N$-vinilcarbazol}

A primeira etapa da síntese foi a purificação do monômero $\mathrm{N}$-vinilcarbazol. Este foi recristalizado duas vezes, conforme descrito anteriormente para a remoção de impurezas. Nessa síntese, foram utilizados iniciadores BPO/TEMPO.

A partir do monômero foi iniciado o processo de polimerização. Uma parte de monômero, e os iniciadores foram colocados em um tubo de ensaio. A proporção utilizada foi de 1:1,33. O tubo de ensaio foi imerso em banho de óleo de silicone com temperatura de $130^{\circ}$ e é deixado por 141 horas, mantendo sempre a temperatura de $130^{\circ} \mathrm{C}$.

O produto resultante foi diluído em clorofórmio e, para diminuir o tempo do processo foi colocado em banho de ultra-som. O polímero resultante teve um aspecto sólido e assim não foi possível sua remoção do tubo de ensaio. Após a diluição com o clorofórmio, a solução foi purificada, para garantir a ausência de monômero de $\mathrm{N}$-vinilcarbazol, e para isso foi usado metanol (7 vezes o volume de solução), ou seja, para cada $1 \mathrm{ml}$ de solução (PVK+clorofórmio), foi incorporado $7 \mathrm{ml}$ de metanol. Passando essa nova solução por um filtro de papel, foi obtido um precipitado. O precipitado em forma de pó branco foi seco em meio ambiente, por 24 horas.

A reação de polimerização do $N$-vinilcarbazol foi obtida conforme mostrado na Figura 9. 


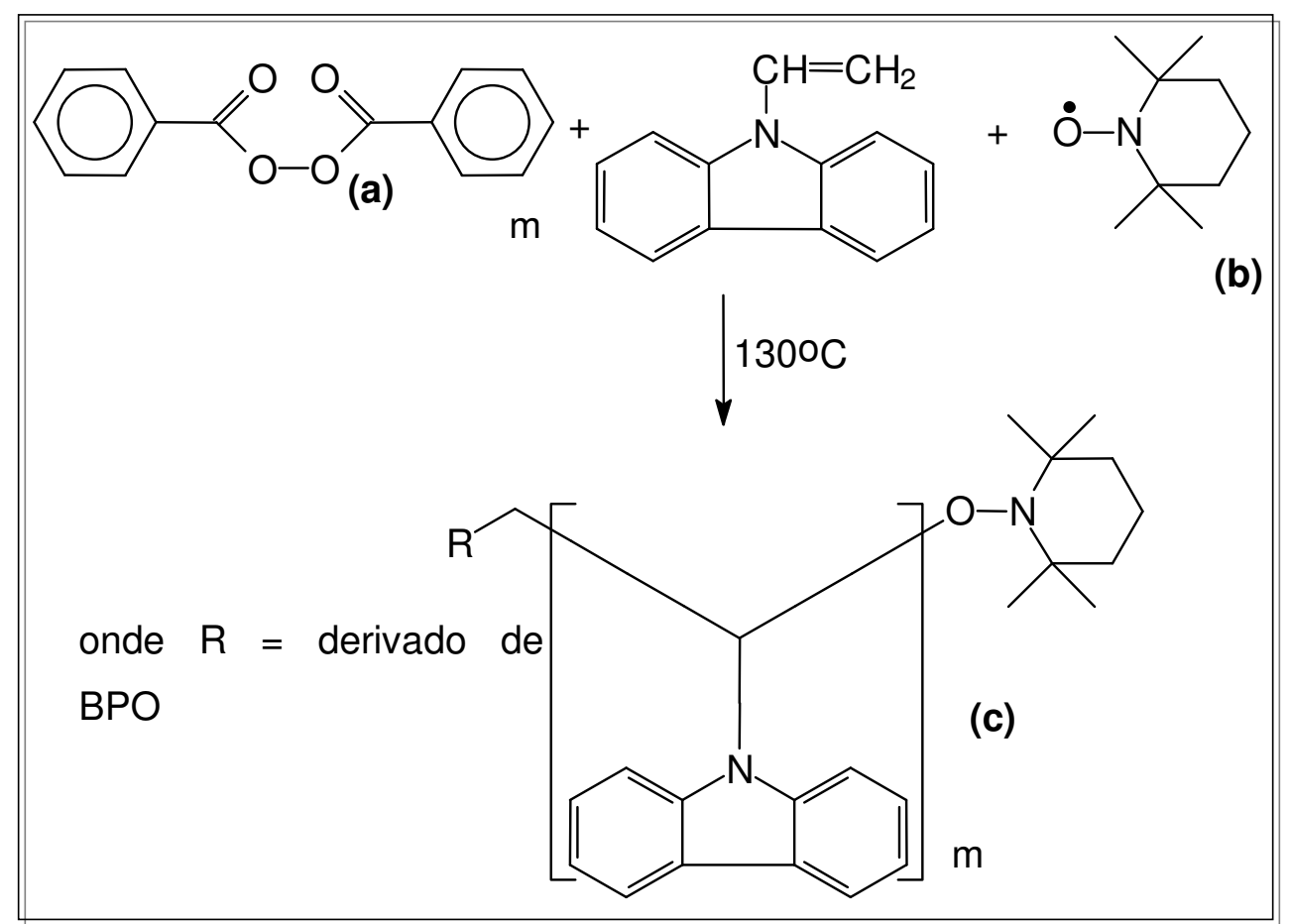

Figura 9: Polimerização de $N$-vinilcarbazol, via radical livre, utilizando um sistema de iniciadores bimoleculares. (a) BPO, (b) TEMPO e (c) homopolímero de Poli(N-vinilcarbazol) (PVK).

A massa molar pretendida é de $50.000 \mathrm{~g} / \mathrm{mol}$, já que em um estudo anterior ${ }^{6}$ foi demonstrado que essa massa molar, de $50.000 \mathrm{~g} / \mathrm{mol}$ oferece um polímero com a melhor condutividade elétrica possível $\left(\sim 10^{-7} \mathrm{~S} / \mathrm{cm}\right)$, na ausência do processo de dopagem. 


\subsection{Fabricação do Filme}

Existem varias técnicas para se realizar o revestimento de uma superfície com filmes finos micrométricos ${ }^{98}$. Nessa seção serão descritas duas técnicas de fabricação de filmes poliméricos.

\subsubsection{Spinner}

O spinner (espalhamento por rotação ou centrifugadora), na qual consiste em uma máquina com um prato giratório circular adequável ao tamanho da lâmina, que está conectado a um sistema de vácuo para prender a lâmina. O prato é rotacionado por um motor controlado eletronicamente, com velocidade entre 1000 a $7000 \mathrm{rpm}$.

O equipamento é acondicionado em uma caixa metálica com um painel de controle. A uniformidade do filme obtido sobre o substrato simples (lâmina de vidro, metal, polímero, etc.) deve ser em torno de $\pm 15 \mathrm{~nm}$ para assegurar a reprodutibilidade das larguras de linhas e tempos de revelação ${ }^{99}$.

A aplicação do material é realizada da seguinte maneira:

- A lâmina (substrato) é colocada sobre a plataforma giratória ("chucker"), centrada no eixo de rotação e prende-se a lâmina;

- Deposita-se um volume de polímero suficiente para cobrir por volta de 2/3 da área da lâmina a partir do centro;

- Logo em seguida é iniciada a rotação da lâmina até uma velocidade préselecionada ( entre 1000 e 7000 rpm);

- A operação é mantida por um tempo previamente estabelecido (aproximadamente 30 segundos) e em seguida a lâmina é removida do sistema, com o filme espalhado formando a película desejada.

O filme obtido nesse método apresenta boa homogeneidade no centro, mas pode apresentar falha nas bordas, devido ao rápido espalhamento pelo substrato. 
A espessura do filme também está relacionada ao solvente utilizado, assim, a combinação do solvente utilizado, com a porcentagem do mesmo no polímero e a rotação do equipamento definem a espessura do filme.

Quanto maior a porcentagem de solvente, mais fino o filme fica, pois esse espalha mais. A porcentagem do solvente com relação ao polímero utilizado nesse trabalho está detalhada nas próximas seções.

Os filmes obtidos por essa técnica obtiveram espessura média de 3,5 $\mu \mathrm{m}$, a espessura foi medida com o auxilio de um perfilômetro.

\subsubsection{Casting}

Outro método de obtenção de filme é chamado de "casting" nesse método, o polímero é colocado sobre a lâmina e esse espalha naturalmente. A lâmina com o filme depositado pode ser seca em estufa ou em ambiente aberto.

Ambos os métodos descritos anteriormente foram utilizados para a fabricação do filme: "spin coating" e "casting". A grande vantagem do "spin coating" é a possibilidade de obtenção de várias espessuras, controlando-se a rotação.

Para se obter o filme de PVK através de "spin coating", esse deve estar diluído. Para cada medida de volume $(\mathrm{ml})$ de clorofórmio se usa $5 \%$ de medida de massa(g) de PVK. Estudos anteriores mostraram que a proporção ideal é de 5\%, já que a de proporção de $10 \%$ em massa era uma solução muito viscosa e, quando gotejada sobre a lâmina, ela evaporava rapidamente, fazendo com que o filme obtido seja de baixa qualidade, com péssima uniformidade.

A espessura dos filmes foram medidas com o auxilio do perfilômetro ALPHA STEP500 do Laboratório de Microeletrônica da USP. 


\subsection{Processo de Corrosão}

Nesse item está descrito o processo de remoção do PVK usando dois processos de corrosão: úmida e seca.

\subsubsection{Corrosão Úmida}

O processo de corrosão úmida basicamente é a imersão de um material em meio aquoso e, através de ataque químico ou por dissolução, ocorre a remoção do material.

A lâmina passa por um processo de limpeza padrão do laboratório e após essa etapa o filme de PVK foi depositado por "spinner".

Para proteger determinadas áreas do PVK e obter a geometria desejada, a lâmina com o filme de PVK depositado passa pelo processo fotolitográfico. No substrato de vidro, com o filme de PVK é depositado fotoresiste. O fotoresiste foi aplicado a uma rotação de 3000rpm, por 30s, e os processos de cura foram feitos, também conforme o padrão do laboratório do LME.

Utilizando o Gerador de Padrões, a área requerida é sensibilizada e posteriormente é revelado. A área a ser removida é definida, podendo iniciar o processo de corrosão em si.

Para o processo de remoção do PVK, foi escolhido o tolueno, o qual é um solvente do PVK, mas não agride o resiste utilizado.

Foi utilizada para remoção do fotoresiste a acetona. Estudos anteriores comprovaram que o PVK não é solúvel em acetona ${ }^{6}$. O solvente utilizado para dissolver o polímero foi o clorofórmio (como visto anteriormente na seção 3.1.3). Então, testes preliminares de solubilidade do polímero e do fotoresiste foram realizados, já que era necessário um solvente que atacasse o polímero, mas não o fotoresiste utilizado AZ1518 e, outro que atacasse o fotoresiste, mas não o PVK. 


\subsubsection{Corrosão Seca}

A corrosão seca é um método para o ataque de uma determinada superfície sólida, com íons. Esse ataque pode ser físico, por bombardeamento de íons ou até mesmo químico reagindo com as espécies reagentes do material exposto. Existe a possibilidade de combinação dos mecanismos físicos e químicos.

Nesse estudo foram utilizados dois equipamentos. Um plasma é gerado por corrente continua e outro por radio freqüência, conforme já mencionado nas seções 2.8.1 e 2.8.2. Em cada equipamento foi utilizado um gás diferente. O plasma obtido a partir da corrente contínua (DC), foi utilizado o argônio e o plasma obtido a partir d rádio freqüência $(\mathrm{RF})$ foi utilizado oxigênio. No primeiro ensaio com plasma de argônio, utilizamos uma máscara mecânica. $O$ argônio, gás inerte, remove o polímero por bombardeamento através de íons, podendo promover maior degradação no material. Nesse processo ocorreu a degradação do filme, devido ao acúmulo de cargas elétricas na máscara mecânica metálica, em um primeiro momento. Posteriormente a geometria desejada foi obtida a partir de fotolitografia. Esse ensaio evitou as correntes de Foucault e protegeu o polímero na região prédeterminada, evitando assim, o problema de degradação do material após a exposição ao plasma de argônio.

No primeiro ensaio no plasma de R.F., utilizou-se a fotolitografia para a determinação das áreas a serem removidas e verificou-se a possibilidade de se utilizar o $\mathrm{O}_{2}$ como agente de corrosão no PVK.

As taxas de corrosão do fotoresiste são compatíveis com o esperado, já que o fotoresiste desempenha seu papel de proteção das geometrias a não serem atacadas.

No estudo do plasma de argônio, foi observada grande dificuldade de medir a espessura removida. Foi observado que o resiste penetra no filme polimérico devido a alta energia dos íons, esses "empurram" a camada de resiste na interface resiste/PVK. Diferente do que pode ser observado na corrosão por plasma de oxigênio. 


\section{Capítulo IV - Resultados}

Nesse capitulo são mostrados, os resultados do primeiro estudo sobre as trilhas obtidas pelos métodos expostos nos capítulos anteriores. No item 4.1, Análise do Poli( $N$-vinilcarbazol), foram feitas análises físico-químicos, mostrando o rendimento, qualidade e propriedades do material sintetizado.

No item 4.2 e 4.3 os resultados referentes a fabricação do filme, compatibilidade com o fotoresiste, respectivamente. Os resultados com as etapas de plasma de argônio, de oxigênio, bem como a utilização do Gerador de Padrões são mostrados nas seções 4.4, 4.5 e 4.6. As medidas de condutividade elétrica e caracterizações por microscopia eletrônica de varredura são mostradas nas seções 4.7 e 4.8 .

\subsection{Análise do Poli( $N$-vinilcarbazol) sintetizado}

Após o processo de obtenção do PVK (3.1.3) foram feitas as caracterizações do material sintetizado como: massa molecular média (GPC), rendimento, espectroscopia de infravermelho (IR) e espectroscopia de absorção na faixa de visível e ultravioleta (UV-Vis).

\subsubsection{Cromatografia de Permeação em Gel (GPC)}

A massa molecular média obtida foi de $50.000 \mathrm{~g} / \mathrm{mol}$ (obtida a partir da análise do GPC), conforme era esperado. Nessa massa molar foram observados os melhores resultados de condutividade elétrica, conforme descrito por Possidonio ${ }^{6}$. No trabalho de Possidonio é mostrado que a partir de massas molares de $50.000 \mathrm{~g} / \mathrm{mol}$ a condutividade do material não aumenta consideravelmente, sendo incompatível a síntese de materiais com altas massas molares, não sendo produtivo, 
pois o rendimento cai muito, e o beneficio não é compatível com os custos da síntese.

O rendimento do polímero foi de $64,4 \%$. Esse resultado foi excelente para o tipo de polimerização em cadeia e em massa. Trabalhos anteriores obtiveram rendimentos de no máximo $49 \%$.

\subsubsection{Infravermelho}

Caracterizações de infravermelho (IR) foram feitas para a análise de pontos característicos do material, comparando com os dados da literatura.

Caracterizações de IR foram realizadas com o equipamento BioRad Digilab Division QS-300 FTS-40, disponível no LME.

Os filmes obtidos para as analises de IR foram feitos utilizando o método de "casting" (o substrato nesse ensaio foi silício) o material foi seco em estufa, com temperatura de $100^{\circ} \mathrm{C}$ por 30 minutos. Em seguida foi levado imediatamente para a análise de IR, pois os filmes dopados com $\mathrm{LiClO}_{4}$ oxidam rapidamente.

Os filmes dopados com $\mathrm{LiClO}_{4}$ foram preparados utilizando porcentagens em massa de perclorato de lítio. Não foi determinada a real porcentagem de dopagem do material, ou seja, a porcentagem de perclorato de lítio que atua nas cadeias do polímero modificando a condutividade elétrica.

No espectro são mostrados na faixa de $931-945 \mathrm{~cm}^{-1}$ são anions livres de $\mathrm{CLO}_{4}{ }^{-100}$. 


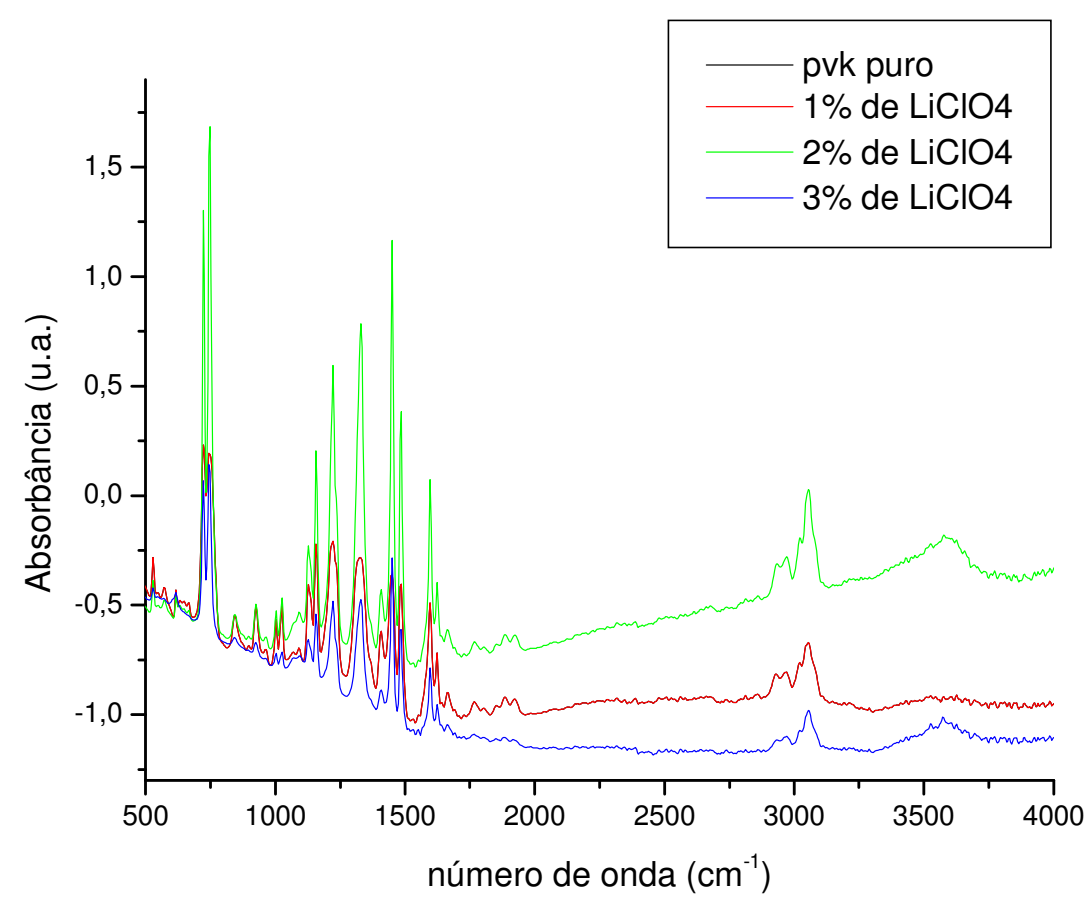

Z

Figura 10: Espectro de infravermelho para amostras de PVK puro e dopado com porcentagens de $1 \%, 2 \%$ e $3 \%$ de $\mathrm{LiClO}_{4}$.

No espectro da Figura 10, a curva do PVK puro, se confunde com a curva do PVK dopado com $1 \%$ de $\mathrm{LiClO}_{4}$ em massa.

$\mathrm{Na}$ Figura 11 (detalhe do espectro anterior), pode-se observar os pontos característicos do material sem dopantes, em 722 e $747 \mathrm{~cm}^{-1}$, devido o a ligação nitrogênio característica do PVK, conforme era esperado. Caracterizações feitas por Possidonio, também apresentaram os mesmos picos para o PVK.

Os picos de $721 \mathrm{~cm}^{-1}$ são referentes à deformação no anel de substituição da estrutura aromático do PVK, em $742 \mathrm{~cm}^{-1}$ é observado o pico devido à vibração das terminações de cadeia de $\mathrm{CH}_{2}$. Já em $1220 \mathrm{~cm}^{-1}$ é observado a ligação $\mathrm{C}-\mathrm{H}$ no plano de deformação do anel aromático, em $1329 \mathrm{~cm}^{-1}$ é referente à ligação $\mathrm{C}-\mathrm{H}$ do plano de vibração do grupo vinílico, enquanto em $3060 \mathrm{~cm}^{-1}$ temos a vibração de C-H assimétrico da estrutura aromática finalmente em $1450 \mathrm{~cm}^{-1}$, o pico é devido ao anel vibracional de $\mathrm{PVK}^{101}$. Todos esses picos afirmam que a polimerização ocorreu, o polímero obtido foi o PVK e os dopantes não afetam a estrutura morfológica do 
material, tendo em vista que mesmo com porcentagens de até $3 \%$ de $\mathrm{LiClO}_{4}$ não há mudanças nos picos característicos do PVK.

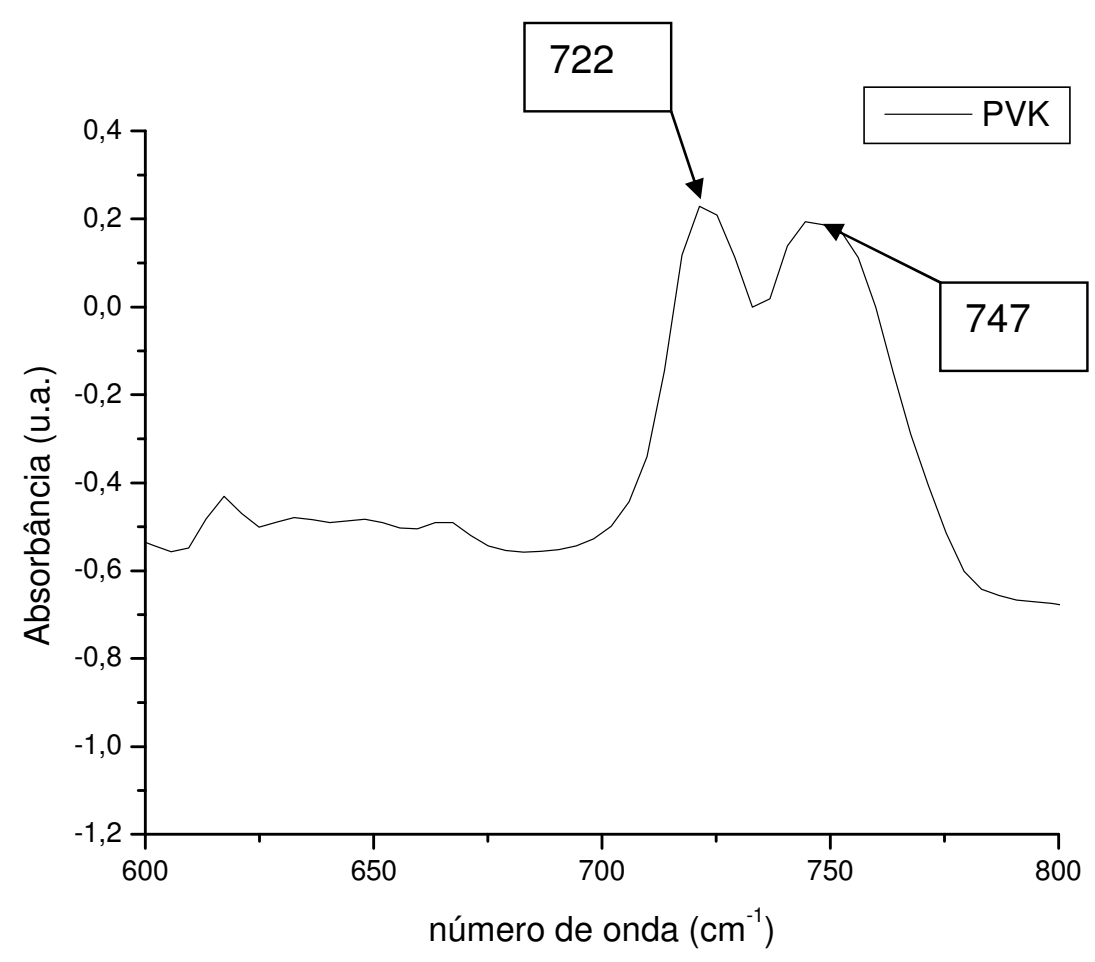

Figura 11: Espectro de infravermelho para amostras de PVK sem dopantes.

O PVK foi dopado com perclorato de lítio em porcentagens diferente, e a caracterização de IR foi feita. Como se pode observar na Figura 12, os picos característicos foram mantidos, mesmo com o processo de dopagem. Os espectros de PVK sem dopantes e com $1 \%$ de perclorato de lítio em massa, foram iguais. Assim as linhas foram sobrepostas. Esse gráfico é o detalhamento na faixa de 400 a $1000 \mathrm{~cm}^{-1}$ do gráfico da Figura 10. 


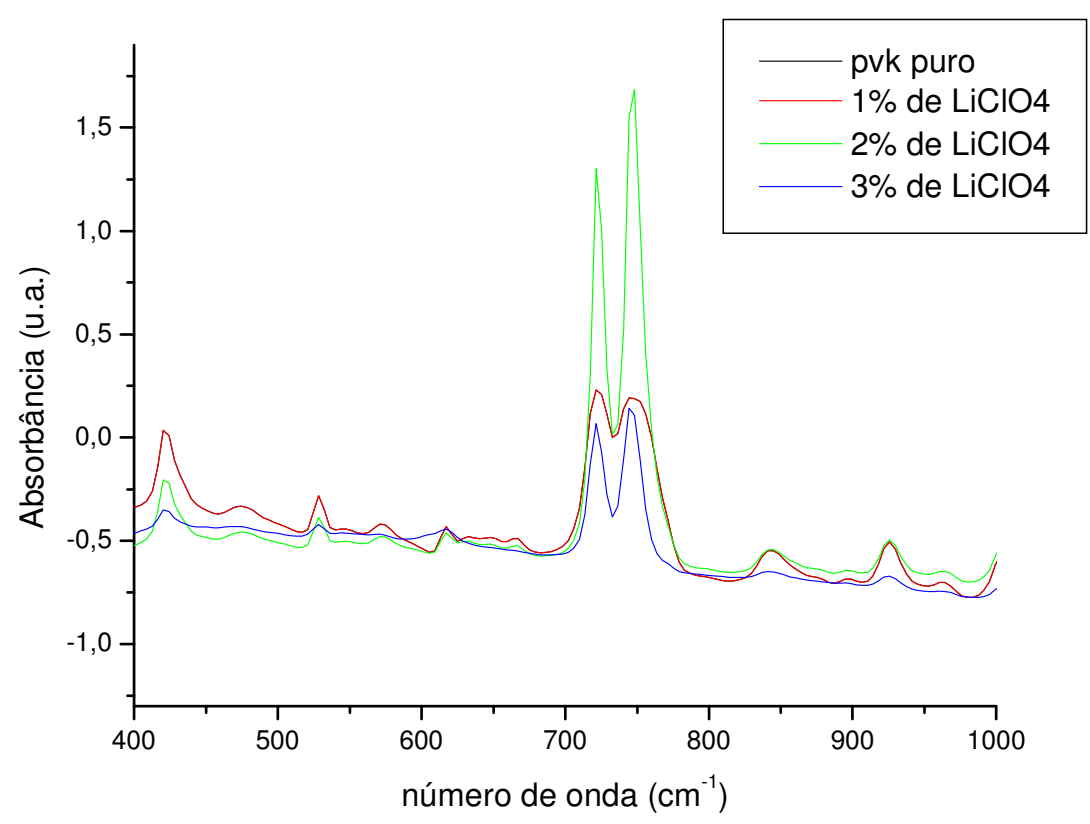

Figura 12: Espectro de infravermelho para amostras de PVK puro e dopado com porcentagens de $1 \%$, $2 \%$ e $3 \%$ de $\mathrm{LiClO}_{4}$, na faixa de 400 a $1000 \mathrm{~cm}^{-1}$.

Em todos os gráficos é observado diferença na intensidade de absorbância, mas como pode ser visto os picos estão nos números de onda. A diferença na intensidade da absorbância se deve a diferenças nas espessuras dos filmes.

Esses filmes foram obtidos por método de "casting" não havendo determinação previa das espessuras dos filmes, nem controle das espessuras, já que o polímero é colocado no substrato e o espelhamento ocorre naturalmente na lâmina, não havendo controle da espessura. 


\subsubsection{Ultravioleta e visível (UV-Vis)}

Para a análise de UV-Vis, filmes de PVK dopados e não dopados, foram preparados conforme os processos anteriores obtidos pelo método "spin coating", usando uma lâmina de vidro como substrato a uma rotação de 2000 rpm durante 20 segundos. Essas amostras não possibilitaram uma análise no equipamento UV-Vis devido a sua espessura muito fina $(<1 \mu \mathrm{m})$.

Os filmes obtidos pelo método "casting" usaram dois procedimentos para a remoção do solvente: no primeiro foram colocados em meio ambiente $\left(T \sim 25^{\circ} \mathrm{C}\right)$ e no segundo, em estufa à vácuo a uma temperatura de $63^{\circ} \mathrm{C}$. Apesar dos filmes obtidos por "casting" serem muito frágeis e quebradiços, foi possível medir a intensidade de absorbância e foi feito uma comparação entre os espectros obtidos com os filmes não dopados (duas amostra) e dopados (duas amostras) onde os solventes foram removidos em meio ambiente. $O$ tempo utilizado foi de 30 minutos. $O$ mesmo procedimento foi realizado para os filmes obtidos em estufa. Os filmes novamente apresentaram aparência fragilizada e certas regiões ficaram quebradiças. Entretanto a aderência no substrato de vidro melhorou visivelmente.

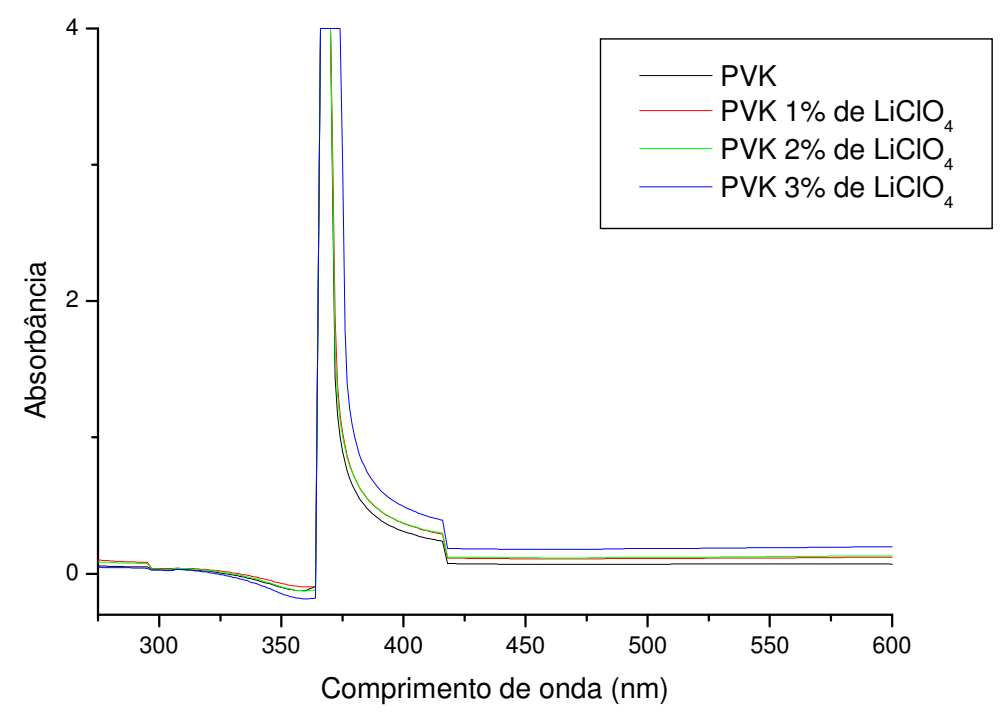

Figura 13: Espectro de UV-Vis para PVK puro e dopado com porcentagens em massa de $\mathrm{LiClO}_{4}$. 
Os resultados mostraram que os picos de absorção do PVK e PVK dopado com 1, 2 e 3\% de $\mathrm{LiClO}_{4}$, não apresentaram diferenças, sendo assim, pode-se concluir que o dopante praticamente não modifica a faixa de absorção do polímero conforme pode ser observado no gráfico da Figura 13.

O material apresentou picos em $375 \mathrm{~nm}$, diferente do que era esperado da literatura $(341-345 \mathrm{~nm})^{102},{ }^{103}$. Como o material ficou armazenado por vários dias antes de realizar a medida, essa diferença (deslocamento) provavelmente é conseqüência da degradação do material.

\subsubsection{Calorimetria Diferencial de Varredura (DSC)}

O material foi submetido a caracterização de Calorimetria Diferencial de Varredura (DSC), no equipamento DSC Q10 V7.3 Build 249, Standard Cell FC.

A amostra de polímero foi colocada em um cadinho de alumínio fechado, o fluxo de nitrogênio no ensaio foi de $50 \mathrm{ml} / \mathrm{min}$, e a temperatura foi reduzida até $-90^{\circ} \mathrm{C} \mathrm{com} o$ auxílio de nitrogênio líquido.

O DSC permite verificar a temperatura de transição vítrea do polímero. A $T_{g}$ é a propriedade do material onde se pode obter a temperatura da passagem do estado vítreo para um estado "maleável", sem ocorrência de uma mudança estrutural.

A parte amorfa do material (parte onde as cadeias moleculares estão desordenadas) é a responsável pela caracterização da temperatura de transição vítrea. Abaixo da $T_{g}$, o material não tem energia interna suficiente para permitir deslocamento de uma cadeia com relação a outra por mudanças conformacionais. Portanto, quanto mais cristalino for o material, menor será a representatividade da transição vítrea. 


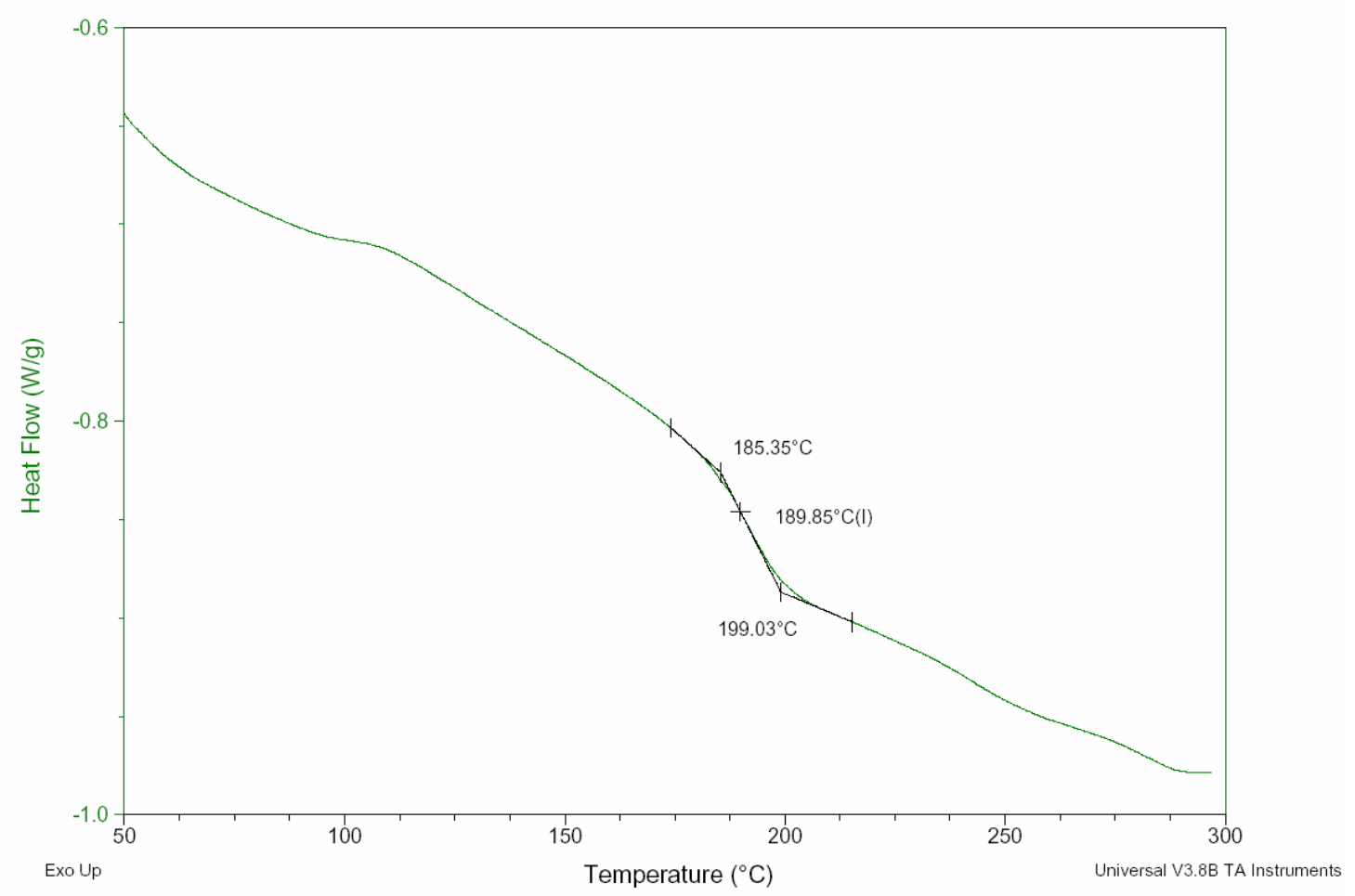

Figura 14: Dados de Calorimetria Diferencial de Varredura (DSC), variação de temperatura de 50 a $300^{\circ} \mathrm{C}$, com passos de $10^{\circ} \mathrm{C}$.

No ensaio $T_{g}$ é $189,85^{\circ} \mathrm{C}$, as condições foram passos de $10^{\circ} \mathrm{C}$ e variação de temperatura de $-90^{\circ} \mathrm{C}$ a $300^{\circ} \mathrm{C}$, o gráfico abaixo, como pode ser visto, apresenta 0 início de temperatura apenas em $50^{\circ} \mathrm{C}$.

É importante a determinação da temperatura de transição vítrea pois é uma característica fundamental do material. O PVK tem $\mathrm{T}_{\mathrm{g}}$ alta, mas essa propriedade pouco tem sido explorada por conta da fragilidade dos filmes obtidos. Para a possível utilização do PVK como material eletricamente condutor em um dispositivo eletro-eletrônico, é importante conhecer as propriedades térmicas do material, para maximizar a sua utilização, bem como combinar propriedades térmicas de outros componentes do dispositivo.

Nos ensaios desse trabalho, o plasma não atingiu temperaturas próximas da $T_{g}$, logo não existe possibilidade de degradação do material no processo de corrosão. A placa dentro do reator do plasma, na qual é colocada as amostras, é muito grande, mantendo a temperatura da amostra. A temperatura na superfície do 
filme polimérico não ultrapassa $120^{\circ} \mathrm{C}$, tendo em vista a não degradação do fotoresiste.

\subsection{Fabricação de Filmes}

A etapa inicial consiste em colocar de uma determinada quantidade de soluto (polímero em g) em um determinado volume de solvente previamente escolhido (em $\mathrm{ml}$ ), o clorofórmio e agitar até obter uma solução livre de particulados. Em certas ocasiões, é necessário o uso do banho ultra-som.

O primeiro método utilizado foi o "casting" (espalhamento natural), na qual uma quantidade de solução é despejada no substrato de vidro e esta tende a se espalhar naturalmente e, em contato com o meio ambiente, o solvente começa a

evaporar. É necessário que o solvente seja o mais volátil possível. Essa técnica é muito simples e o polímero não mostrou interação com o meio ambiente. Porém os filmes formados foram muito espessos e esses desprendiam do substrato com facilidade depois de um determinado tempo, além da irregularidade e nãohomogeneidade da espessura dos filmes obtidos. A partir desses resultados, esse método tornou-se inviável para as próximas etapas de processo na obtenção de dispositivos eletrônicos.

Outro método utilizado foi o "spin coating" (espalhamento por rotação controlada). Essa técnica consiste em depositar a solução polimérica (por volta de 4 gotas, ou $150 \mu \mathrm{l}$ ) no substrato e submeter o conjunto todo a uma rotação préestabelecida, conforme mostra a Figura 15. 


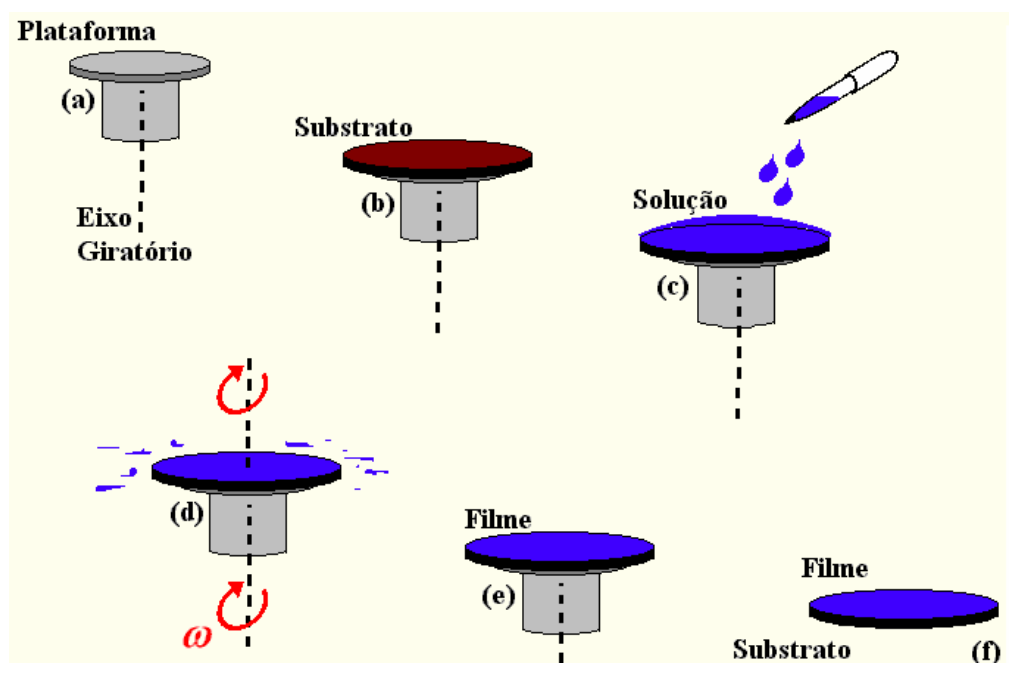

Figura 15: Esquema de obtenção de filme de PVK a partir do método denominado de "spin coating".

Para as diversas concentrações soluto/solvente, foram feitos alguns ensaios. Foi escolhida a melhor proporção de solução como visto anteriormente $(5 \%$ em massa de PVK, para cada $1 \mathrm{ml}$ de clorofórmio). A partir dessa proporção de solução, outros testes foram feitos para a obtenção de melhores filmes. Foi pretendido filmes de cerca de $3 \mu \mathrm{m}$, para tal a melhor rotação foi de 2000 rpm por 30 segundos.

Os filmes foram secos em ambiente aberto e o tempo de secagem foi de 10 minutos, permanecendo apenas uma película polimérica para ser usada nos ensaios de corrosão por plasma e úmida.

Os filmes de fotoresiste fora obtidos por "spin coating", com rotação de 300 rpm por 30 segundos. Após a obtenção dos filmes de fotoresiste esses eram secos em estufa com temperatura de $80^{\circ} \mathrm{C}$ por 30 minutos.

Conforme será visto, seção 4.3, testes com o fotoresiste foram feitos para verificar a compatibilidade nos processos de fabricação das trilhas. 


\subsection{Testes com o Fotoresiste.}

Nessa etapa foi estudado o comportamento entre os filmes de PVK e o fotoresiste AZ 1518. O fotoresiste foi utilizado para a proteção do PVK nos processos de corrosão.

Após a fabricação do filme fino, o fotoresiste foi aplicado conforme os padrões do laboratório e foi fotogravado uma geometria pré-selecionada.

Não foi possível continuar a utilização do clorofórmio como solvente do PVK nessa etapa, pois o clorofórmio degrada o fotoresiste AZ 1518. Sendo assim, o solvente utilizado para o Poli $(N$-vinilcarbazol $)$ foi o tolueno. Testes iniciais foram realizados e conclui-se que esse solvente não ataca o fotoresiste AZ1518 utilizado. $O$ resiste AZ 1518 é facilmente removido na presença de acetona.

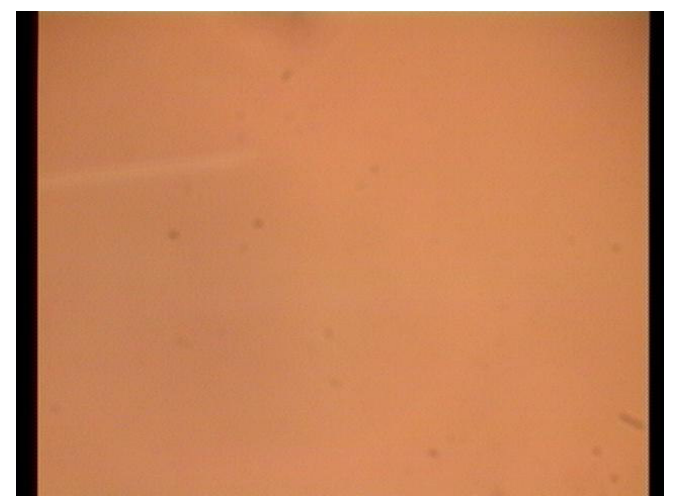

a)

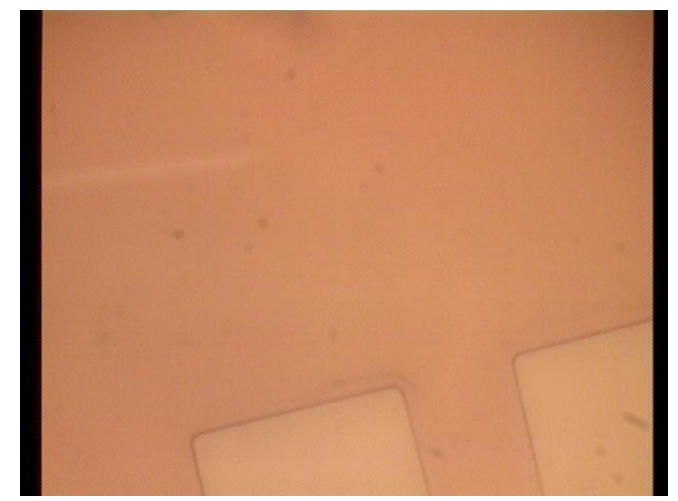

b)

Figura 16: Fotos de Microscopia óptica, de resiste AZ1518 antes (a) e depois (b) da exposição com tolueno. (aumento de 500 vezes).

A acetona é o solvente comumente usado pra remoção do $A Z 1518$, mas não remove o Poli( $N$-vinilcarbazol).

Na Figura 16, é observada que após a exposição do resiste ao tolueno, o fotoresiste não altera coloração, espessura. Não existe vestígio de ataque do resiste.

Dessa maneira, o tolueno foi usado para a remoção do PVK e, usando o fotoresiste como proteção das camadas inferiores, o PVK não foi removido resultando nas mesmas geometrias definidas pelo fotoresiste, posteriormente removido com acetona. 
Entretanto, essas trilhas obtidas, continham muitas fissuras de dimensões consideráveis de maneira a prejudicar a continuidade das trilhas condutoras de PVK.

No processo de corrosão úmida, o polímero, devido a presença de substancias líquidas, sofre um processo de expansão e contração e fica sujeito a rupturas e fissuras (stress), conforme pode ser observado no microscópio óptico, conforme observado na Figura 17.

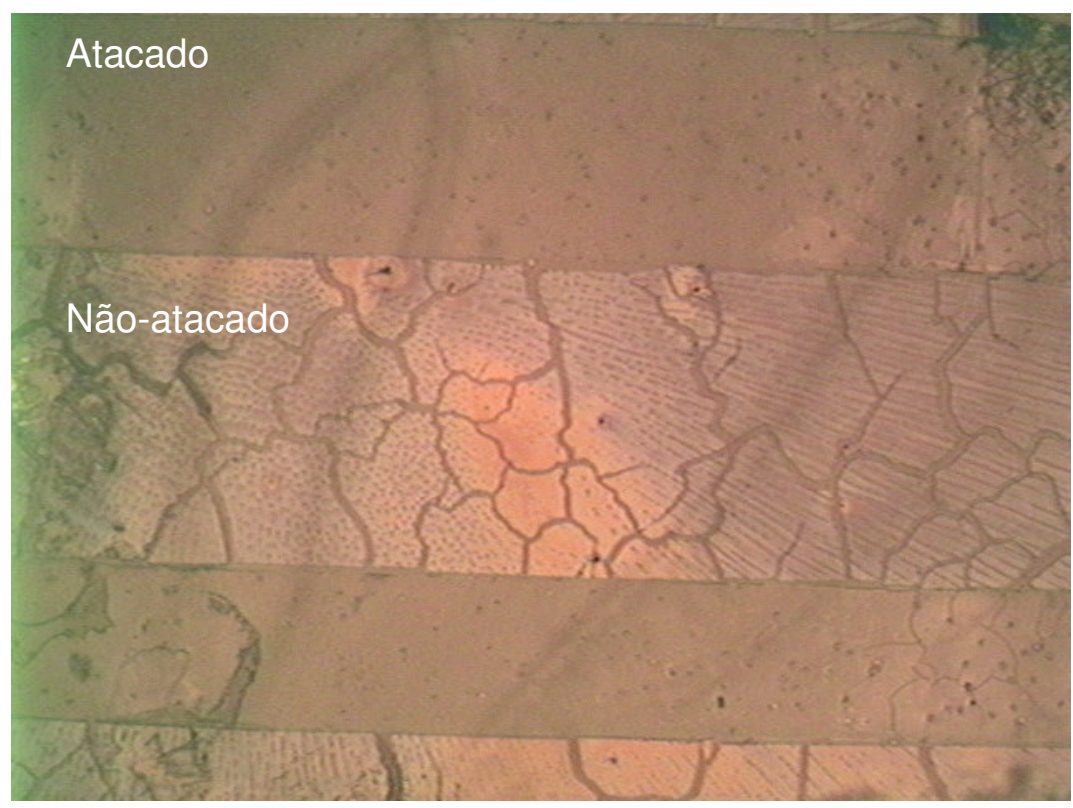

Figura 17: Microscopia óptica de trilha obtida a partir de corrosão úmida com tolueno.

Essas fissuras são responsáveis pela descontinuidade das trilhas de PVK, o que dificulta a passagem de cargas elétricas em uma situação de condução, podendo ocorrer uma situação de ruptura da continuidade,.isso pode ser explicado pelo inchamento do resiste pelo tolueno, comumente utilizado para reverter o tom do resiste óptico positivo. 


\subsection{Plasma de Argônio}

Uma outra técnica de remoção de material além de corrosão úmida, foi a utilização do plasma de argônio. Testes preliminares provaram a possibilidade de corrosão do PVK, por plasma de argônio.

O substrato contendo o filme polimérico foi colocado sobre o eletrodo ativo, o plasma de argônio teve sua ignição a partir de uma determinada tensão constante. A câmara possui um disco com diâmetro de $12 \mathrm{~cm}$ (eletrodo ativo) e é alimentado pelo secundário de um transformador elevador de tensão. O controle de potência é realizado no primário do transformador.

O sistema de vácuo é assistido por uma bomba turbo molecular e uma bomba mecânica. Entre a bomba turbo molecular e a câmara existe uma válvula gaveta. Durante a deposição, essa válvula gaveta fica na mínima vazão e a pressão do sistema controlada pelo fluxo de argônio.

As condições do plasma foram: pressão de 2,0.10-1 mbar, com picos de até $5,9.10^{-1}$ mbar, devido a controle ruim da válvula gaveta, a potência foi de $20 \%$ da potencia total do equipamento, não havendo grande elevação de temperatura. $O$ plasma agiu durante 2 min, o que não permitiu total remoção da parte não protegida.

Substrato de vidro

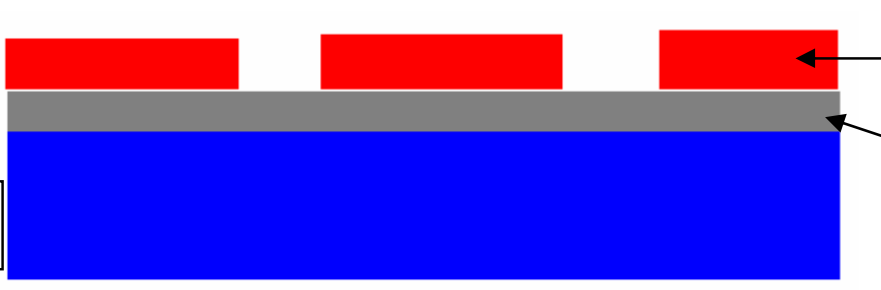

Fotoresiste

PVK

Figura 18: Filme de PVK com fotoresiste: taxa de corrosão de $0,855 \mu \mathrm{m} / \mathrm{min}$.

Substrato de vidro

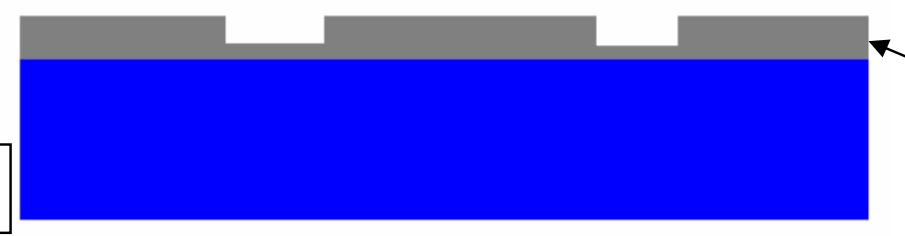

PVK

Figura 19: Filme de PVK sem fotoresiste: taxa de corrosão de 1,180 $\mu \mathrm{m} / \mathrm{min}$. 
Nessas condições, foi possível medir a taxa de corrosão resultando em de $0,855 \mu \mathrm{m} / \mathrm{min}$. com o fotoresiste e $1,180 \mu \mathrm{m} / \mathrm{min}$ sem fotoresiste. A taxa de remoção foi de $38 \%$ maior sem fotoresiste conforme ilustra as Figura 18 e Figura 19 :

A Figura 19 mostra a camada de PVK removida em função do tempo de exposição ao plasma de Ar.

No início da corrosão a taxa é pequena provavelmente pela estrutura do PVK ser mais rígida. O mesmo acontece quando o filme de PVK fica mais próximo a superfície do substrato de vidro. Uma explicação para esse comportamento é a presença de microbolhas no volume do material e ausente nos externos.

Quando depositado por "spin coating", a camada próxima a interface PVK-vidro espalha de maneira a não formar essas microbolhas e a camada externa em contato com o meio ambiente evita a sua formação.

Foi observada uma condição ótima entre 1 e 2 minutos de corrosão, nesse intervalo a taxa de remoção é alta, após esse período ocorre a saturação de corrosão.

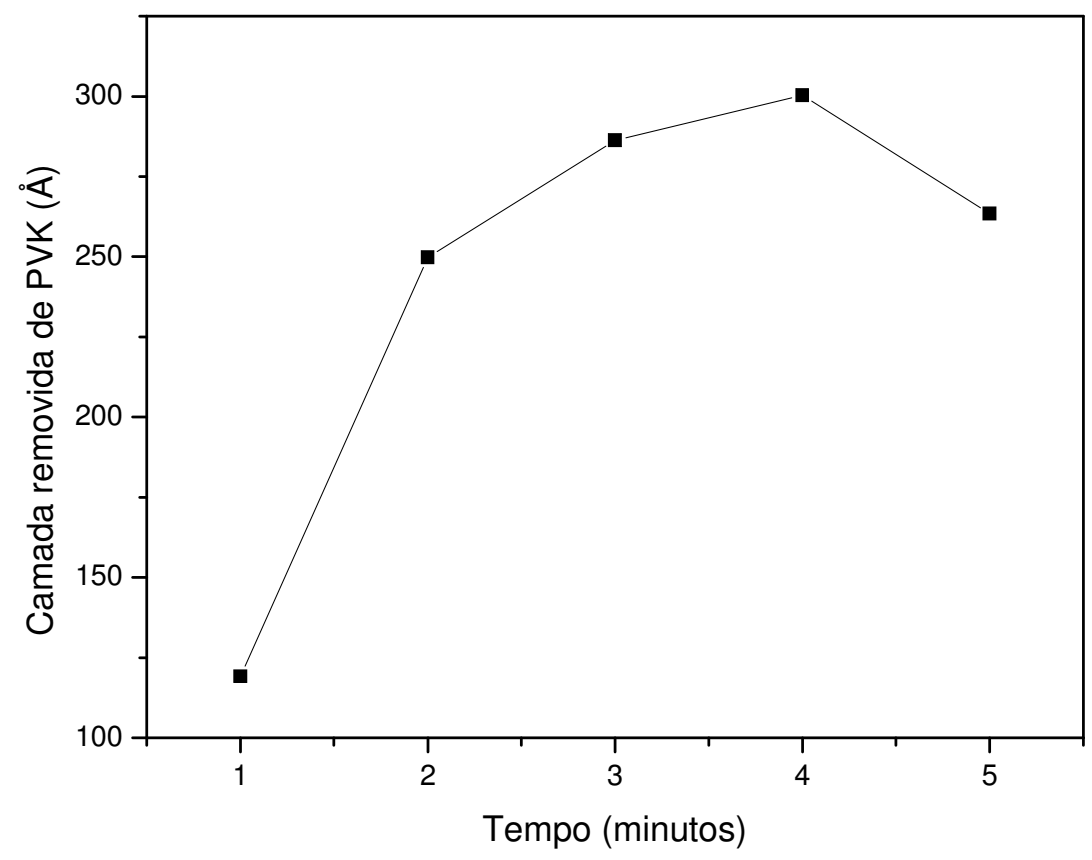

Figura 20: Comportamento da espessura em função do tempo de exposição do filme de PVK no plasma DC de argônio. 
A definição das trilhas usando esse método de corrosão por plasma é mais eficaz do que a corrosão úmida, havendo uma confiabilidade maior para a finalidade desse estudo, que é desenvolver trilhas condutoras para a aplicação em dispositivos. É um método mais limpo, pois há pouca exposição com reagentes químicos, os filmes ficam nas câmaras de vácuo por mais tempo.

Usando processo por corrosão por plasma e as condições estudadas, foi realizado um processo onde metade do PVK foi protegido pelo fotoresiste e a outra metade exposta ao plasma. O resultado está ilustrado na Figura 21a e Figura 21b.

A Figura 21 mostra claramente a região protegida (não atacada) e a região exposta (atacada). Entretanto observando-se uma descontinuidade do filme de PVK depositado conforme mostra uma ampliação da região da Figura 21b.

Apesar das condições do ensaio estarem programadas para condições ótimas, as trilhas obtidas não são adequadas para a finalidade desejada.

A explicação é que o fenômeno de nucleação é muito intenso provocando possíveis interrupções nas trilhas; impedindo então a condução dos portadores de carga (Figura 21).

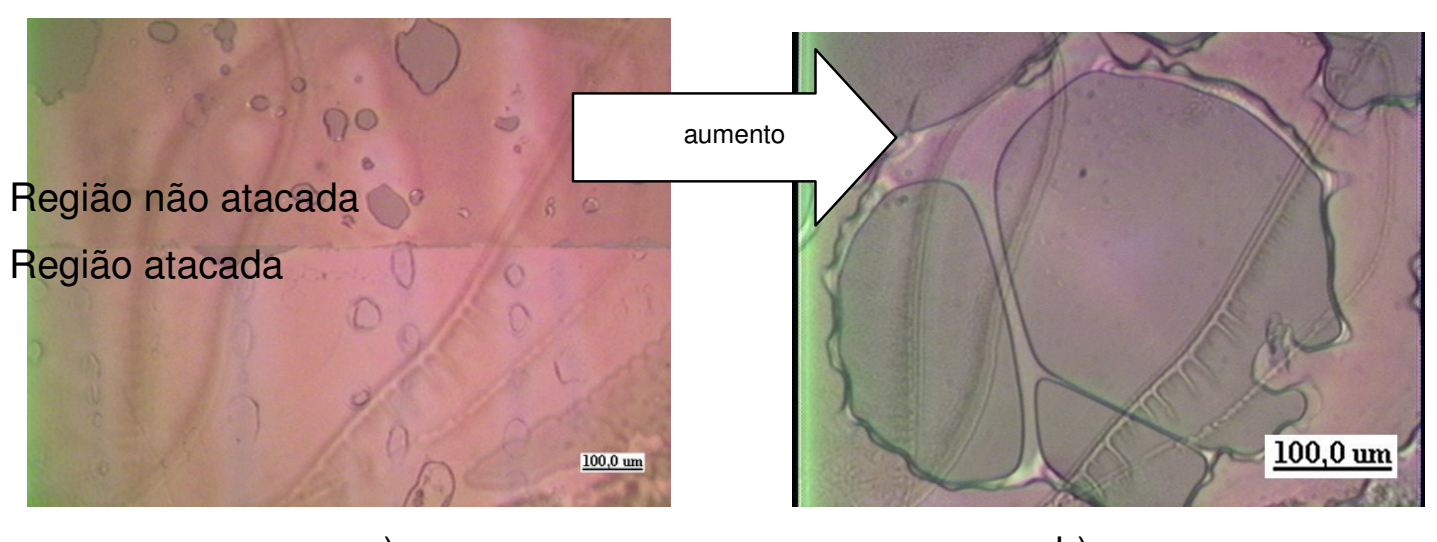

a)

b)

Figura 21: a) Microscópio óptico com aumento de 500 vezes. b) Detalhe ampliado da foto.

A seguir foram realizadas imagens a partir do microscópio eletrônico de varredura (MEV) do filme polimérico antes (Figura 22a) e após (Figura 22b) o ataque com plasma de argônio. É possível observar que o ataque com plasma de argônio não é homogêneo indicando nucleação durante o processo de remoção. 


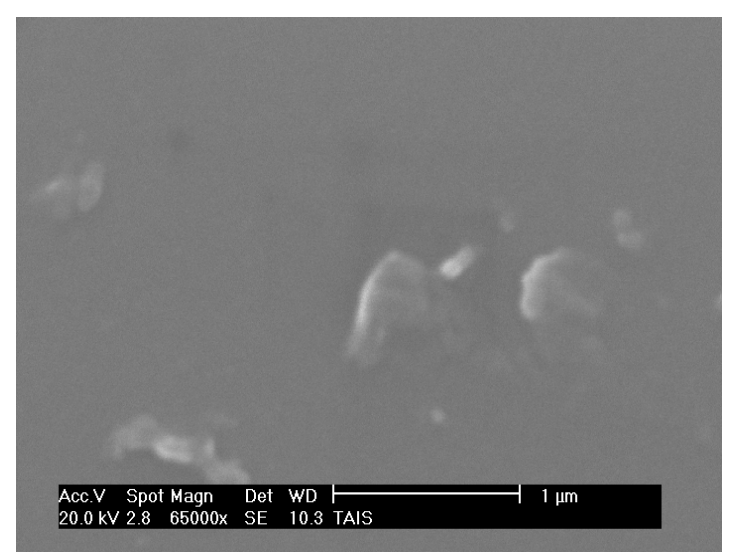

a)

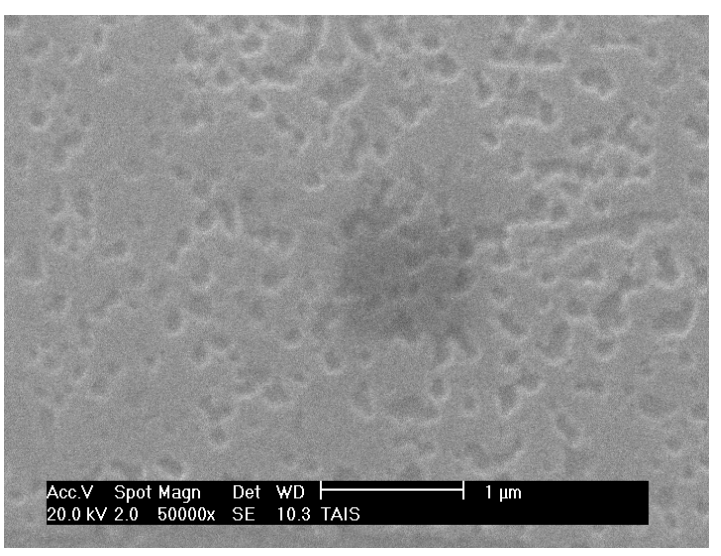

b)

Figura 22: Fotos obtidas por MEV, a) antes e b) após a exposição do filme de PVK no plasma de argônio.

É observado que a superfície do filme polimérico é muito agredida pelos íons de argônio, existem muitos resíduos de fotoresiste, mesmo após a remoção com acetona. Para a remoção do resiste, após o ataque com plasma de argônio, a lamina contendo o filme polimérico e o resiste fora mergulhados em acetona e mantidos em banho de ultra-som por 20 minutos. A olho nu pode ser observado alguns vestígios de fotoresiste, o qual permaneceu na superfície do filme de PVK. O fotoresiste é implantado para o filme polimérico, podendo provocar defeitos na condução elétrica, em uma possível aplicação no dispositivo eletro-eletrônico. 


\subsection{Plasma de Oxigênio}

Nessa etapa foi feito um estudo de corrosão usando o plasma de oxigênio. Utilizando uma fonte de radio freqüência (RF).

As condições do plasma foram de potência de 100W, com fluxo de gás de 20 sccm, pressão de $100 \mathrm{~m}$ Torr e tempo de ataque de até 4 minutos. As lâminas foram colocadas na câmara e pressão foi estabilizada em 100mTorr para o início da corrosão.

O plasma de oxigênio ataca melhor o Poli( $N$-vinilcarbazol), resultando em uma deformação superior em relação ao plasma de Ar, conforme é observado na Figura 23.

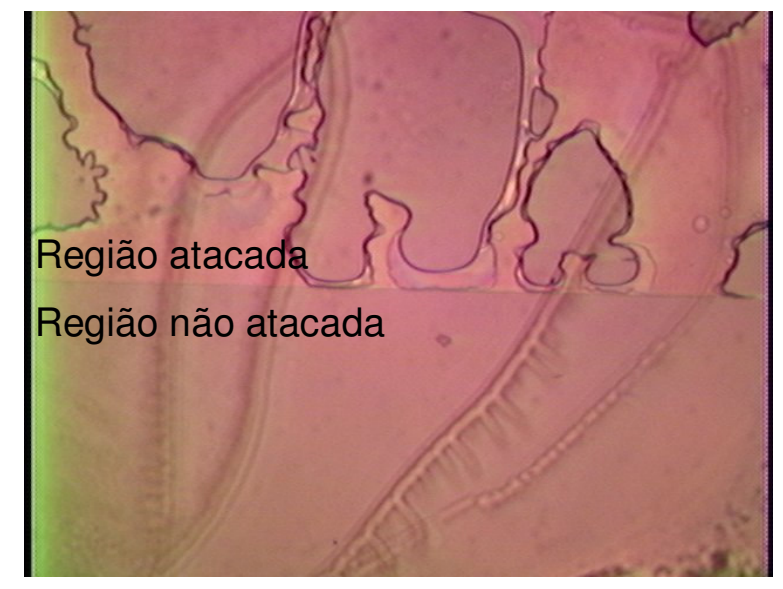

Figura 23: Foto (MO) do PVK da região atacada e protegida (não atacada) com aumento de 500 vezes.

Nessa etapa foi feito um estudo com a finalidade de determinar a taxa de corrosão dos polímeros envolvidos (Poli( $N$-vinilcarbazol) e fotoresiste). A Figura 23 mostra o comportamento da taxa de corrosão do polímero.

A partir dessa figura verifica-se que a taxa de corrosão aumenta levemente com o aumento do tempo de exposição. No início do processo, a camada mais rígida desfavorece a remoção. Mas a presença de microbolhas, que, além de aumentar o volume do PVK facilita a sua remoção devido o aumento da superfície de conato com o plasma. 


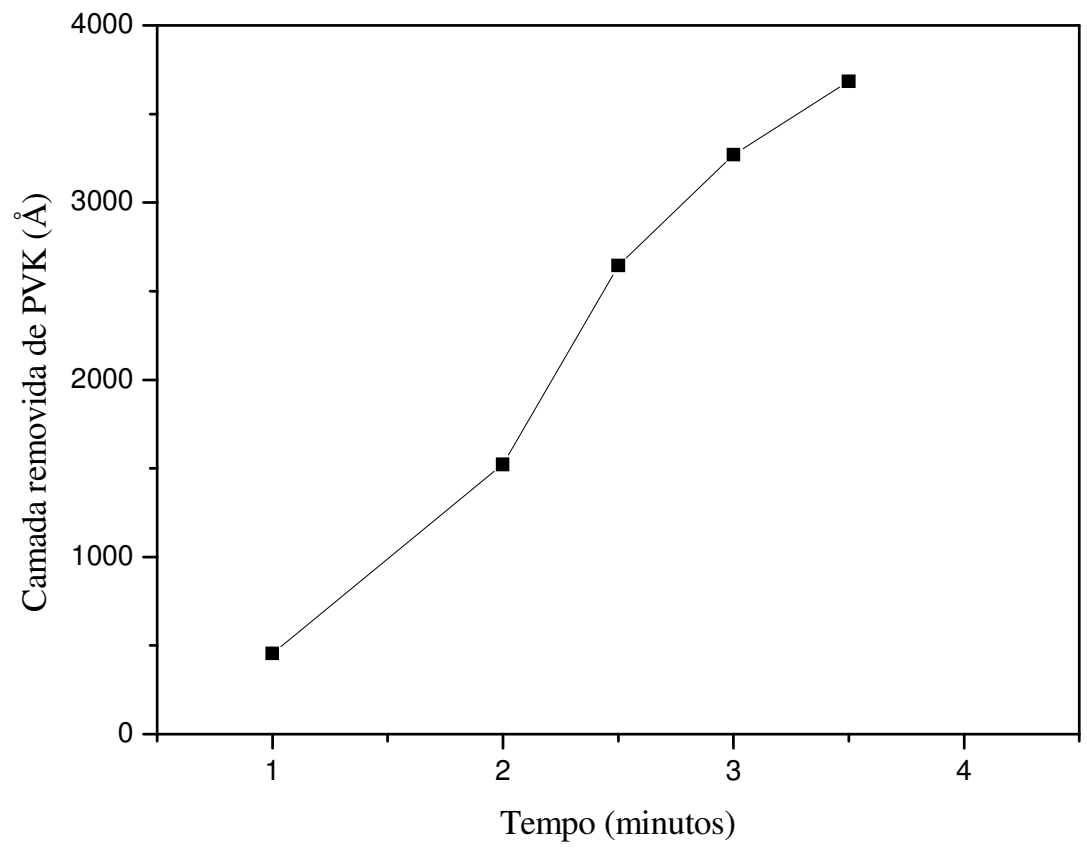

Figura 24: Camada de Poli( $N$-vinilcarbazol) removida em função do tempo para o plasma de oxigênio.

Sobre o fotoresiste, a taxa de corrosão foi de $0,14249 \mu \mathrm{m} /$ minuto não mostrou variação comparada com a corrosão do Poli( $N$-vinilcarbazol). Mas também não foi observada nenhuma relação entre a taxa de corrosão e o tempo de exposição ao plasma. Sendo assim não se pode prever com exatidão sobre as taxas com relação ao tempo de exposição do fotoresiste. Portanto o fotoresiste desenvolve muito bem seu papel de proteção do PVK.

Devido às condições de corrosão utilizando solventes químicos e plasma o estudo foi concentrado na utilização do plasma de oxigênio para a remoção do material devido a sua reprodutibilidade. 


\subsubsection{Estudo dos parâmetros de Plasma de oxigênio}

Nessa etapa as condições do plasma de oxigênio foram modificadas com a finalidade de determinar o comportamento da taxa de corrosão em função de alguns parâmetros do equipamento de plasma de oxigênio.

As condições modificadas foram de potência de plasma, fluxo de oxigênio e pressão na câmara. A temperatura foi sempre mantida a $25^{\circ} \mathrm{C}$, pois é a condição de funcionamento do equipamento. A faixa dos parâmetros a serem estudados foi determinada pelos limites do equipamento.

O polímero PVK foi previamente depositado em uma lâmina de vidro pelo método de "spin coating", posteriormente inserido na câmara do reator e exposto ao plasma por 2 minutos. Em cada filme foi feito uma medida de espessura, antes e depois da exposição ao plasma de oxigênio e foi utilizado o perfilômetro ALPHA STEP500. Em cada ensaio foi utilizada duas lâminas com o filme polimérico depositado.

O primeiro parâmetro estudado nesse subitem foi o fluxo de gás de oxigênio. O fluxo de gás foi medido através de um rotâmetro. O fluxo na câmara foi variado de $10 \mathrm{sccm}$ até $100 \mathrm{sccm}$ e o passo do ensaio foi de $10 \mathrm{sccm}$. Outras variáveis nesse processo foram mantidas constantes como a potência foi de $100 \mathrm{~W}$ e a pressão na câmara em 150mTorr.

Conforme pode ser visto na Figura 25, taxa de corrosão aumenta conforme ocorre o aumento do fluxo de gás. Isso se deve ao aumento de íons reagentes dentro da câmara aumentando a chance de remoção do filme na superfície. Também pode supor que haja um platô de corrosão, ou seja, mesmo com o aumento do fluxo de gás dentro da câmara não haveria mudança significativa na taxa de corrosão. 


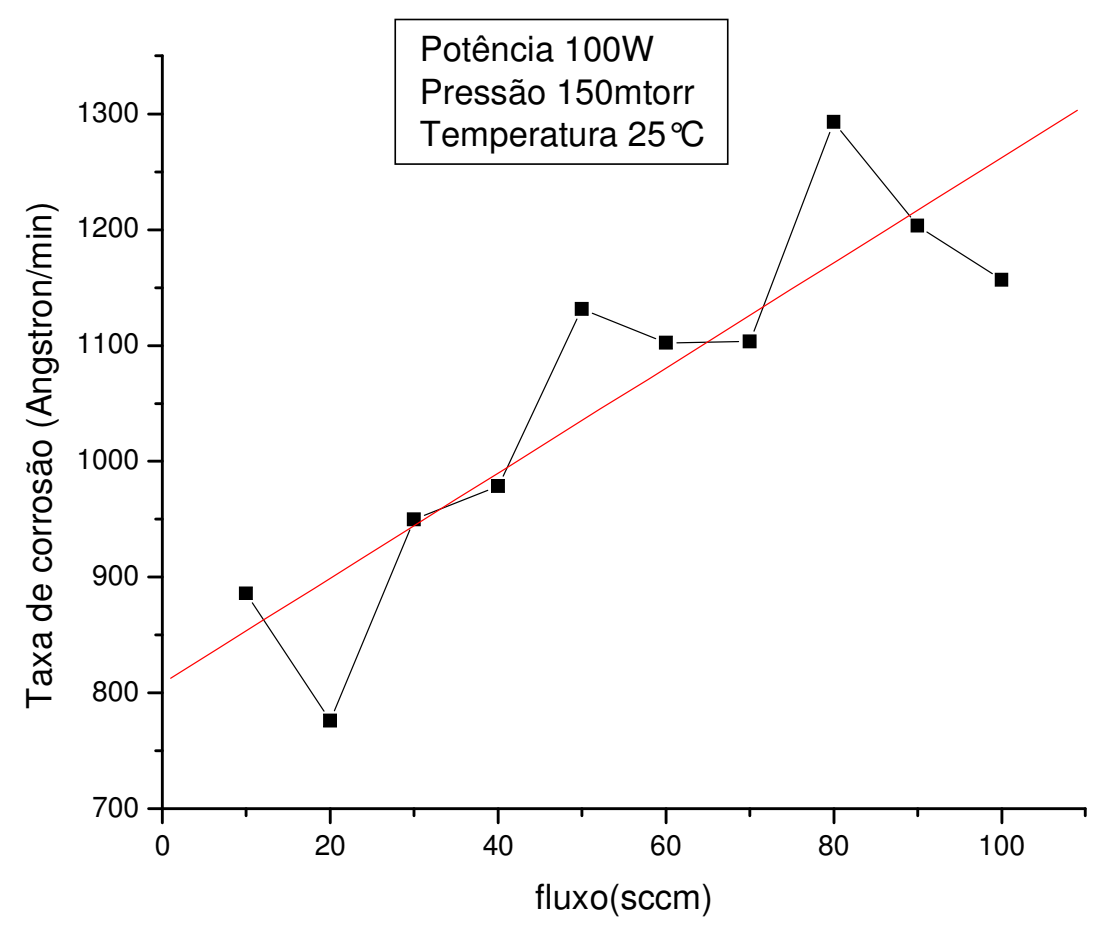

Figura 25: Taxa de remoção de Poli( $N$-vinilcarbazol) em função do tempo fluxo de gás.

O outro parâmetro estudado foi a potência, fornecida para a câmera a partir de um gerador de RF. As condições de plasma demais parâmetros foram mantidos constantes. O fluxo de gás foi de $50 \mathrm{sccm}$, pressão em $150 \mathrm{mTorr}$. A potência foi variada de 50 a $150 \mathrm{~W}$ com intervalos de $10 \mathrm{~W}$. Com o aumento da potência do RF, conforme a figura 27 , ocorre o aumento da taxa de corrosão do filme polimérico e, isso pode ser explicado pelo amento da energia cinética dos íons reagentes, favorecendo assim, a remoção do filme. 


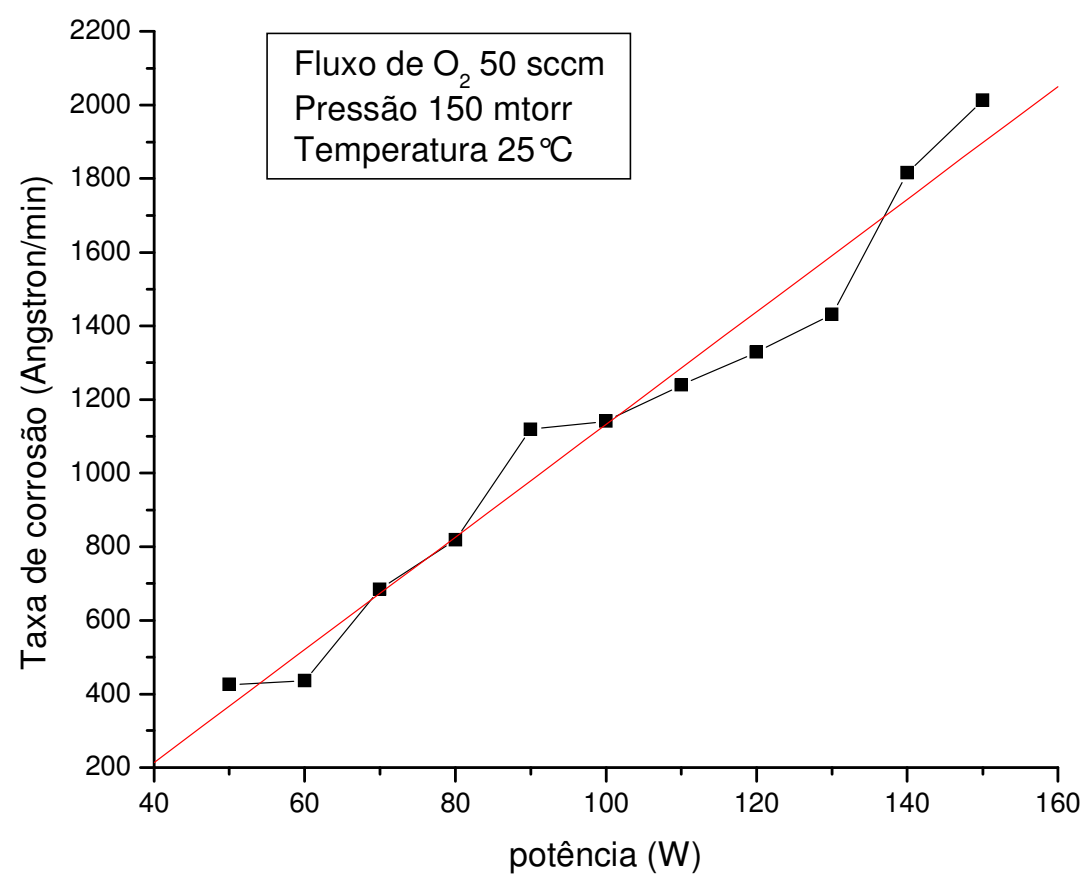

Figura 26: Taxa de remoção de Poli( $N$-vinilcarbazol) em função da potência.

As condições mantidas constantes para o ensaio com a variação de pressão foram de $100 \mathrm{~W}$ de potência, fluxo de gás $50 \mathrm{sccm}$. A variação de pressão foi de $100 \mathrm{~m}$ Torr até $500 \mathrm{~m}$ Torr com intervalos de 50mTorr. Diferente dos dois casos anteriores, fluxo de gás e potência de RF, com a variação da pressão na câmara pode-se observar na Figura 27 a diminuição da taxa de corrosão. 


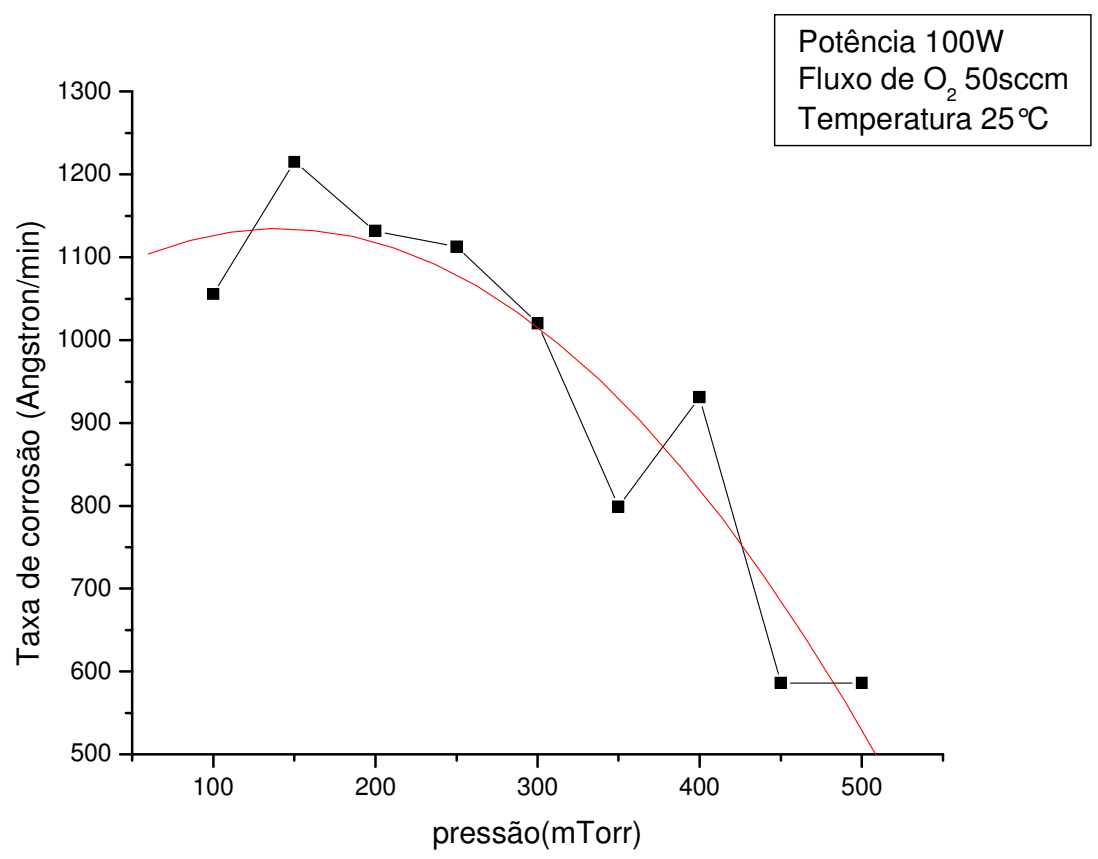

Figura 27: Taxa de remoção de Poli( $N$-vinilcarbazol) em função da pressão de gás.

Isso é resultado da diminuição da mobilidade das partículas reagentes dentro do reator e consequentemente, minimizando a taxa de corrosão na superfície do polímero.

\subsubsection{Estudo dos parâmetros de plasma de oxigênio e fotoresiste $A Z$}

Esse estudo foi apenas comparativo, para determinar as condições de variação de taxa de corrosão com o fotoresiste utilizado nesse trabalho. Para essa finalidade, o fotoresiste foi depositado pelo método de "spin coating", obedecendo o procedimento padrão esta descrito na sessão 3.2.1. Assim como no estudo da taxa de corrosão com plasma de argônio e oxigênio em filmes de PVK, os ensaios foram feitos conhecendo previamente as espessuras do fotoresiste, medido no perfilômetro ALPHASTEP500. Para cada ensaio foi colocado duas lâminas com fotoresiste.

A temperatura foi mantida em $25^{\circ} \mathrm{C}$. 
O primeiro parâmetro a ser estudado foi o fluxo de gás de oxigênio, com potência de RF fixada em 100W, e pressão de oxigênio mantida constante em 150 mTorr. O fluxo de gás foi variado de $10 \mathrm{sccm}$ até $100 \mathrm{sccm}$, com intervalo de $10 \mathrm{sccm}$.

Como pode ser observada na Figura 28 a taxa de corrosão do fotoresiste praticamente aumentou com o aumento do fluxo de oxigênio, mas a inclinação da curva de ajuste não é inferior à curva do filme com PVK (Figura 25).

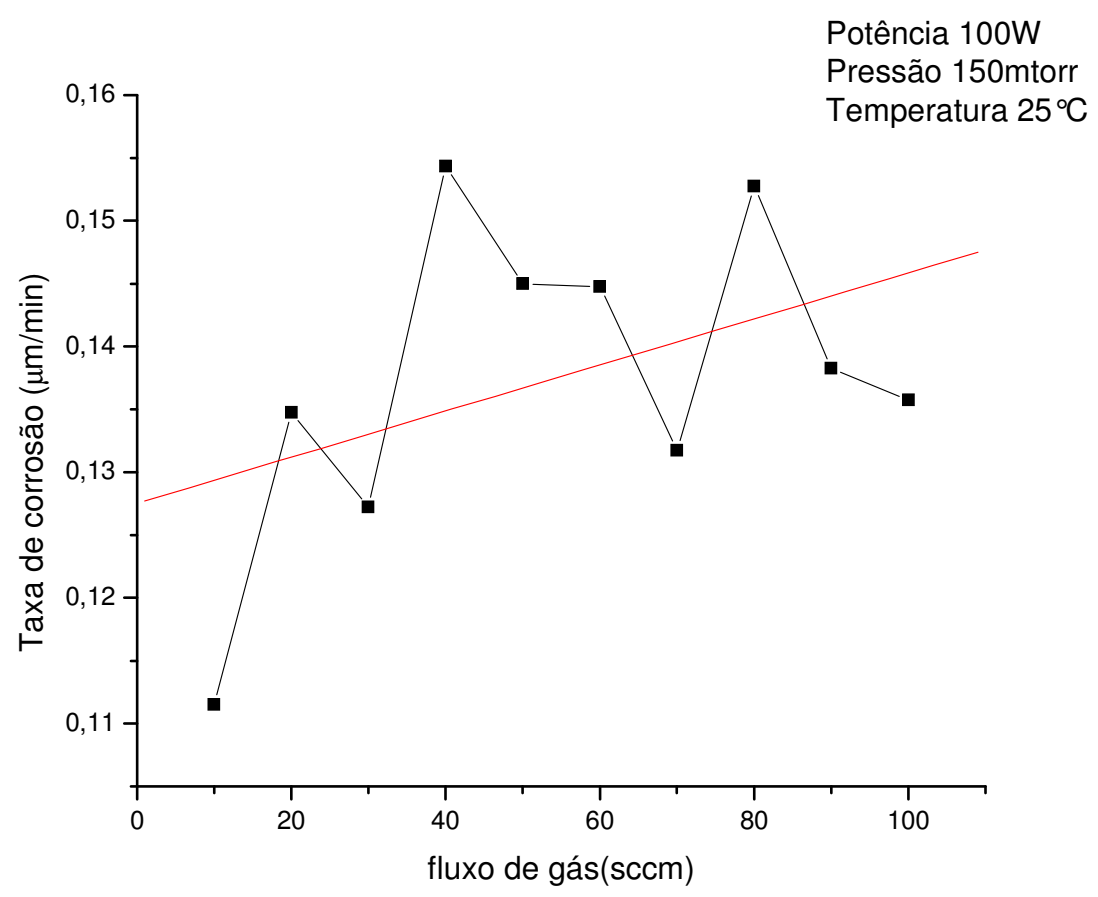

Figura 28: Taxa de remoção de resiste em função do tempo fluxo de gás.

Um outro estudo ${ }^{104}$ mostra a pouca influência do fluxo de gás na taxa de corrosão, conforme pode ser observada na Figura 29. 


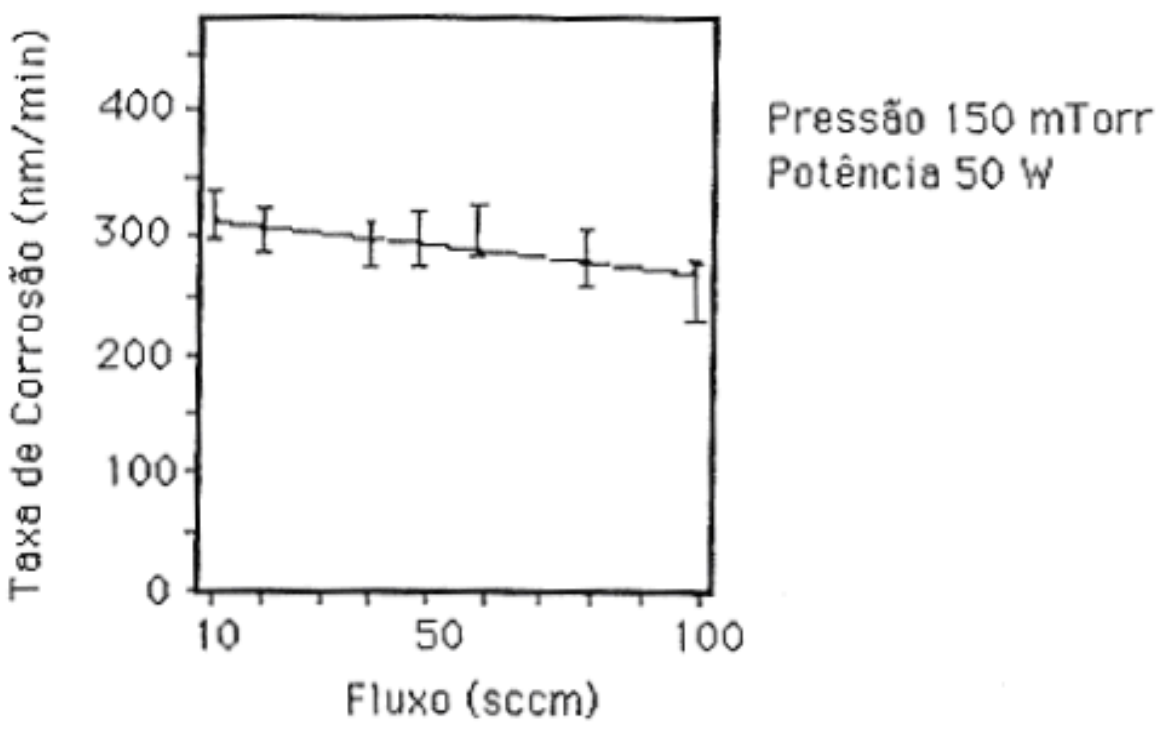

Figura 29: Taxa de remoção de resiste em função do fluxo de gás (extraído da referência 104).

Nesse estudo, o gás utilizado é oxigênio, mas o resiste não é o mesmo, mas uma variação do $A Z$.

Outro parâmetro comparado com a literatura foi a potência de RF, que variou de $50 \mathrm{~W}$ até $150 \mathrm{~W}$, o fluxo foi mantido em 50 sccm e a pressão em $150 \mathrm{mTorr}$.

Como era esperada a taxa de corrosão aumenta com o aumento da potência de RF, esse aumento foi compatível com a literatura (Figura 30). 


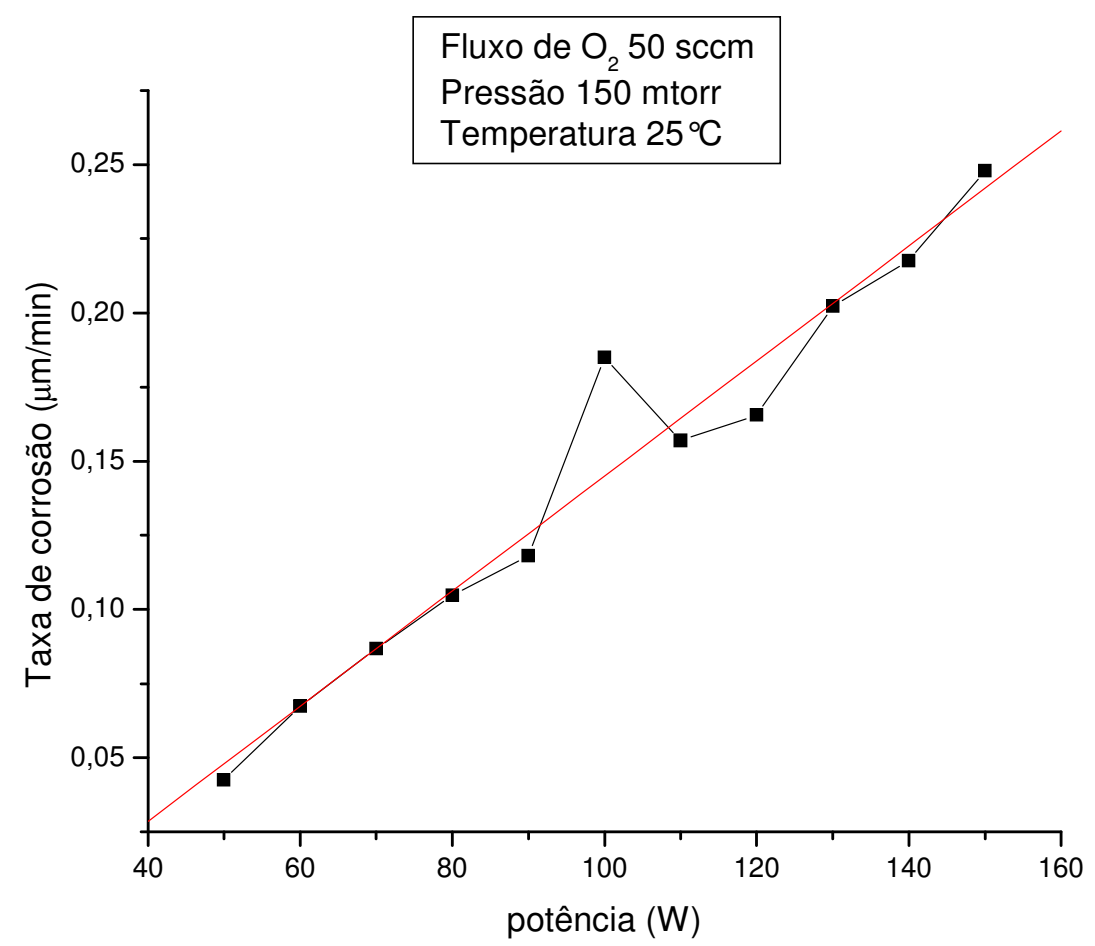

Figura 30: Taxa de remoção resiste em função da potência.

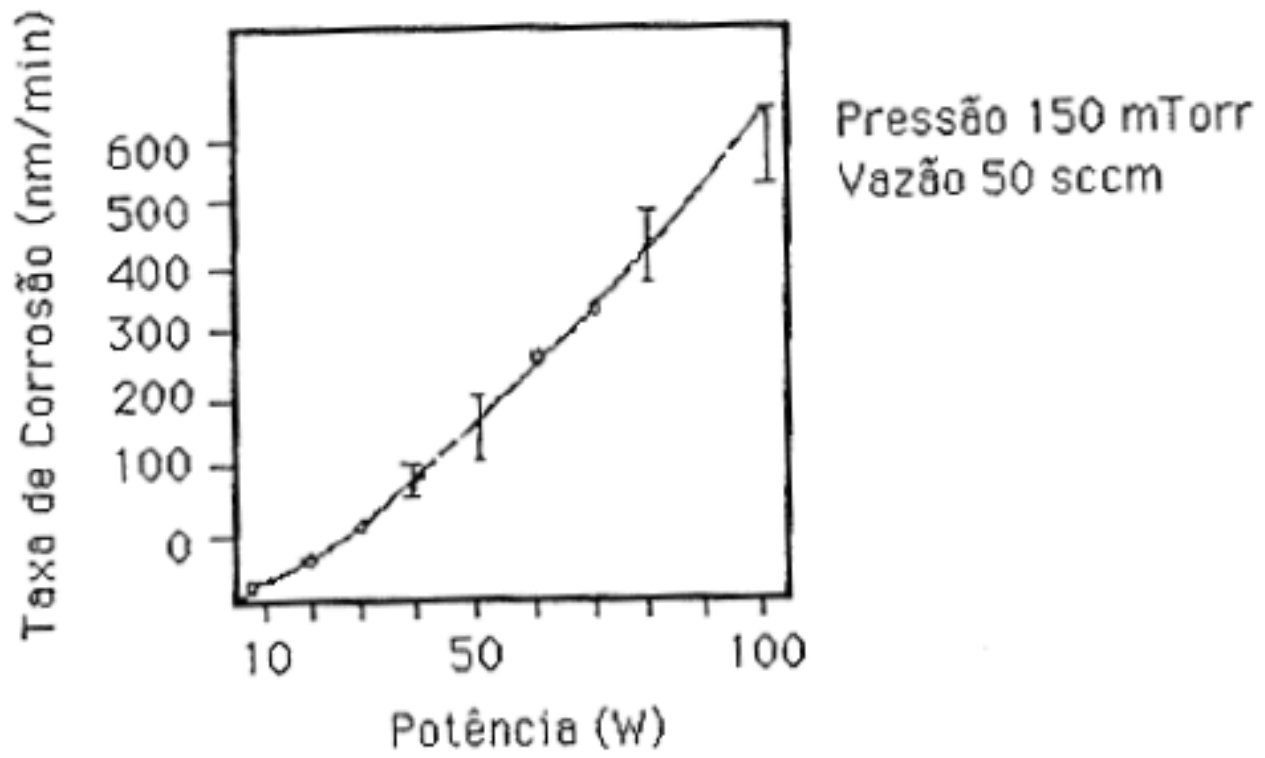

Figura 31: Taxa de resiste em função da potência (extraído da referência 104). 


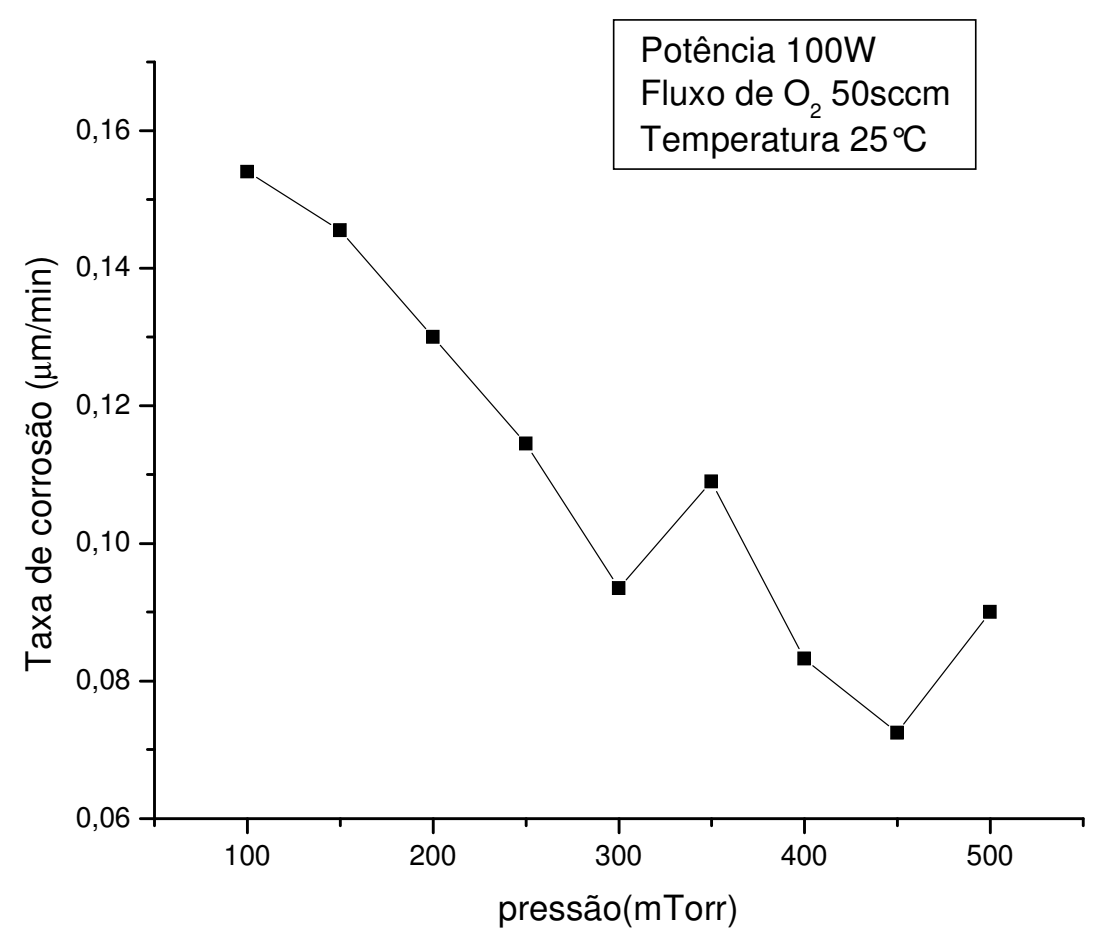

Figura 32: Taxa de resiste em função da pressão.

No estudo do parâmetro pressão da câmara, a potência foi mantida em 100W e o fluxo em $50 \mathrm{sccm}$. O decréscimo da taxa de corrosão com a diminuição da pressão deve-se a diminuição da mobilidade dos íons reagentes, dificultando a corrosão na superfície do fotoresiste, como já foi explicado.

A diferença nesse estudo comparado com a literatura foi o pequeno aumento da taxa de corrosão na faixa de $75 \mathrm{mTorr}$ até $100 \mathrm{mTorr}$, como o equipamento não opera nessa faixa com boa precisão, essas medidas nessa faixa não foram realizadas. A taxa de corrosão em ambos os casos cai pela metade, na mesma faixa de variação de pressão, como pode ser visto na Figura 33. 


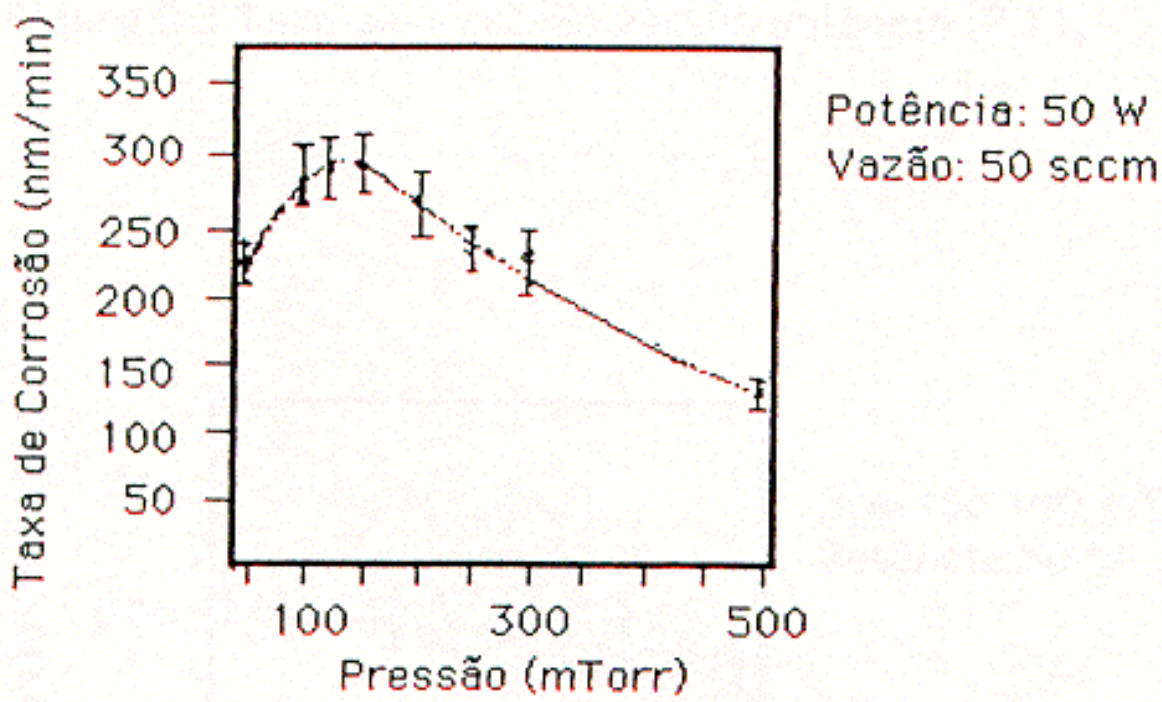

Figura 33: Taxa de remoção de resiste em função da pressão (extraído da referência 104).

Nesse estudo comparativo entre o fotoresiste o parâmetro que mais manteve a curva característica de corrosão foi de pressão na câmara, dentro da pressão do experimento realizado.

As taxas de corrosão do PVK e do AZ são compatíveis, e o fotoresiste cumpre sua função, já que a espessura dele é bastante superior a camada do PVK depositado. 


\subsection{Fabricação das trilhas usando "Pattern Generator"}

Para a fabricação das geometrias de PVK foi utilizado o "Pattern Generator IMAGE 100" do laboratório de microeletrônica.

O filme polimérico foi previamente depositado segundo as condições já explicitadas. Após a secagem em meio ambiente, o fotoresiste positivo foi aplicado na superfície e seco em estufa, a temperatura de $80^{\circ} \mathrm{C}$, por 20 minutos.

As lâminas foram expostas no "Pattern Generator". Para cada geometria temos os tempos totais de exposição, conforme a Tabela 1:

Tabela 1 - Tempo previsto pelo equipamento e tempo cronometrado em cada exposição.

\begin{tabular}{|c|c|c|}
\hline Geometria & Tempo previsto (minutos) & Tempo real (minutos) \\
\hline $\mathrm{L}$ & 10 & 2 \\
\hline $\mathrm{L}$ & 15 & 5 \\
\hline & 4 & 1 \\
\hline & 13 & 4 \\
\hline
\end{tabular}

A objetiva utilizada em todos os processos foi a de 20X, o filtro "LP" e "Light", o tempo de exposição também foi testado, chegando ao tempo ótimo de 0,8 segundos.

Para a revelação do fotoresiste foi utilizado o revelador AZ 351, a lâmina foi imersa no revelador, em seguida seca, com jato de nitrogênio. $O$ tempo de contato com o revelador é bem pequeno, por volta de 3 segundos. 


\subsubsection{Calibração do "Pattern Generator"}

Um grande problema encontrado foi a calibração do equipamento "Pattern Generator", problemas de foco provocavam falhas graves na fotogravação, como pode-se observar nas Figura 34 e Figura 35.

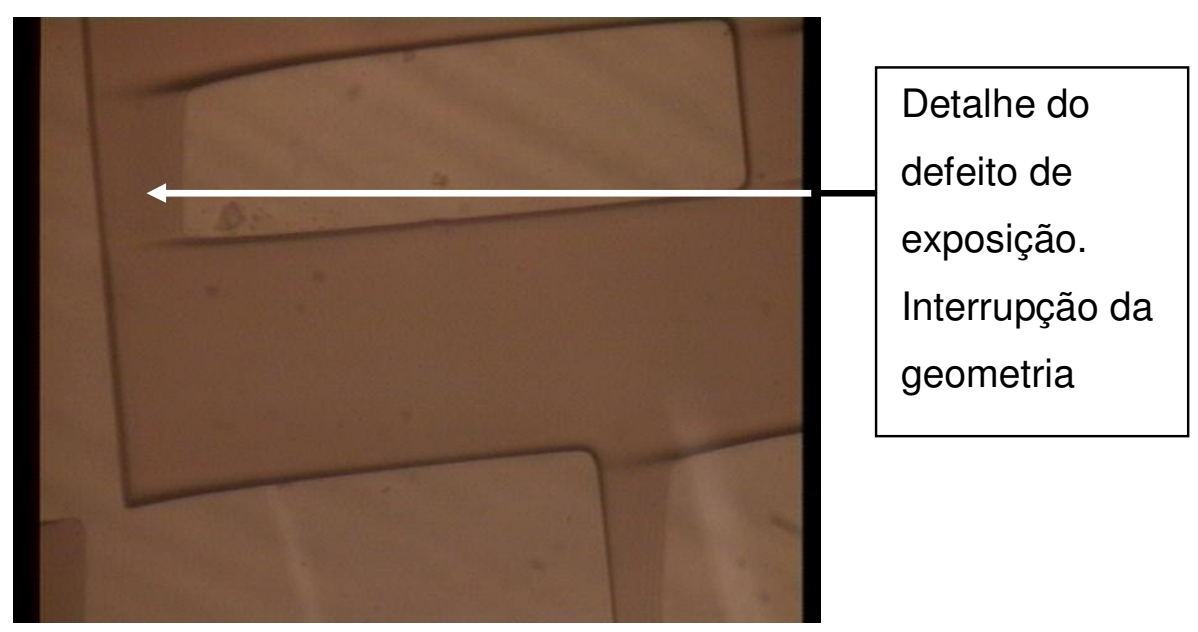

Figura 34: Detalhes no defeito de fotogravação, problema na abertura, imagem de microscopia óptica.

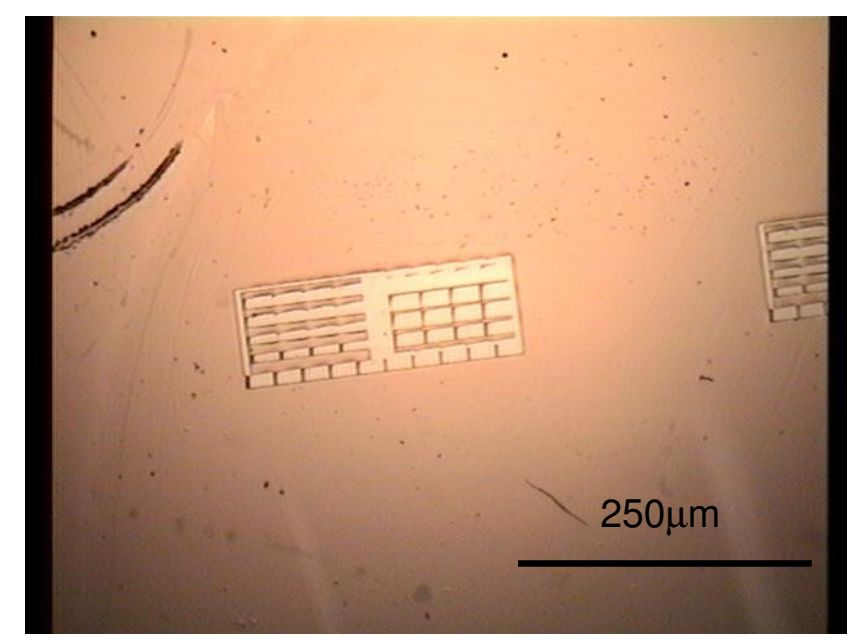

Figura 35: Trilhas interrompidas por falhas na fotogravação, imagens de microscopia óptica. 
O retângulo aberto para a passagem de luz não estava totalmente correto, comprometendo a fotogravação e como resultado, falhas nas estruturas desejadas.

Outro problema após a gravação foi o tempo de ajuste da revelação, inicialmente as estruturas sofreram o chamado "over etch", ou seja, o tempo que o fotoresiste permanece no revelador foi em demasia, provocando decapagem além dos limites pré-estabelecidos das geometrias como pode ser observado na Figura 36.

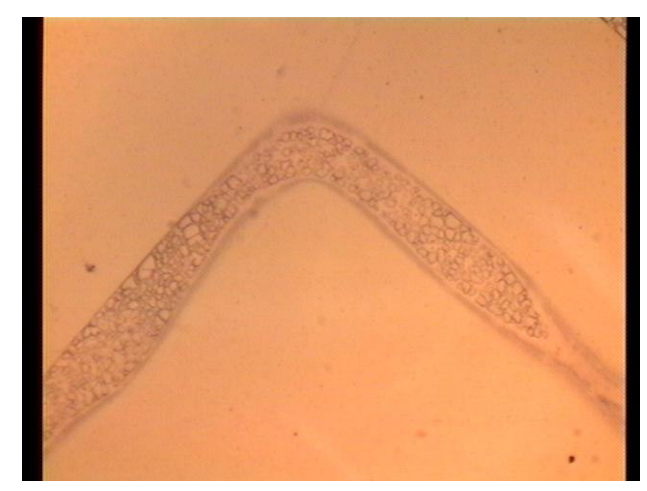

a)

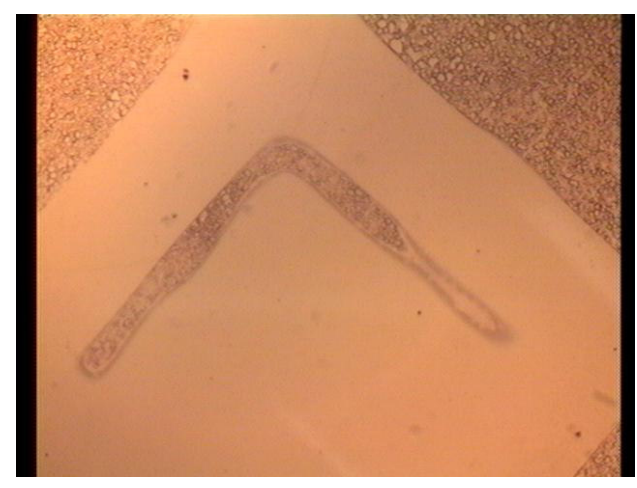

b)

Figura 36: Estruturas que apresentaram "over etching", imagens de microscopia óptica.

Esse problema foi facilmente solucionado adequando o tempo de revelação. O procedimento foi colocar as lâminas no revelador, interronper a ação do revelador com água deionizada, logo em seguida secada com jato de nitrogênio e esse processo foi repetido até observar uma revelação adequada. O melhor tempo de permanência da amostra no revelador foi de aproximadamente 4 segundos.

Nesse estudo o PVK foi depositado por meio de "spin coating" seco em ambiente aberto, posteriormente foi aplicado o fotoresiste nos filmes e expostos no gerador de padrões.

Na Figura 37 observa-se imagens de microscopia óptica de fotogravações sem falhas graves. As trilhas na primeira Figura 37a variam de 10 a $50 \mu \mathrm{m}$ e na segunda Figura 37b de 50 a $100 \mu \mathrm{m}$. 


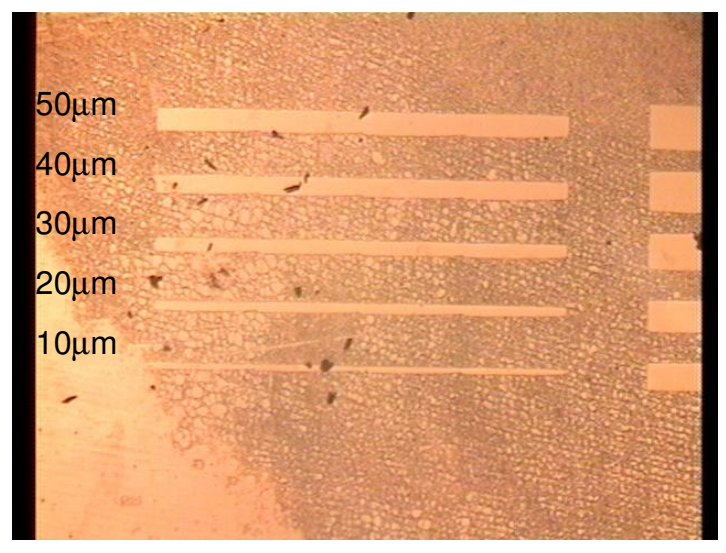

a)

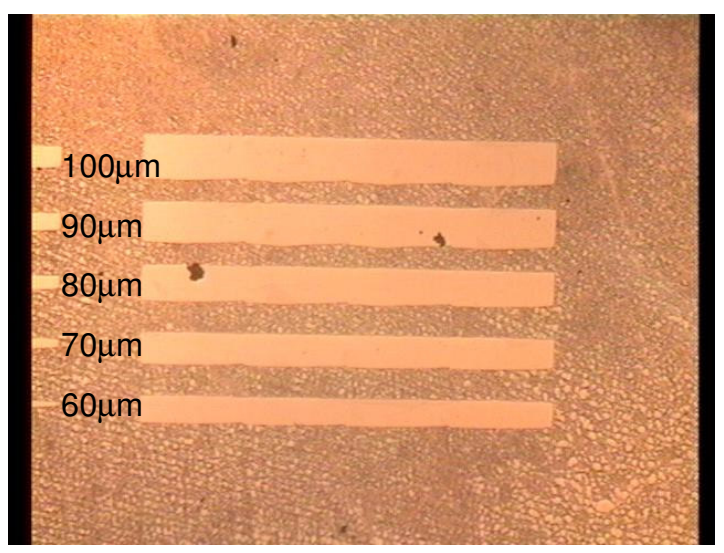

b)

Figura 37: Microscopia óptica de trilhas com aumento de 250 vezes.

As imagens são após o processo de corrosão com plasma de oxigênio. Essas trilhas estão conforme o esperado, a parte clara há ausência de polímero, na parte mais escura há polímero.

Como pode ser observado na Figura 37 a e b as trilhas não apresentam interrupções na geometria, indicando a possibilidade de obtenção de trilhas eletricamente condutoras na geometria desejada a partir de $10 \mu \mathrm{m}$ de definição. 


\subsection{Medidas de condutividade elétrica}

Para obter uma condução elétrica do PVK, os filmes foram dopados com perclorato de lítio em diferentes porcentagens em massa. O PVK puro obtido na síntese normalmente é isolante ou muito pouco condutor elétrico. Os filmes foram depositados pelo método "spin coating", com rotação de 2000rpm, por 20 segundos.

Após a secagem na estufa por 40 minutos e temperatura de $100^{\circ} \mathrm{C}$, foi depositado alumínio pelo processo convencional a vácuo e por filamento.

A espessura depositada com o auxílio de uma máscara mecânica obteve geometrias circulares de $1 \mathrm{~mm}$ de diâmetro e espessura de 280 Angtrons.

Para as medidas de condutividade elétrica foi usado o Analisador de parâmetros HP4145 e uma estrutura de medidas com pontas, Went worth model 900, conforme visto na Figura 38:

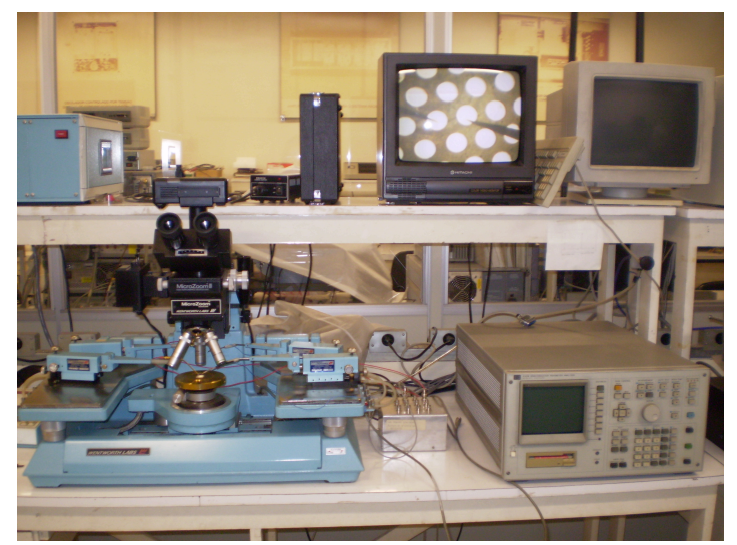

a)

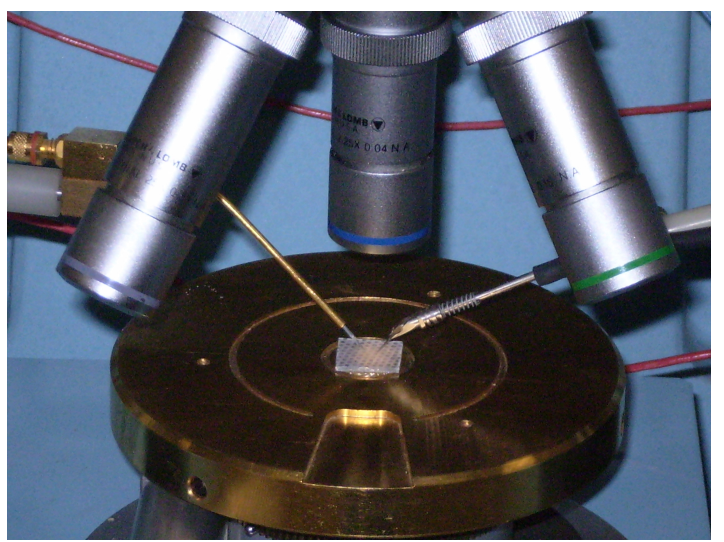

b)

Figura 38: Analisador de parâmetros, e detalhe das pontas em seqüência.

Na Figura 39 pode-se observar um esquema das medidas de condutividade elétrica do material. 


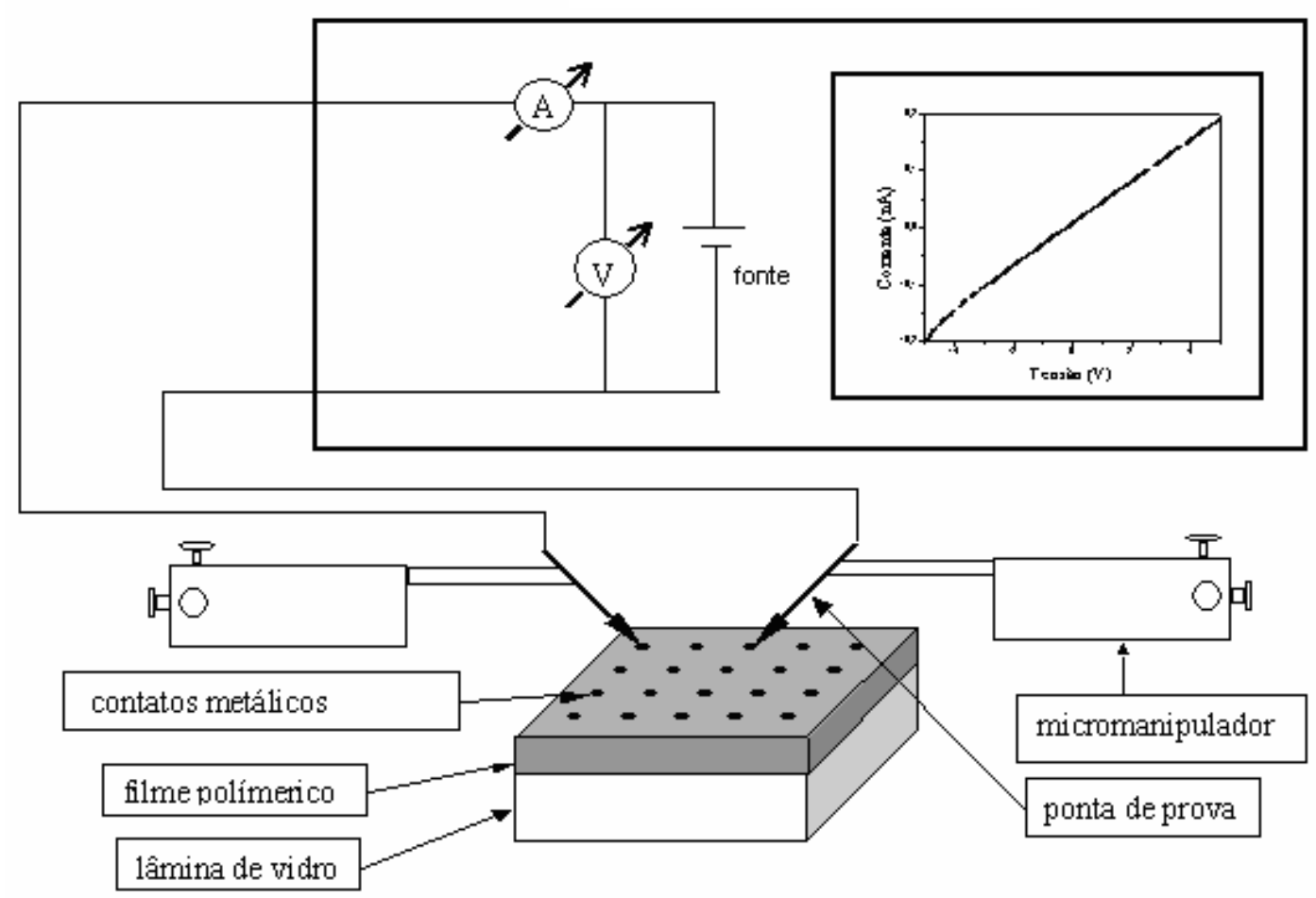

Figura 39: Diagrama esquemático para as medidas elétricas.

O polímero foi mantido em estufa na maior parte do tempo, para que não ocorresse oxidação do mesmo. Somente nas medidas elétricas o material ficou exposto em ambiente aberto.

A Tabela 2 mostra os valores de resistividade elétrica do material, com a porcentagem de dopante correspondente.

Tabela 2 - Valores de resistividade elétrica e condutividade elétrica em função da porcentagem de dopantes no PVK.

\begin{tabular}{|c|c|c|c|c|c|c|c|}
\hline$\%$ de dopante & $0 \%$ & $1 \%$ & $2 \%$ & $3 \%$ & $4 \%$ & $5 \%$ & $6 \%$ \\
\hline$\rho(\Omega . \mathrm{m})$ & 1250 & 650 & 337,5 & 187,5 & 16,4 & 30,7 & 63,8 \\
\hline $\begin{array}{c}\text { Condutividade } \\
(\Omega \mathrm{cm})^{-1}\end{array}$ & $8.10^{-7}$ & $1,510^{-5}$ & $2,910^{-5}$ & $5,310^{-5}$ & $6,010^{-4}$ & $3,210^{-4}$ & $1,510^{-4}$ \\
\hline
\end{tabular}

Só foi possível obter material dopado com porcentagem de até 6\% quando fica totalmente saturado. As amostras com $7 \%$ de perclorato de lítio em massa, 
apresentaram particulados, de sal de lítio na amostra, indicando que o material PVK não consegue mais absorver o dopante sólido.

A Tabela 2 e o gráfico da Figura 40 mostra a diminuição da resistividade elétrica até a porcentagem de $4 \%$. A partir desse valor ocorre o aumento da resistividade. Uma provável causa desse comportamento é a presença de uma alta porcentagem de $\mathrm{ClO}_{4}^{-}$que resulta no armadilhamento do $\mathrm{Li}^{+}$, impedindo a movimentação das lacunas, principal portador e gerador da corrente elétrica.

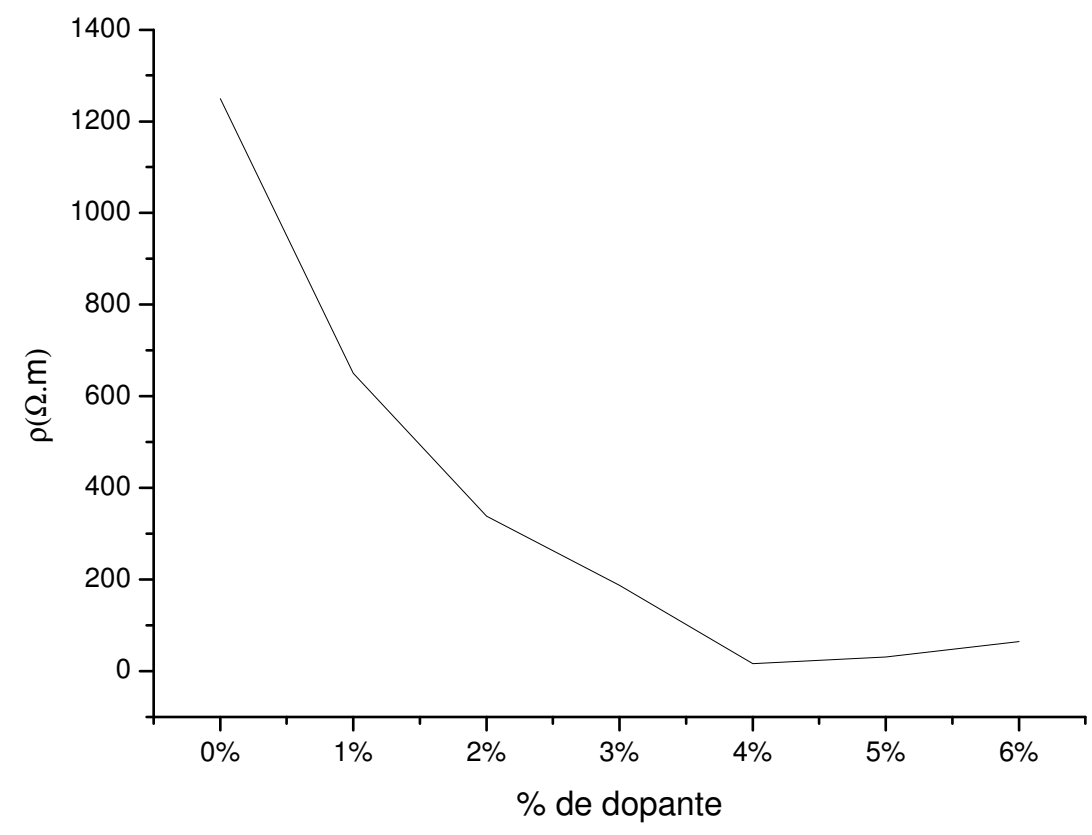

Figura 40: Gráfico da resistividade em função da porcentagem de $\mathrm{LiClO}_{4}$.

Conseqüentemente é observado um aumento da condutividade elétrica até $4 \%$, após ocorre uma brusca diminuição da condutividade elétrica, conforme é observado na Figura 41. 


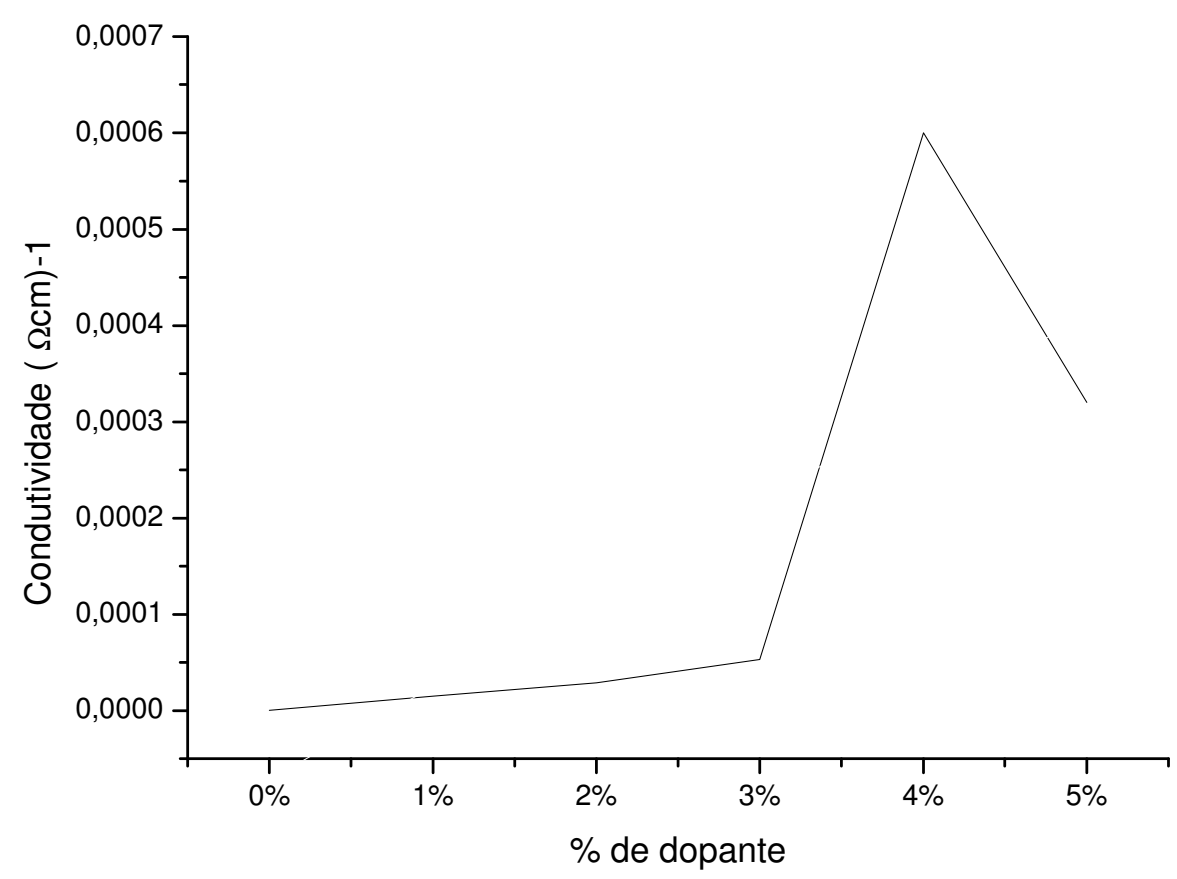

Figura 41: Relação da condutividade elétrica em função da porcentagem de $\mathrm{LiClO}_{4}$.

Esses resultados são satisfatórios se comparados com a literatura ${ }^{6,105,106}$.

Esses aspectos de condutividade e resistividade elétrica podem ser comparados com as imagens de microscopia eletrônica de varredura, podendo-se observar as deficiências das trilhas obtidas para a aplicação em dispositivos eletroeletrônicos, conforme será visto na sessão 4.8 . 


\subsection{Microscopia eletrônica de varredura}

Nesse item foram realizados analise com Microscopia Eletrônica de Varredura (MEV) para estudar detalhes na estrutura dos filmes de PVK, as definições das geometrias desejadas e os problemas de aderência dos filmes. Todos os filmes passaram por processo de cura a $100^{\circ} \mathrm{C}$ por 40 minutos.

\subsubsection{Deposição de ouro}

A deposição de ouro para a microscopia eletrônica de varredura (MEV), foi feita no equipamento "SputterCoater S150B", no Laboratório de Sistemas Integráveis (LSI). A pressão na câmara foi de $2.10^{-1} \mathrm{Torr}$, com fluxo de argônio de $2,5 \mathrm{sccm}$ em temperatura ambiente $\left(20^{\circ} \mathrm{C}\right)$. A corrente foi de $40 \mathrm{~mA}$ e uma tensão $6 \mathrm{kV}$, obtendo uma taxa de deposição de 70 Angstron/min. O tempo total foi de 3 minutos, resultando uma espessura de 210 Angstrons.

Os filmes dopados foram analisados, conforme podem ser visto na Figura 42. Filmes sem dopante e com até $2 \%$ em massa de $\mathrm{LiClO}_{4}$ não apresentaram nenhuma estrutura diferenciada. $\mathrm{O}$ filme dopado com $3 \%$ em massa de $\mathrm{LiClO}_{4}$ apresentou estruturas diferenciadas, caracterizando a saturação do filme.
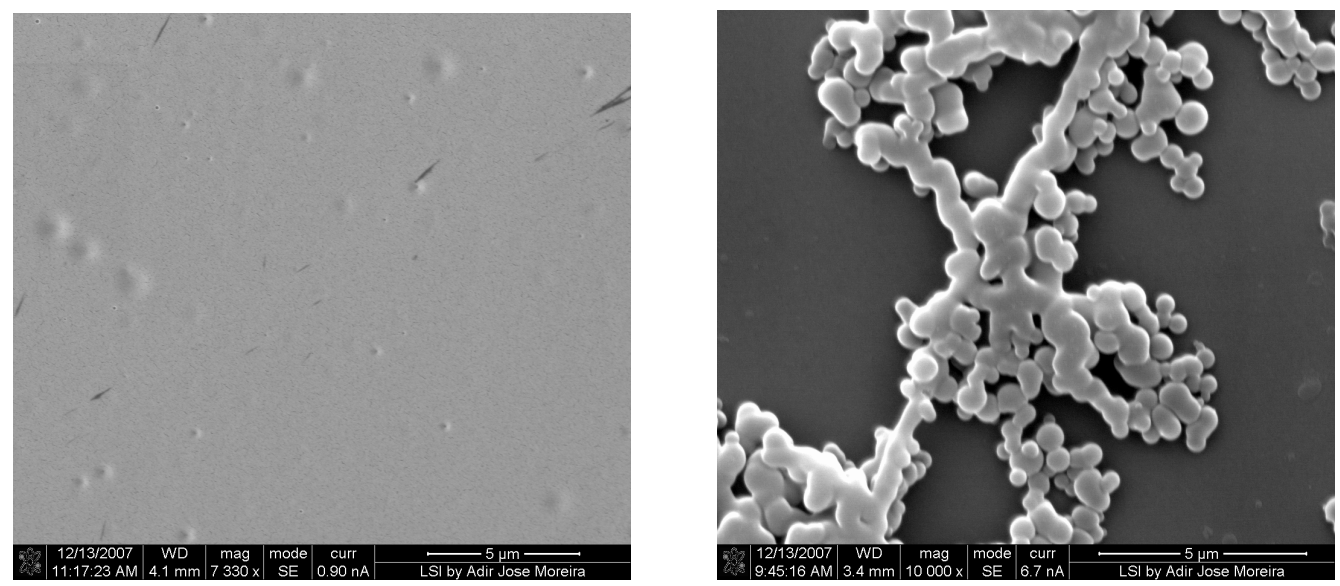

Figura 42: Filme de PVK dopado com 2\% de $\mathrm{LiClO}_{4}$ e dopado com $3 \%$ de $\mathrm{LiClO}_{4}$. 
A microscopia eletrônica de varredura também permitiu uma análise mais detalhada dos limites das geometrias.

As estruturas foram fotogravadas nas mesmas condições e nas Figura 43 pode-se observar estruturas de trilhas, com aumento de 118 vezes, em filmes com PVK puro e PVK dopado com 1\% em massa de $\mathrm{LiClO}_{4}$.
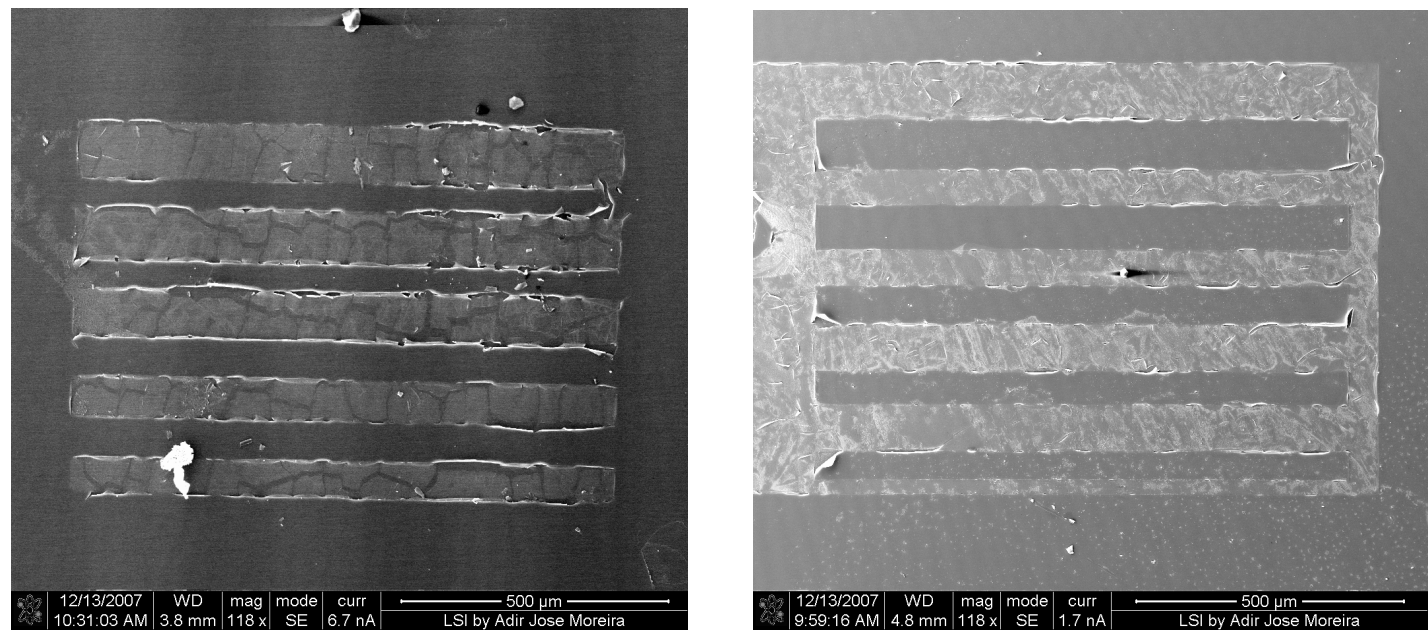

Figura 43: Microscopia eletrônica de varredura, aumento de 118x, de estruturas com PVK e PVK dopado com 1\% de $\mathrm{LiClO}_{4}$, respectivamente.
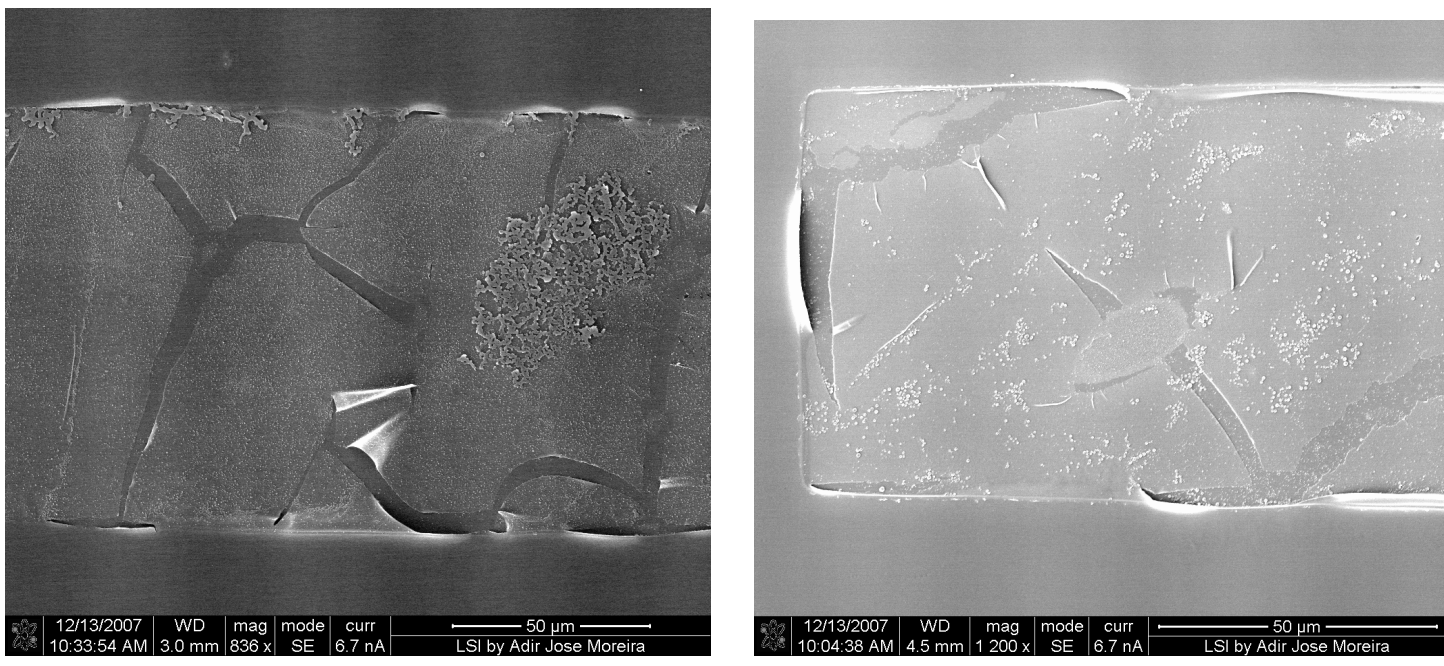

Figura 44: Microscopia eletrônica de varredura com aumento de 1200x, de estruturas com PVK e PVK dopado com 1\% de $\mathrm{LiClO}_{4}$, respectivamente.

As estruturas da Figura 44 são estruturas idênticas. A diferença está na concentração de dopantes. A primeira com PVK puro e a segunda com PVK dopado 
com $1 \%$ em massa de $\mathrm{LiClO}_{4}$. Verifica-se a melhor definição de bordas na amostra dopada, o filme também apresenta menos defeitos, e mais uniformidade superficial.

Comparando estruturas com mesmo filme, mas com geometrias diferentes, L e $L$ dentro de quadrado, observa-se melhor limite da estrutura $L$, porém a estrutura limite da quina do $\mathrm{L}$ apresenta melhor qualidade na estrutura de $\mathrm{L}$ dentro do quadrado, tanto na parte inferior como na superior.
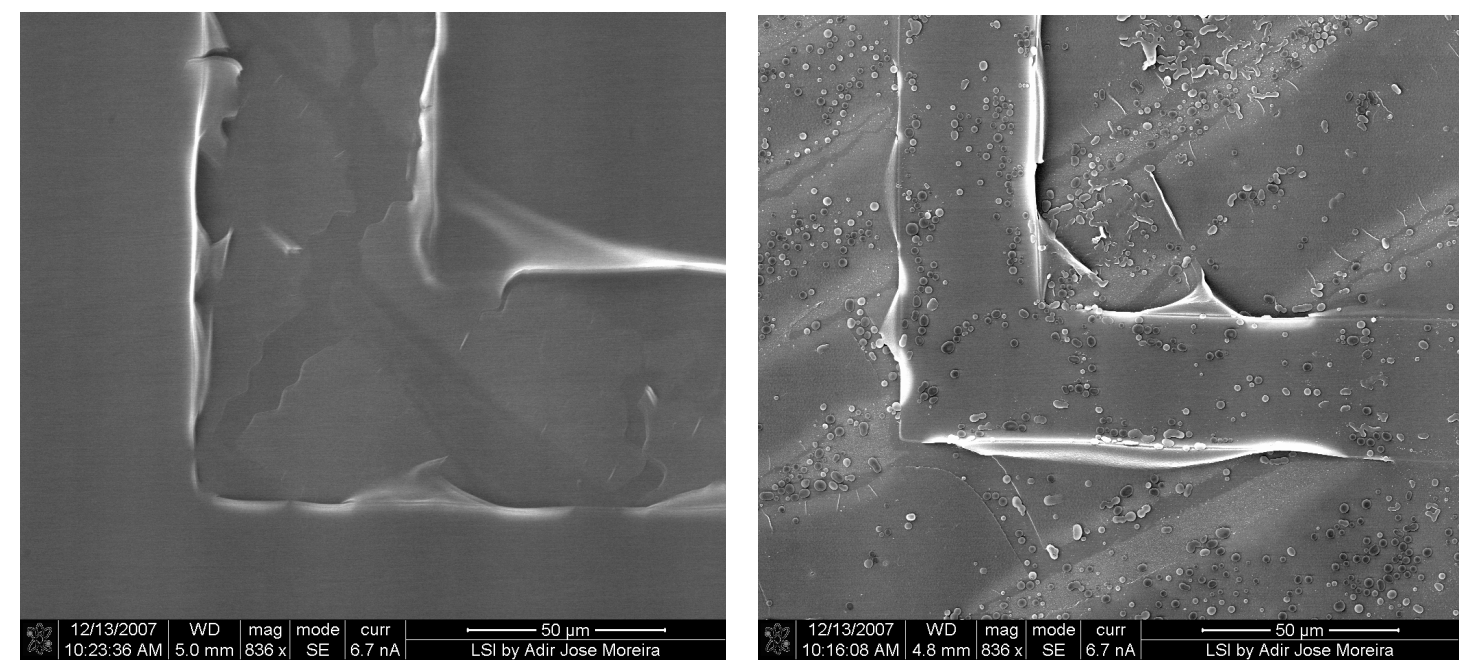

Figura 45: Microscopia eletrônica de varredura com aumento de 836x, de estruturas com PVK dopado com $1 \%$ de $\mathrm{LiClO}_{4}$. 


\section{Capítulo V - Conclusões}

Esse trabalho permitiu concluir alguns pontos como:

- O PVK pode ser dopado com $\mathrm{LiClO}_{4}$ em diferentes porcentagens, mantendo as características estruturais do polímero;

- Existe relação de porcentagem de dopante e aumento da condutividade elétrica;

- É possível fabricar vários tipos de geometrias (retas e curvas), com largura mínima de $10 \mu \mathrm{m}$;

- Fotoresiste efetivamente protege o PVK sem modificar as propriedades elétricas;

- É possível fazer estruturas com PVK com as técnicas de corrosão seca e úmida;

- O melhor método foi corrosão por plasma de oxigênio;

- Não ocorre influência do fotoresiste no processo por plasma de oxigênio;

- Não houve mudança nas características elétricas do PVK após a exposição de plasma de oxigênio;

- Os limites de borda foram bons, especialmente no polímero dopado com $1 \%$ em massa de $\mathrm{LiClO}_{4}$;

- Existe a possibilidade de melhoria do filme polimérico com tratamento térmico;

- É possível obter trilhas condutoras de PVK, para a utilização em circuitos integrados e;

- Ensaios de corrosão em plasma de oxigênio foram repetidos várias vezes, obtendo boa reprodutibilidade nos resultados das trilhas. 


\section{Sugestões de trabalhos futuros}

- Fabricação de estruturas do tipo "Kelvin" para medidas de resistividade elétrica de contato entre o metal e o polímero;

- Caracterização por AFM para análise da topografia do filme polimérico antes e depois do:

- ataque com plasma de oxigênio;

- tratamento térmico.

- Uso efetivo de trilhas eletricamente condutoras em circuitos impressos, OLED's, transistores, diodos onde a camada ativa é um polímero. 


\section{REFERÊNCIAS}

1 BLEWER, R. in: "Advanced Mettalization for VLSI/ULSI Applications", Y. Shacham, J. W. Swart, R. Blewer, et. al., realizado na Faculdade de Engenharia Elétrica da Unicamp, maio, 1994.

2 BLAIS, P.; MICHAELS, M. Lithography Tool Selection Strategy. In: GLENDINNING, W.B. AND HELBERT, J.N. Handbook of VLSI Microlithography: Principles, Technology and Applications. Noyes Publications, 1991. Cap. 1, p. 30.

3 ASSOCIATION, S.I. Processes of the Future. Solid State Technology. v.38, n.2, pp.42-6, feb 1995.

4 CHIANG, C.K.;FINGCHER, C.R.;PARK, Y.M.; HEERGER, A.J.; SHIRAKAWA, H.; LOUIS, E.J; GAU, S.C.; MACDIARMID, A.G. Eletrical-Conductivity in Doped Polyaectylene. Physical Review Letters, 1977, v.39 (17), p.1098-1101.

5 HOEGL, H. On Photoelectric Effects in Polymers and Their Sensitization by Dopants. The Journal of Physical Chemastry. Vol 69, March 1965. pp $755-766$

6 POSSIDONIO, S. Síntese e caracterização de copolímeros diblocos com segmentos de vinilcarbazol e derivados de estireno. Tese de doutorado EPMat, 2006.

7 WANG. Y, Advances in Photochemistry, in: D.C. NECKERS, D.H. VOLMAN, G. VON BUNAU, vol. 19, Wiley, New York, 1995.

8 SHARP, J.H.; SMITH, M.; Physical Chemistry, vol. 10, ch.8, Academic Press, New York, 1969.

9 MACDIARMID, A.G,; EPSTEIN, A.J.; Processings of the first conference on frontiers of polymer research, India: Jan 1991

10 CHIANG, C.K.; FINCHER, C.R.; PARK, Y. HEEGER, A.J.; SHIRAKAWA, H. LOUIS, E.J.; GAU,S.S.; MACDIARMID, A.G.; Electrical-conductivity in doped polyacetylene, Phys. Rev. Lett., v.39, p.1098, 1977 
11 KANER, R.B.; MACDIARMID, A.G.; Plastics that conduct eletricity, Scient. Am., v.258, p.106, 1988.

12 VOROTYNTSEV, M. A.; DAIKIN, L. I.; LEVI, M. D.; Modelling the impedance properties of electrodes coated with electroactive polymer films. Journal of Electroanalytical Chemistry, 1994, volume 364, Issues 1-2 pg. 37-49.

13 PICKUP, G.; REN, X.; Coupling of ion and electron transport during impedance measurements on a conducting polymer with similar ionic and electronic conductivities Journal Chem.. Soc. Faraday Trans. 1993, 89, 321.

14 DESLOUIS, C.; MUSIANI, M.M.; TRIBOLLET, B.; Impedance of redox reactions at a polypyrrole membrane Synthetic Metals,1997, Volume 84, Issues 1-3, Pages 827-828.

15 De PAOLI, M.-A.; SILVA, G. G.; LEMES, N. H. T.; POLO da FONSECA, C. M. N.; Solid state polymeric electrolytes based on poly(epichlorohydrin). Solid State lonics, Volume 93, Issues 1-2,December 1996, Pages 105-116

16 DE PAOLI, M. A.; WOLFENSON, A. E.; TORRESI, R. M.; BONAGAMBA, T. J.; PANEPUCCI, $\mathrm{H} . ;{ }^{13} \mathrm{C}$ NMR and conductivity measurements of ethylene oxide-epychloridrine copolymer doped with $\mathrm{LiClO}_{4}$. J. Phys. Chem. B. 1997, vol. 101,Pages 219-223.

17 LI-MING, D.; JING, S.; YUN-QING, L.; CHENG-ZONG, Y.; XUEBAO, H. 1997, 55, 254. (Chemical Abstracts $\mathrm{n}^{\circ}$ 126:238940)

18 MASAYOSHI, W.; SOKUTEI, N.; 24, 12. (Chemical Abstracts $\mathrm{n}^{\circ}$ 126:245186) 1997.

19 PENDZIG, P.; DIETERICH, W.; KNOEDLER, D.; NTZAN, A.; OLENDER, R.; Charged Particle Dynamics in Disordered Systems: Monte Carlo Simulations of Glassy and Polymeric electrolytes. Materials Science Fórum, 1996, vol. 61 pg. 223.

20 VINCENT, C. A.; Polymer electrolytes in: Progress in Solid State Chemistry, Volume 17, Issue 3,1987, Pages 145-261. 
21 BRETT, M. A.; BRETT, A. M. O.; Electroquímica: Princípios, Métodos e Aplicações; Oxford; New York 1996; p 91.

22 KHARKATS, Y. I.; NOSKOV, A. V.; Some peculiarities of diffusion-migration ionic transport in electrochemical systems containing fixed charges. Electrochimica Acta,Volume 42, Issue 5,1997, Pages 813-817

23 SCROSATI, B.; Applications of Electroative Polymers; Chapman \& Hall; London, 1993, p32.

24 RANDLES, J. E. B.; General discussion. Disc. Faraday Soc. , 1, 11,1947

25 ANDRÉ, J.M.; LADIK, J. Electronic Structure of Polymers and Molecular Crystals. P Plenum Pub Copr, New Yaork (1974). ISBN: 0306357097

26 NALWA, H.S.Handbook of Advanced Eletronic and Photonic Materials and Devices. NGUTEN, T-P.;MOLINIE,P.; Vol 10. Device Applications Destruel, P.Ed. Academic Press, 2001. ISBN:0125137451

27 SZWARC, M.;Living Polymers. Nature, 1956, v.178 (4543), p.1168-1169.

28 KRAFT A. ; GRIMSDALE A. C. ; HOLMES A. B. ; Electroluminescent Conjugated Polymers: Seeing Polymers in a New Light 1998, vol. 37, nº 4, pp. 403-428 [26 page(s) (article)] Angewandte Chemie. International edition in English (Angew. Chem., Int. ed. Engl.) ISSN 0570-0833.

29 BURN,P.L.;SAMUEL, I.D.W. Light-emitting polymers - The shape of things to come?. Materials Today, 1998, v.1, p3.

30 PEARSON, J.M. "Vinylcarbazole Polymers" in Encyclopedia of Polymer Science and Engineerring, Wiley:New York, 1989

31 DAVIDGE, H. Poly-N-vinylcarbazole. II. Preparation, moulding and dielectric properties. Journal Appl Chem,1959. Volume 9 Issue 10 , Pages 553-560. 
32 BARRALES-RIENDA, J.M.; GONZÁLES-RAMOS, J.; DABRIO, M.V. Kinetics of thermal degradation of semi-stiff macromolecules II. Poly-N-vinyl-carbazol. Angew Makromol Chem 1975;43:105-123.

33 PEARSON, J.M.; STOLKA, M. Poly(N-vinylcarbazole) in:Polymer monograph vol. 6, Gordon and Breach, New York (1981).

34 HALLENSLEBEN, M.L., "Other Polyvinyl Compounds" in Ullmann's Encyclopedia of Industrial Chemistry, $5^{\text {th }}$ ed. Elvers, B.; Hawkins, S.; Schultz, G., Eds., VHS:New York, 1992.

35 PEARSON, J.M. In: Mark HF, Bikales NM, Overberger CG, Menges G, editors. Encyclopedia of Polymer Science and Engineering, 17. New York: Wiley; 1989. p. 257.

36 PENWELL, R.C.; GANGULY, B.N.; SMITH, T.W. Poly(N-vinylcarbazole): A selective review of its polymerization, structure, properties, and electrical characteristics. J Macromol Sci, PartC: Macromol Rev 1978;vol. 13. pg.63-160.

37 JOHNSON, G.E. Spectroscopic study of carbazole by photoselection. J Phys Chem 1974;vol. 78. pg.1512

38 ITO, S.; YAMASHITA, K.; YAMAMOTO, M.; NISHIJIMA, Y. Photophysical properties of poly[2-(9-carbazolyl)ethyl methacrylate] films: Energy migration and carrier generation in films having no excimer-forming site. Chem Phys Lett 1985;vol.117. pg171.

39 ITAYA, A.; OKAMOTO, K.; KUSABAYASHI, S. SINGLET EXCITATION-ENERGY TRANSFER IN VINYL-POLYMERS WITH PENDANT CARBAZOLYL GROUPS Bulletin Chem. Soc. Japan 1977;vol. 50(1):pg 22-26.

40 LEDWITH, A.; RAWLEY, N.J.; WALKER, S.M. Fluorescence emission from poly[2-(9-ethyl)carbazolyl-methylmethacrylate]. Polymer (1981);vol. 22. pg.435-436. 
41 KEYANPOUR-RAD, M.; LEDWITH, A.; HALLAM, A.; NORTH, A.M.; BRETON, H.; HAYLE, C.; GUILLET, J.E. Some Photophysical Properties of Five New Carbazole-Containing Methacrylate Polymers Macromolecules 1978;vol. 11. pg.1114.

42 ARORA, K.S.; OVERBERGER, G.C.; JOHNSON, G.E. Photophysical properties of $\mathbf{N}$-acylated linear polyethylenimine and dehydroalanine mainchain polymers containing carbazole or pyrene groups in side chains.J Polym Sci, Part B: Polym Phys 1986;vol. 24. pg. 2275-2292.

43 STROHRIEGL, P,:GRAZULEVICIUS J.V.Photocondutive Polymers. Nalwa H.S. Handbook of Organics Conductive Molecules and Polymers, vol.1 Chargetranfeer Salts, Fullerenes and Photoconductors, Ed. John Wiley \& Sons LTD, New York, 1997. ISBN:0-471-9693-6.

44 KRICHELDOR, H.R. Handbook of Polymer Synthesis, parte B, Marcel Dekker, New York, 1992, ISBN: 0824785142.

45 ALLEN, G.; Comprehensive Polymer Science, vol. 3, Pergamon Press, New Yaork, 1989. ISBN:0080325157.

46 WANG ,Y.; HERRON, N. Photoconductivity of CdS nanocluster-doped polymers. Chem Phys Lett 1992;vol. 200, pg. 71.

47 BLOCK, H.; COWD, M.A.; WALKER, S.M. Conductivities of poly(N-vinyl carbazoles) containing cation-radicals. Polymer 1977;vol. 18. pg.781.

48 COMPTON ,R.G.; DAVIES, F.J.; GRANT ,S.C. The anodic oxidation of poly(Nvinylcarbazole) films. J Appl Electrochem 1986; vol. 16, pg. 239-249.

49 SAFOULA G.; NAPO K.; BERNEDE, J.C.; TOUHRI S.; ALIMI K., Electrical conductivity of halogen doped poly( $\mathrm{N}$-vinylcarbazole) thin films. Eur. Polym. J. 2001, vol. 37, pg. 843-849.

50 BARBASZEWSKI, T.; DEWIEGA M.; LIPINSKA E.; STARZYK F.; lodine Implantatiom in Poly-N-Vinylearbazole-an Organic Semiconductor. Phys Stat Sol (A)1986; vol. 94, pg. 419-422. 
51 ALLEN, G.,Comprehensive Polymer Science, vol3, Pergamon Press, New Yaork, 1989. ISBN:0080325157

52 SWARC, M. Living Polymers. Nature, 1956, v.178(4543), p. 1168-1169.

53 SWARC, M..; LEVY, M.; MILKOVICH, R.; Polymerization Initiatedd by Electron Transfer to Monomer- A New Method of Formation of Block Polymers. Jounal of the American Chemical Society, 1956, v.78(11), p.2656-2657.

54 MALMSTROM, E.E.; HAWKER, C.J. Macromolecular Engineering Via "Living" Free radical Polymerizations. Macromolecular Chemistry and Physics, 1998, v.199(6), p 923-935.

55 LUTZ, P.J.; BEINERT, G.; REMPP, P.F.Anionic-Polymerization of 1,3Diisopropenylbenzene and 1,4-Diisopropenylbenzene. Makromolekulare Chemie- Macromolecular Chemistry and Physics, 1982, v.183 (11), p.2787-2797.

56 QUIRK, R.P.; LYNCH, T.; Anionic Synthesis of Primary Amine-Functionalized Polystyrenes using 1-[4-[N,N-Bis(Trimethylsilyl)Amino]Phenyl]-1Phenylethylene. Macromolecules, 1993, v.26(6), p. 1206-1212.

57 SOGAH, D.Y.; HERTLER, W.R.; WEBSTER, O.W.; COHEN, G.M.; Group Transfer Polymerization- Polymerization of Acrylic-Monomers. Macromolecules, 1987, v.20(7), p.1473-1488.

58 PUSKAS, J.E.; KASZAS, G.; Living Carbocationic Polymerization of Ressonance-Stabilized Monomers. Progress in Polymer Science, 2000, v.25 (3), p.403-452

59 PATAI, S. The chemistry of Peroxides, New York: John Wiley and Sons Ltd, 1983. ISBN:0471102180.

60 INAGAKI, N. Plasma Surface Modification and Plasma Polymerization, Technomic, Lancaster, Pennsylvania, 1995. ISBN: 1566763371 
61 WETHEIMER, M.R.; THOMAS, H.R.; PERRI, M.J.; KLEMBERG-SAPIEHA, J.E.; MARTINU, L. Plasmas and Polymers: from Laboratory to Large Scale Commercialization. Pure and Applied Chemistry, 1996, v.68(5), p. 1047-1053

62 HAWKER, C.J.; Molecularl-Weigh Control by a Living Free- Radical Polymerization Process. Journal of the American Chemical Society, 1994, v.116(24), p. 11185-11186.

63 D'AGOSTINO,R.; Plasma Deposition, Treatment and Etching of PolymersApplications of Plasma Polymers., 1990. Academic Press.

64 D’AGOSTINO,R.; Plasma Deposition, Treatment and Etching of PolymersPlasma Deposition and Treatment for Biomaterial Applications., 1990 Academic Press.

65 MANSANO, R.D.; Corrosão de Silício por Plasma para Aplicação em Microcanais, São Paulo. 1998, Tese de doutorado, Escola Politécnica, Universidade de São Paulo.

66 COOK, J.M.; Downstream Plasma Etching and Stripping., April 1987. Solid State Technology.

67 GOROWITZ, B.; SAIA, R.; BALCH, E.W.; Methods of Metal Patterning and Etching. 1987 Academic Press,.

68 BEEL, A.T., An Introduction to Plasma Processing., april 1978. Solid State Technology.

69 SAWIN, H.H., A Review of Plasma Processing Fundamentals. April 1985. Solid State Technology.

70 NUNES, A. M., Corrosão por plasma de filmes de silício policristalino e nitreto de silício para Tecnologia MENS e CMOS. Tese de Mestrado, UNICAMP, 2005. 
71 HAWKER, C.J.; HEDRICK, J.L. Accurate Control of Chain-Ends by a Novel Living Free-Radical Polymerization Process, Macromolecules, 1995, v.28(8), p.2993-2995.

72 YASUDA, H.; HIROTSU, T.; Plasma polymerization investigated by the comparison of hydrocarbons and perfluorocarbons. Surface. Science, September 1978. Volume 76, Issue 1, (1), Pages 232-241

73 BIELDERMAN, H.; OSADA, Y., Plasma Polymerization Process. Elvier Amsterdan, 1992. London-New York-Tokyo.

74 GEORGES, M.K.; VEREIGN, R.P.N.; KAZMAIER, P.K.; HAWER, S.K.;Narrow Molecular-Weight Resins by a Free-Radical Polymerization Process. Macromolecules, 1993, v.26(11), p.2987-2988

75 ECKERTOVA, L.; Physics of Thin Films (second edition) Plenum Publishing Corporation, 233 Spring Strrt, New York, N.Y.,10013, p.48.

76 MALLIARAS, G.; KRASNIKOV, V.; BOLINK, H.; HADZIIANNOU, G.. Holographic timeof-flight meassurements of the hole-drift mobility in a photorefractive polymer.Phys. Rev. B, 52:R14324, 1995.

77 NESPÜREK S., SLAVINSKÁ D., KLEIN-SZYMANSKA B., Journal European Polymer, 15 (1979) 465.

78 INOUE M., MORITA H., TAKAI Y., MIZUTANI T. , IEDA M., Jpn. J.Appl.Phys.,25(10)(1986)1495.

79 VOUDAS N., BOUDOUVIS A.G., GOGOGLIDES E., Microelectronic Engineering vol. 77-79 (2005)pag. 474-478.

80 REICHMAIS, E.; THOMPOPSON, L.F. Polymer materials for microlithography. In: Annual Reviews Material Science. 1987 pag 235-71. Annaul Rewiews Inc.

81 ZASNICOFF, L.S. Processos Mos. In BARANAUSKAS, V. Processos de microeletrônica. Campinas, SBV/SBMicro. 1990 Cap. 6, p6. 1-52 
82 DOANE,D.A. A review of optical lithographic techniiques for VLSI. Silicon Processing. Philadelphia. Society for Testing and Materials 1983, p. 85-107.

83 MORAN, J.M.; MAYDAN, D.; High resolution, steep profile resist patterns. Journal of Vacuum Science an Technology, v.16, n6, p. 1620-4, Nov./Dec 1979.

84 THOMPSON, L.F. Na Introduction to microlithography. In: THOMPPSON, L.F.; C.G.; BOWDEN, M.J. Introduction to microlithography: Theory, materials, and processing. ACS v.219, p1-12. USA, America Chemical Society, 1983./ ACS Symposium Series vol.219

85 RUSKA, W. S. Microelectronic Processing: An introduction to the manufacture of integrated circuits. Singapure, McGraw-Hill Book Company,1988, cap.4, p. 114-146: Photolitography. Mc Graw Hill Series in Electrical Engineerring.

86 ZUFFO, J.A. Compendio de microeletrônica: Livro 1/ Processos e tecnologias. Rio de Janeiro, Editora Guanabara Dois S.A., 1984. Cap.1: Tecnnologias Báscias de Microeletrônica, p1-61.

87 McGILLIS D.A. Litography. In:SZE S.M VLSI Technology. USA, Mc GRAW HILL Book Company, 1983. cap 7, p.267-301. Series in Electronical EngineeringElectronics and Eletronics Circuits.

88 P.M. DENTINGER, K.L. KRAFCIK, K.L. SIMISON, R.P. JANEK, J. HACHMAN, High aspect ratio patterning with a proximity ultraviolet source, Microelectron.Eng. 61-62 (2002) 1001-1007.

89 http://www.ee.byu.edu/cleanroom/mask_fab.phtml última consulta em 04/2007.

90 VOLLENBROEK, F.A. Microelectronic Lithography. Escola Politécnica da USP, julho, 1989, p. 65.

91 MOREAU, W.M. Semiconductor Lithography: Principles, Practices, and Materials. Plenum Publishing Corporation, 1987. (Microdevices), p.371. 
92 MOREAU, W.M. Semiconductor Lithography: Principles, Practices, and Materials. Plenum Publishing Corporation, 1987. (Microdevices), p.373.

93 BLAIS, P. AND MICHAELS, M. Lithography Tool Selection Strategy. In: GLENDINNING, W.B. AND HELBERT, J.N. Handbook of VLSI Microlithography: Principles, Technology and Applications. Noyes Publications, 1991. Cap. 1, p. 32.

94 MOREAU, W.M. Semiconductor Lithography: Principles, Practices, and Materials. Plenum Publishing Corporation, 1987. (Microdevices), p.276.

95 BURGGRAAF, P. X-Ray Lithography and Mask Technology. Semiconductor International. v.8, n.4, pp.92-9, Apr. 1985.

96 WOLF, S. AND TAUBER, R.N. Silicon Processing for the VLSI Era: Process Technology. Lattice Press, 1987. v.1, p.468.

97 BURGGRAAF, P. Stepper-track Integration: Solving the Problems. Semiconductor International.v.15, n.9, pp.30-3, Aug. 1992.

98 ELLIOT D.J.Integrated circuit fabrication technology. USA, MC GRALL HILL Book Company, 1982. cap 6, p 125-44: Photoresist coating

99 THOMPSON L.F \& BOWDEN.M.J. Resist processing. . In: THOMPPSON, L.F.; C.G.; BOWDEN, M.J. Introduction to microlithography: Theory, materials, and processing. ACS p. 161-214

100 WANG, J., WU, Y., XUAN, X., WNAG, H., Ion-molecule Interactions in solutions of Lithium Perchlorate in propylene carbonate mixtures: an IR and molecular orbital study. Spectrochimica Acta PART A 58 (2002), p.2097-2104.

101 BALLAV, N.; BISWAS, M. A conducting composite of polyN-vinylcarbazole and polythiophene. Synthetic Metals, 2003.vol. 132. pg. 213-218.

102 ALLEGRINI, M.; ARENA, A.; GIRLANDA, R.; PACE, C.; PATANÈ, S; SAITTA, $\mathrm{G}$. Synthesis and optical characterization of stable and highly luminescent PVK-Alq3 blends. J. Mater. Res., 1999. Vol. 14, No. 6. 
103 HONGAN, X.; YANBO, Z.; ZHONGKAIL, L.; XUEFENG, Q.; JIE, Y.; ZIKANG, Z. Photophysical properties of poly(N-vinylcarbazole) in the meso-channels of zeolite MCM-41. Journal of Materials Science Letters, 2002. vol. 21 pg.1817 $-1818$.

104 MANSANO, R.D.; Corrosão de resistes por plasma para aplicação em litografia de multicamadas, São Paulo. 1993, Dissertação (Mestrado), Escola Politécnica, Universidade de São Paulo.

105 SAFOULA, G.; NAPO, K.; BERNÈDE, J.C.; TOUIHRI, S.; ALIMI, K. Electrical conductivity of Halogen Doped Poly (N-Vinylcarbazole) Thin films. Eurpean Polymer Journal, 2001, v.37 (4), p. 843-849.

106 TOUHRI, S.S.; MOLINE, P.; OURO-DJOBO, S.; NAPO, K.; SAFOULA, G.; BERNĖDE, J.C. Evolution with Temperature of the ESR Signal of Bromine Doped Poly(N-Vinylcarbazole)-The Doping Temperature Used as Parameter. Polymer Degradation and Stability, 2000, v.69 (3), p.333-340 


\section{ANEXO A - APRESENTAÇÃO EM CONGRESSOS}

1. T.A.A.G.Moreira, S.Possidonio, W.S.Hui, and R.K.Onmori.

Study of Argon Plasma Etching of Poly(N-vinilcarbazole),

IV SBPMAT, Recife, PE, Brasil, 2005.

2. T.A.A.G.Moreira, S.Possidonio, J.C. Moreira, W.S.Hui, and R.K.Onmori.

Comparative Study Among Etching of Poly(N-vinilcarbazole),

V Encontro do Projeto Multidisciplinar de Materiais Poliméricos - IMMP, Nazaré Paulista, SP, Brasil, 2006.

3. Taís A A.G. Moreira, S.Possidonio, W.S.Hui and R.K.Onmori.

Poly (N-vinylcarbazole) Conductor Trails for Microelectronics Devices, $17^{\circ} \mathrm{CBCIMat,} \mathrm{Foz} \mathrm{do} \mathrm{Iguaçu,} \mathrm{PR,} \mathrm{Brasil,} 2006$.

4. T.A.A.G.Moreira, S.Possidonio, W.S.Hui and R.K.Onmori. Oxygen Plasma Etching Study for Conductor Trails, V Congresso da SBPMat, Florianópolis, SC, Brasil, 2006.

5. MOREIRA, J. C. ; ALVARES, Daniela Assis ; MOREIRA, Tais Aparecida Garcia; CARMINATI, Romulo Do Amaral ; ONMORI, Roberto Koji .

Morphological and Electrical Characterization of PANi/dEPDM Blends. V Workshop do Instituto Multidisciplinar de Materiais Poliméricos, 2006, São Paulo. Anais do V IMMP, 2006. p. 5.

6. MOREIRA, J. C. ; ALVARES, Daniela Assis ; MOREIRA, Thaís Aparecida Garcia; SCURACCHIO, Carlos Henrique ; ONMORI, Roberto Koji . Morphology of dEPDM Rubber and PANi Blends . World Polymer Congress Macro 2006, 41st International Symposium on Macromolecules, 2006, Rio de Janeiro. Proceedings of the 41st International Symposium on Macromolecules, 2006. p. CDROM. 
7. T.A.A.G.Moreira, S.Possidonio, W.S.Hui and R.K.Onmori.

Oxygen Plasma Etching in Poly(N-vnylcarbazole).

$9^{\circ}$ Congresso Brasileiro de Polímeros, Campina Grande-PB, 2007.

8. T.A.A.G.Moreira, S.Possidonio, D.A.Prado e R.K.Onmori.

Utilização do Polímero Poli(N-vinilcarbazol)-PVK para aplicações

Fotovoltaicas.

II Simpósio Mineiro de Ciência dos Materiais, Ouro Preto-MG, 2007.

9. T.A.A.G.Moreira, S.Possidonio, W.S.Hui and R.K.Onmori.

Lithography process in Poly ( $\mathrm{N}$-vinylcarbazole)

$2^{\text {nd }}$ International Conference on Advanced Nano Materials, ANM 2008.

Aveiro-Portugal, 2008 


\section{ANEXO B - ARTIGOS EM REVISTA}

1. T.A.A.G.Moreira, S.Possidonio, J.C. Moreira, W.S.Hui, and R.K.Onmori. Comparative Study Between Wet and Dry Etching of Poly(N-vinylcarbazole), Macromolecular Symposia: MACRO 2006, 245-246, pág. 430-434. 


\section{ANEXO C - PROCESSO DE CURA}

Cura do fotoresiste:

Pré-backing

Estufa em temperatura de $80^{\circ} \mathrm{C}$ por 20 minutos.

Pós-backing

Estufa em temperatura $100^{\circ} \mathrm{C}$ por 30 minutos. 